DOE/NASA/0058.79/1

NASA CR-159494

\title{
MOD 1 WIND TURBINE GENERATOR \\ FAILURE MODES AND EFFECTS ANALYSIS
}

General Electric Company

Space Division

February 1979

Prepared for

NATIONAL AERONAUTICS AND SPACE ADMINISTRATION

Lewis Research Center

Under Contract NAS 3-20058

for

U.S. DEPARTMENT OF ENERGY

Office of Energy Technology

Division of Distributed Solar Technology

1 MAY 1980

MCDONNELL DOUGLAS

RESEARCH \& ENCINEERING LIBRARY

9T. LOUIS 
NOTICE

This report was prepared as an account of work sponsored by an agency of the United States Government. Neither the United States nor any agency thereof, nor any of their employees, makes any warranty, expressed or implied, or assumes any legal liability or responsibility for any third party's use or the results of such use of any information, apparatus, product, or process disclosed in this report, or represents its use by such third party would not infringe privately owned rights. 
MOD 1 WIND TURBINE GENERATOR

DOE/NASA/0058-79/1

FAILURE MODES AND EFFECTS ANALYSIS

General Electric Company

Space Division

Advanced Energy Systems

Philadelphia, Pennsylvania 19101

February 1979

Prepared for

National Aeronautics and Space Administration

Lewis Research Center

Cleveland, Ohio 44135

Under Contract NAS 3-20058

For

U. S. DEPARTMENT OF ENERGY

Office of Energy Technology

Division of Distributed Solar Technology

Washington, D.C. 20545

Under Interagency Agreement EX-77-A-29-1010 
Introduction . . . . . . . . . . . . . . . . . . ii

Task Approach . . . . . . . . . . . . . . . . . . i i

Summary \& Conclusions . . . . . . . . . . . . . . . iv

Rotor Blade ..................... 1

Yaw Subsystem .................:. 4

Yaw Structure................. 4

Yaw Drive................... 5

Yaw Hydraulics .................. . 7

Drive Train ...................... 8

Rotor Hub . . . . . . . . . . . . . . . . . . 12

Pitch Change Mechanism . . . . . . . . . . . . . 14

PCM Hydraulics . . . . . . . . . . . . . 17

Power Ceneration... . . . . . . . . . . . . . . 24

Nacelle - Fairing . . . . . . . . . ....... . 31

Nacelle - Bedplate.................... . 32

Controls . . . . . . . . . . . . . . . . . . . 33

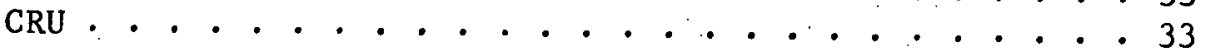

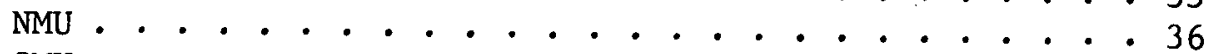

GMU ...................... . . 47

Tower ....................... . . . 52

Structure . . . . . . . . . . . . . . . 52

Lift Device... . . . . . . . . . . . . . 53

Appendix A - Blade

Unbalanced Loads after Blade Separation. ...... A-1

Interface Ring Flange................ A-2

Test Program .................. A-6

Quality Program............... A-10

Appendix B - Rotor Overspeed . . . . . . . . . B-1

\section{FIGURES}

1 FMEA System Diagram $\quad$ v

$2 \quad$ MOD-1 Blade $\quad$ vi

3 Yaw Motor/Drive : vii

4. Yaw Hydraulics viii

5 Drive Train . ix

6 Pitch Change Mechanism. . $x$

$7 \quad$ PCM Hydraulic Package $x i$

8 Power Generation FMEA Diagram xii

$8 \mathrm{a}$ Trip Circuits $\quad x i i$

8b FMEA Diagram/Drawing Cross Reference xiv

9 Control Subsystem xv

9a Control Subsystem (cont.) xvi

10 Emergency Shutdown Redundancy xvii 


\section{FAILURE MODES AND EFFECTS ANALYS IS}

\section{Introduction}

The following figures and tables present the results of a Failure Modes and Effects Analysis (FMEA) of the Mod 1 Wind Turbine Generator. This analysis was of limited scope, in accordance with Statement of Work NAS3-20058, and was directed primarily at identifying those critical failure modes that would be hazardous to life or would result in major damage to the system. As a result, the analysis was conducted from the "top down", minimizing the extent of analysis that would lead to trivial conclusions, had the analysis been approached from the "bottom up". For example, a component-by-component analysis of the lubrication system was not pursued, once it had been established that all lubrication system failures lead to the same, non-critical conclusion.

\section{Evaluation Criteria}

The criteria used for evaluation of the system is that none of the following injuries or damage shall occur because of a single failure or a single failure following an undetected failure of the wind turbine system.

Category I: Failures which would result in death or serious injury to the operator or general public.

Category II: Failures which would result in najor or significant damage to the wind turbine system, extended outage, or damage to the connected utility.

A11 other failures are Category III. The failure categories are listed under Column 9 in the attached tables. 


\section{Task Approach}

Figure 1 illustrates how the Mod 1 Wind Turbine Generator system was broken down for analysis. This organization corresponds roughly to the drawing system, defined by Drawing Tree 298E470. Since subsystem descriptions are beyond the scope of this report, reference should be made to the drawings that are identified on the Drawing Tree, should further details be required. Figures 2 through 10 provide an overview of each subsystem, with circled numbers corresponding to principal line items in the accompanying tables. Figures 8,9 and 10 are simplified diagrams to further break down the Power Generation and Controls subsystems.

Each subsystem was approached from the top down, and broken down to successive lower levels where it appeared that the criticality of the failure mode warranted more detailed analysis. The attached tables, pages 1 through 55, were prepared as worksheets through several stages of review, including review by qualified GE specialists outside of the Mod 1 program and two reviews by knowledgeable' NASA LeRC personne1. These summary tables were supplemented by analyses on topics of special interest that are included as appendices to this report covering:

- Unbalance Loads after Blade Separation

- Blade Interface Ring Flange Stress Analysis

- Blade Test Program

- Blade Quality Program

- Rotor Overspeed 


\section{Summary and Conclusions}

The results of this study have been evaluated and the failure evaluation criteria have been met for all Category I failures, except for the blade and its attachment structure. Should a blade separate, as shown in Appendix A. no additional failures would propagate. Also, the probability of a blade separation is acceptably small based on the other information presented in the Appendices, i.e., the analysis of the interface ring flange, the design verifications to be achieved by the test program (especially the 1.7 .4 tests of fatigue strength of welds), the inspections and checks of the quality program, and the redundancy built into the overspeed shutdown circuits.

A few Category II failures are also possible. These mainly involve conservatively designed items such as shafting, bearings, and gears where the possibility of failure, or premature failure, is acceptably small and it is not practical to comletely avoid such failures. These items are discussed in more detail in the tables.

Some minor changes have been identified as a result of this study and are being incorporated. They are

- Pitch jam circuit redesigned to be fail-safe

- Overspeed reset redesigned to mechanically latch after power failure

- Software revised to check sensors in their non-active state

- Specific inspection points identified for checks during periodic maintenance

It may be necessary to incorporate additional changes later, if, for example, additional Category I or II failure modes are identified during the test and field check-out phases. 


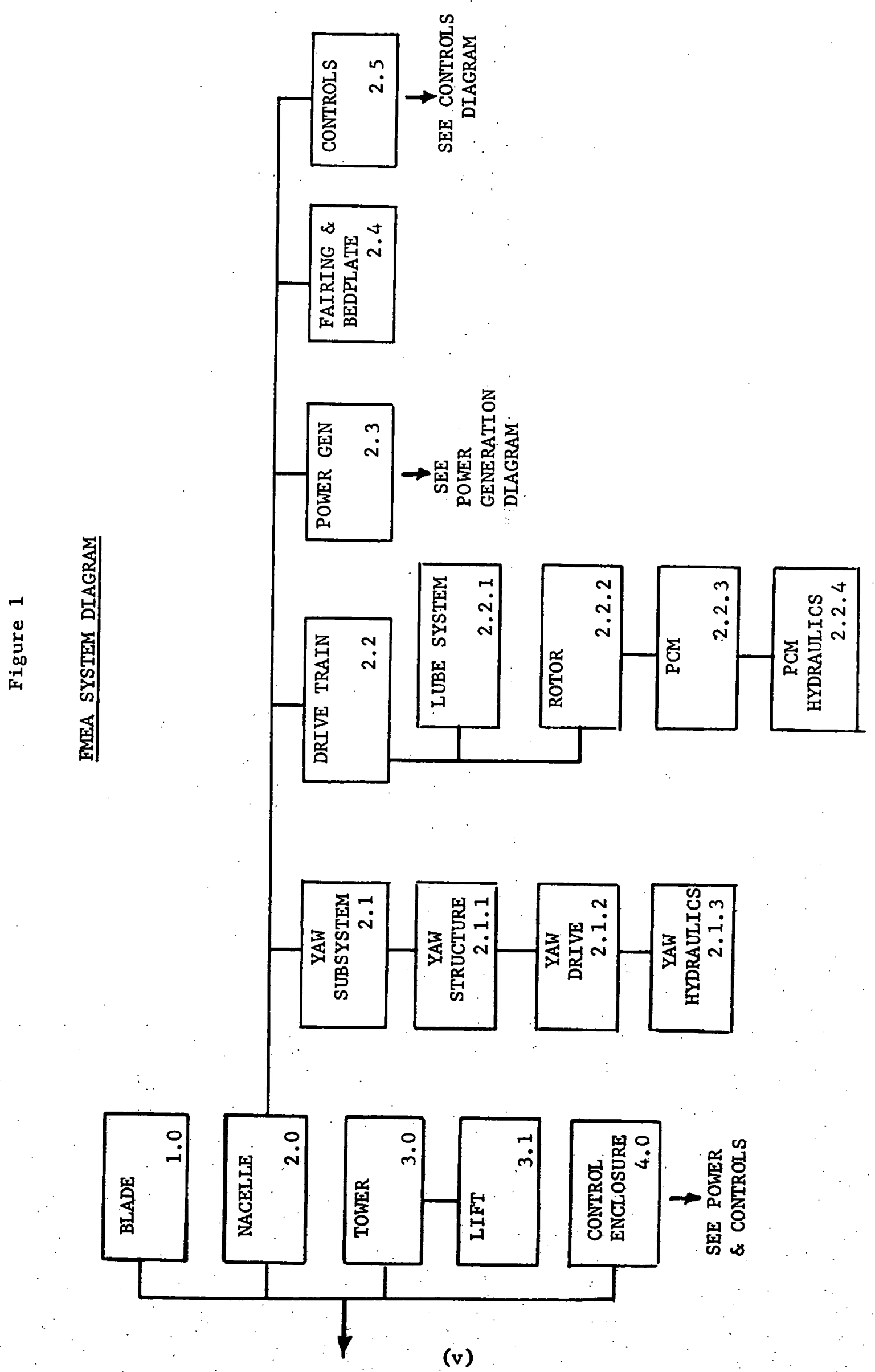




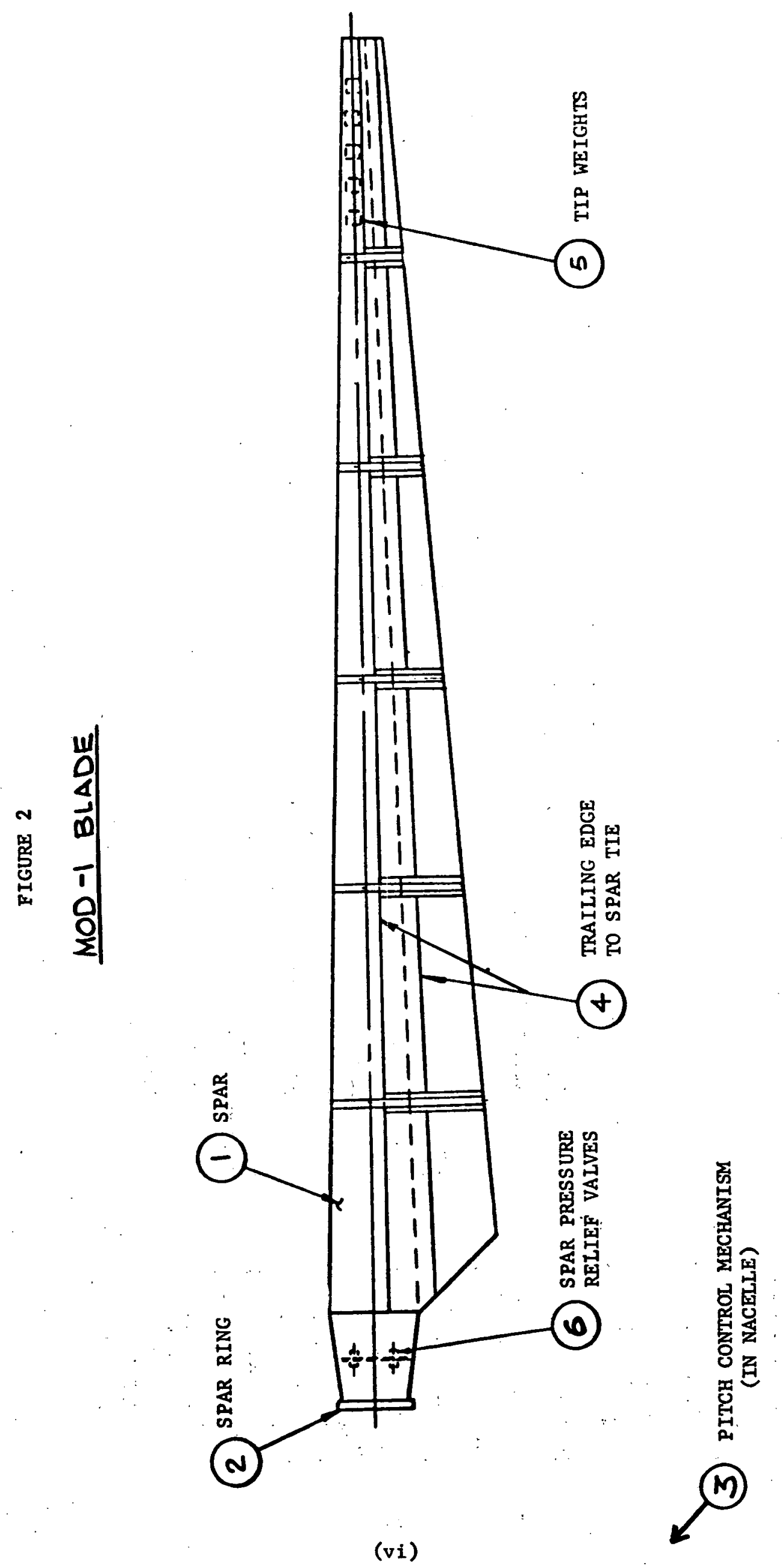




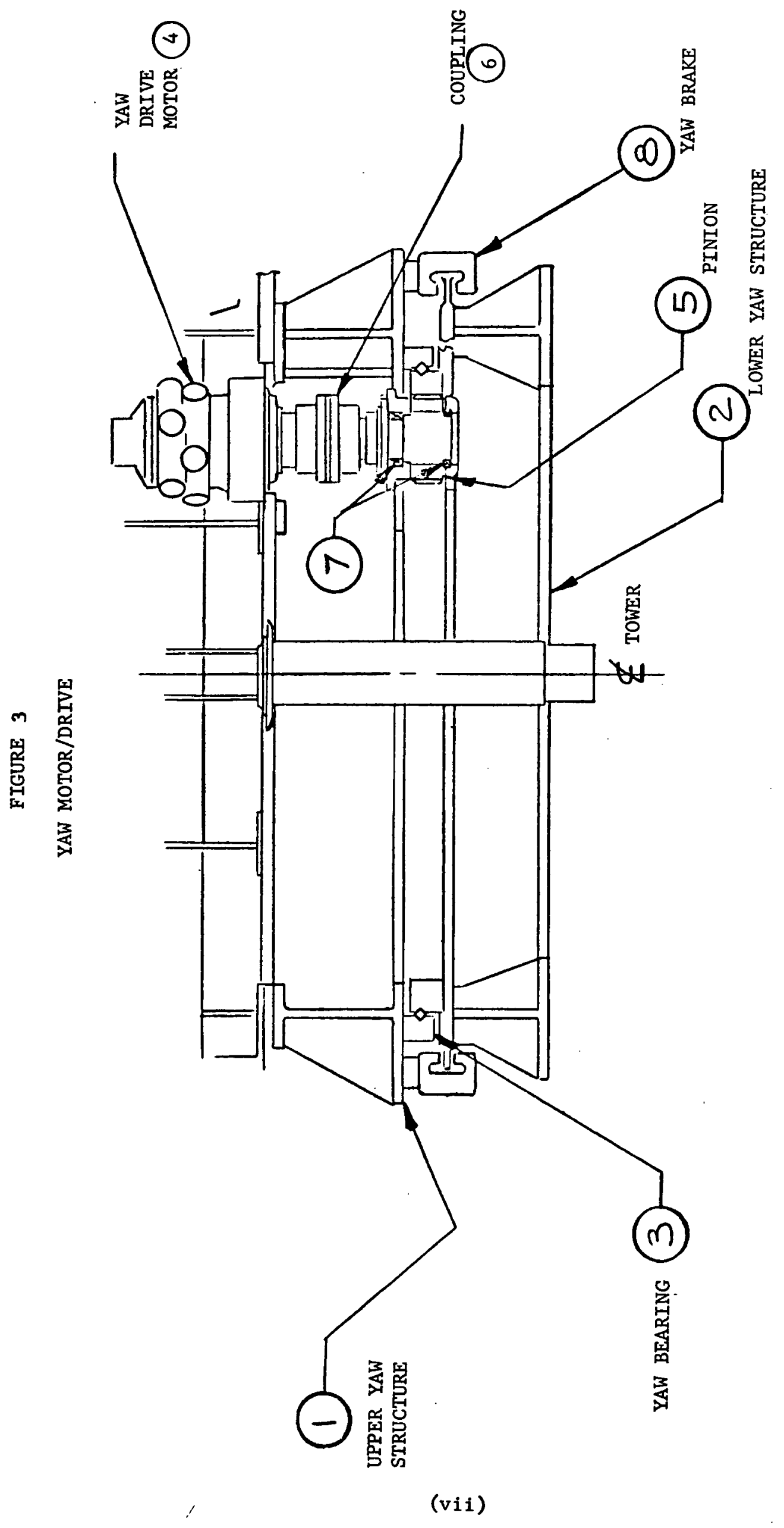




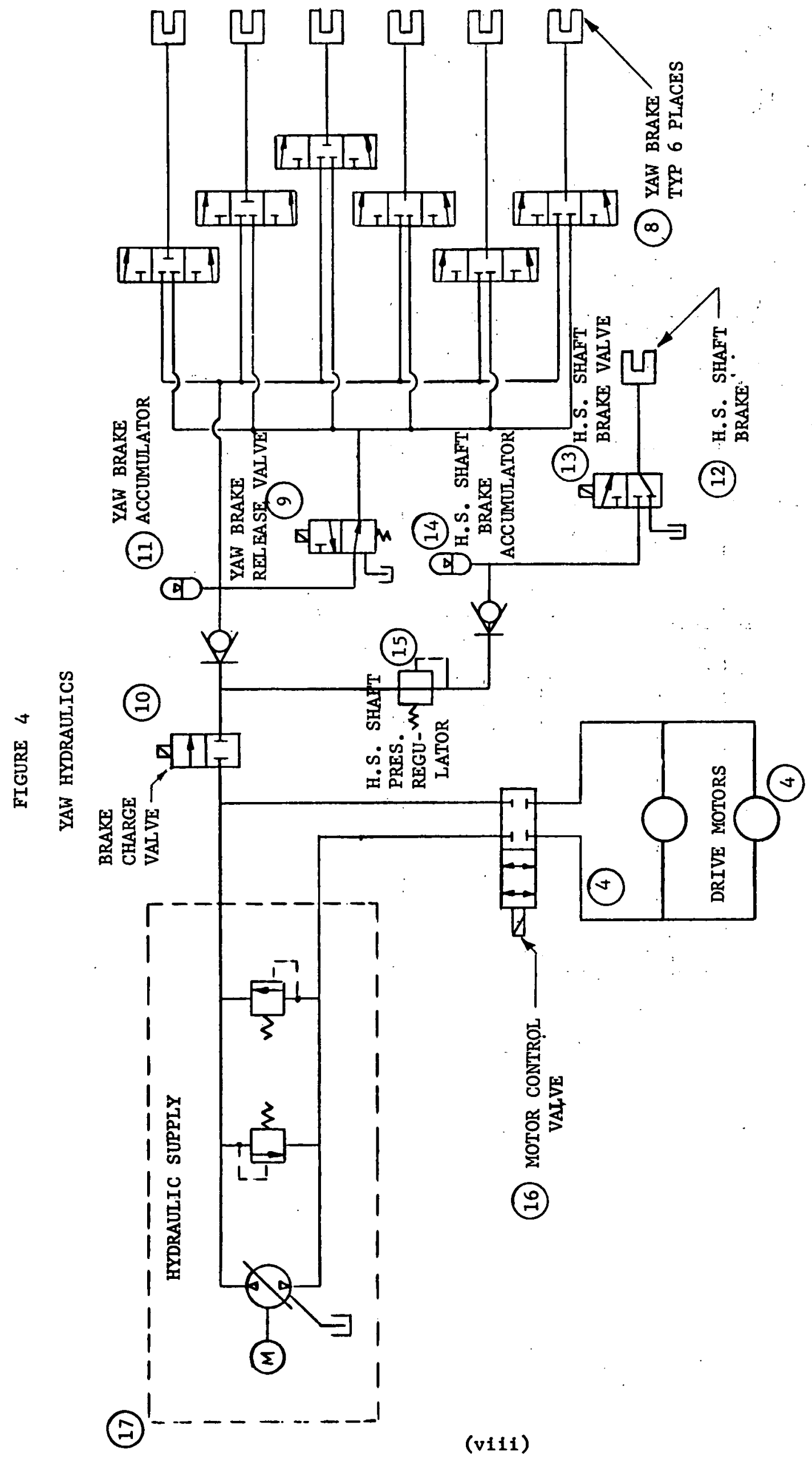


n 点

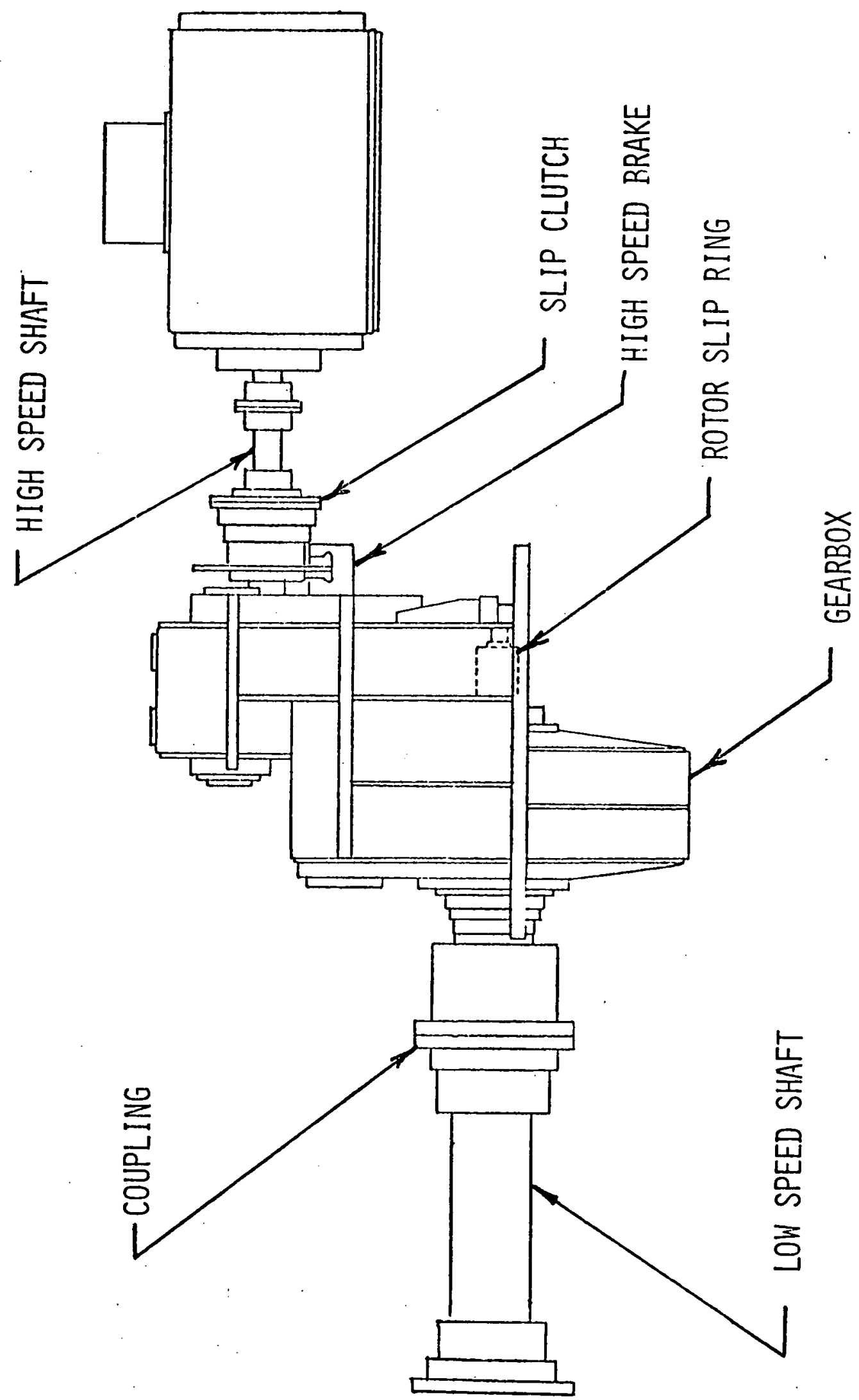




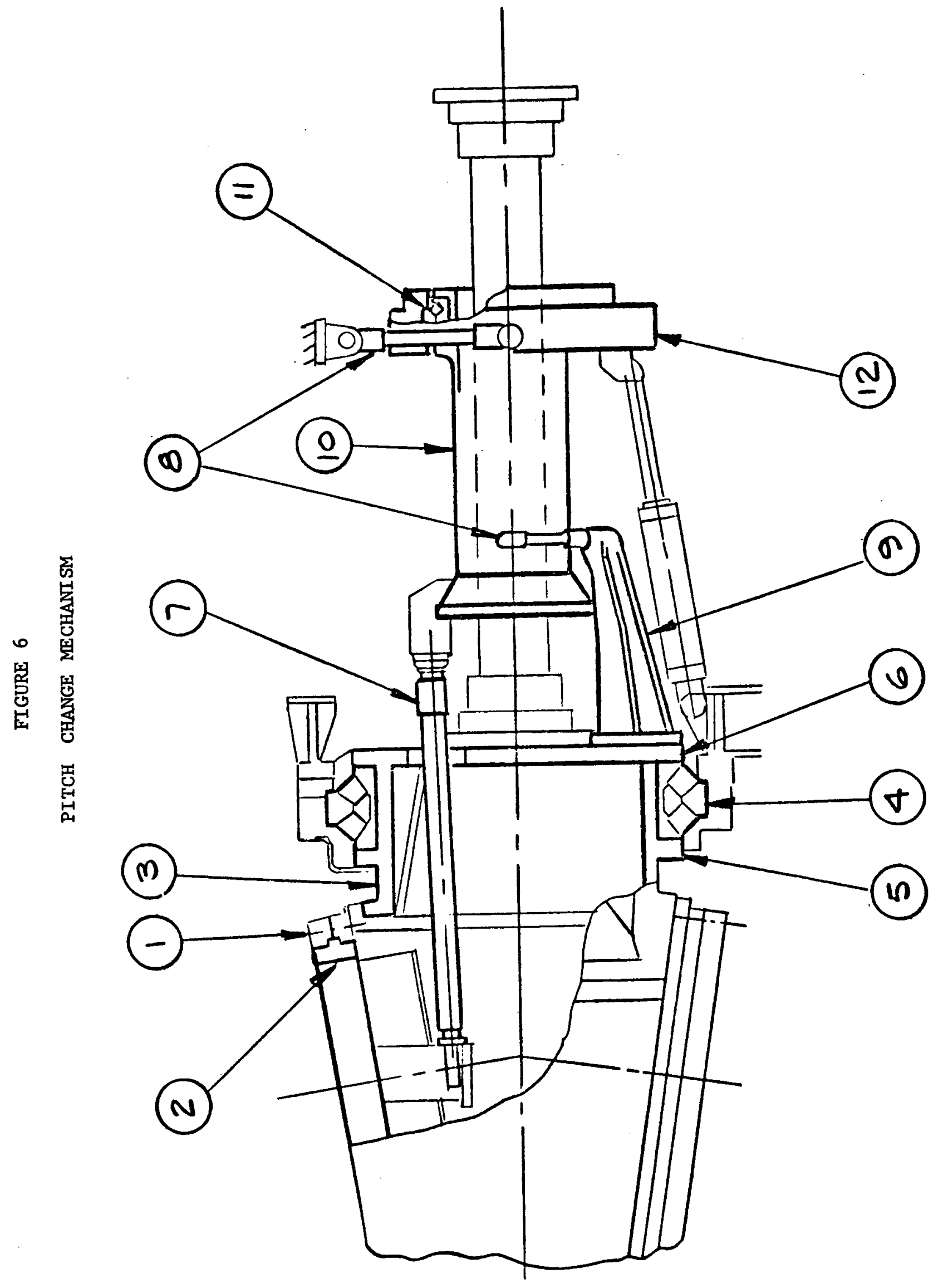

(x) 


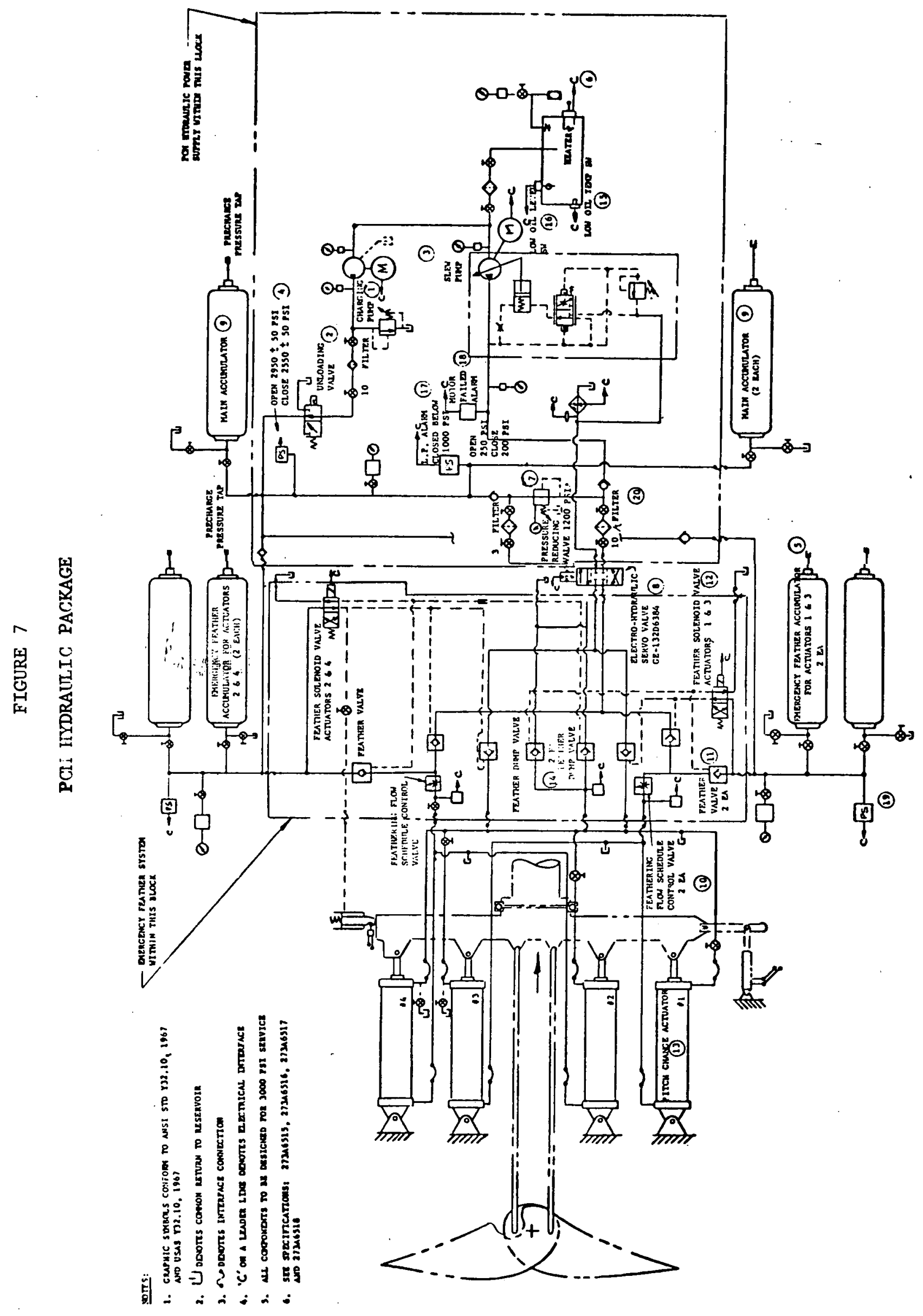




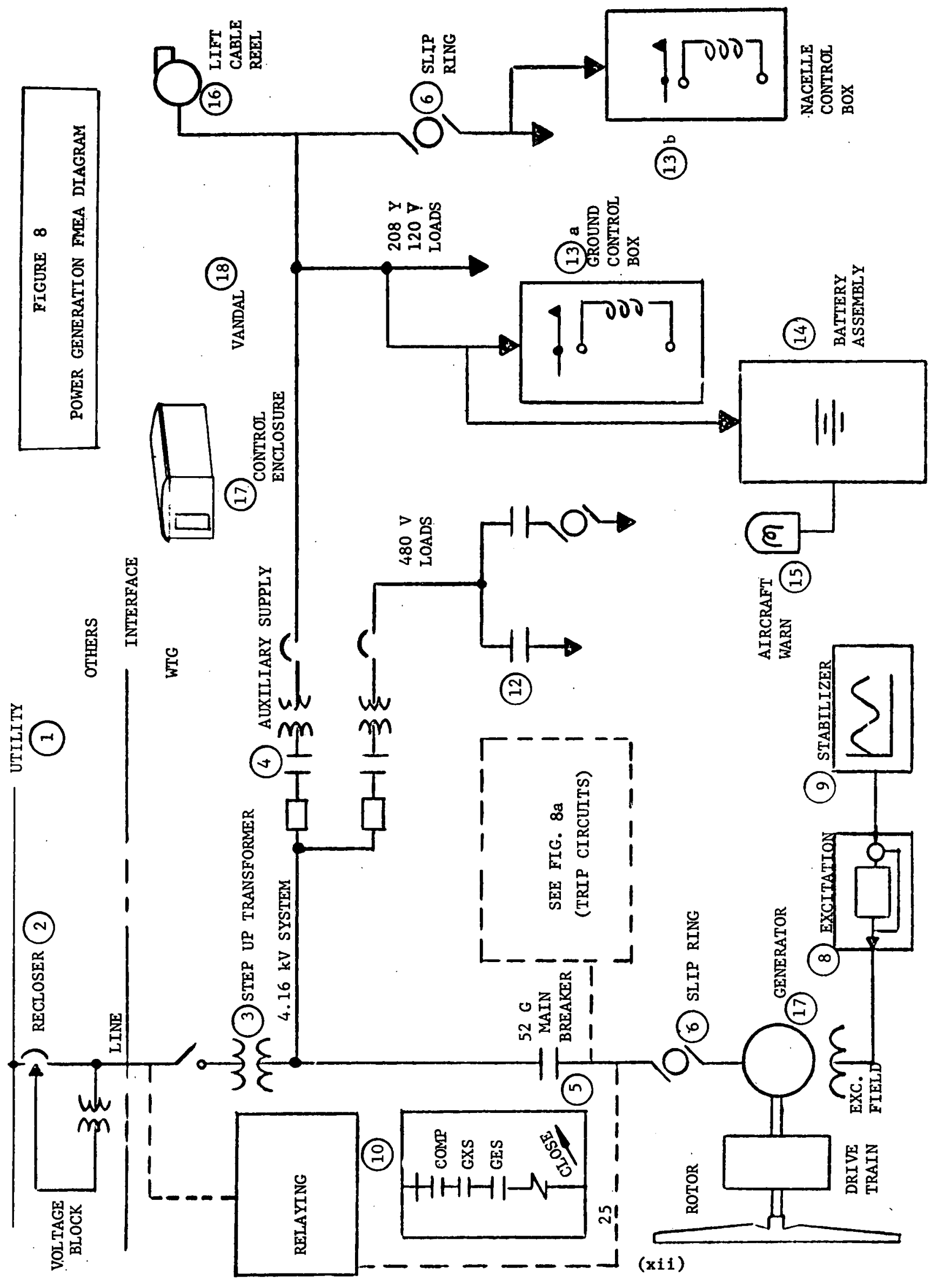




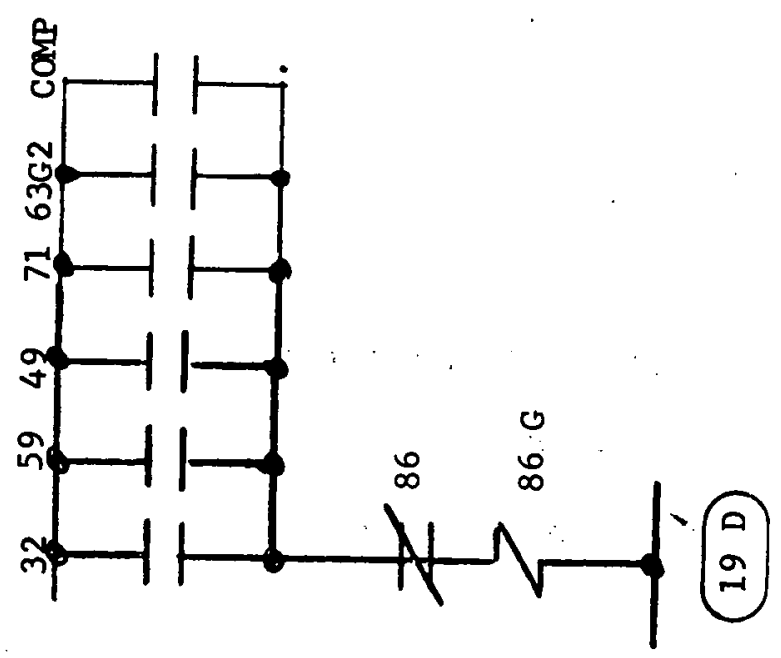

(2)
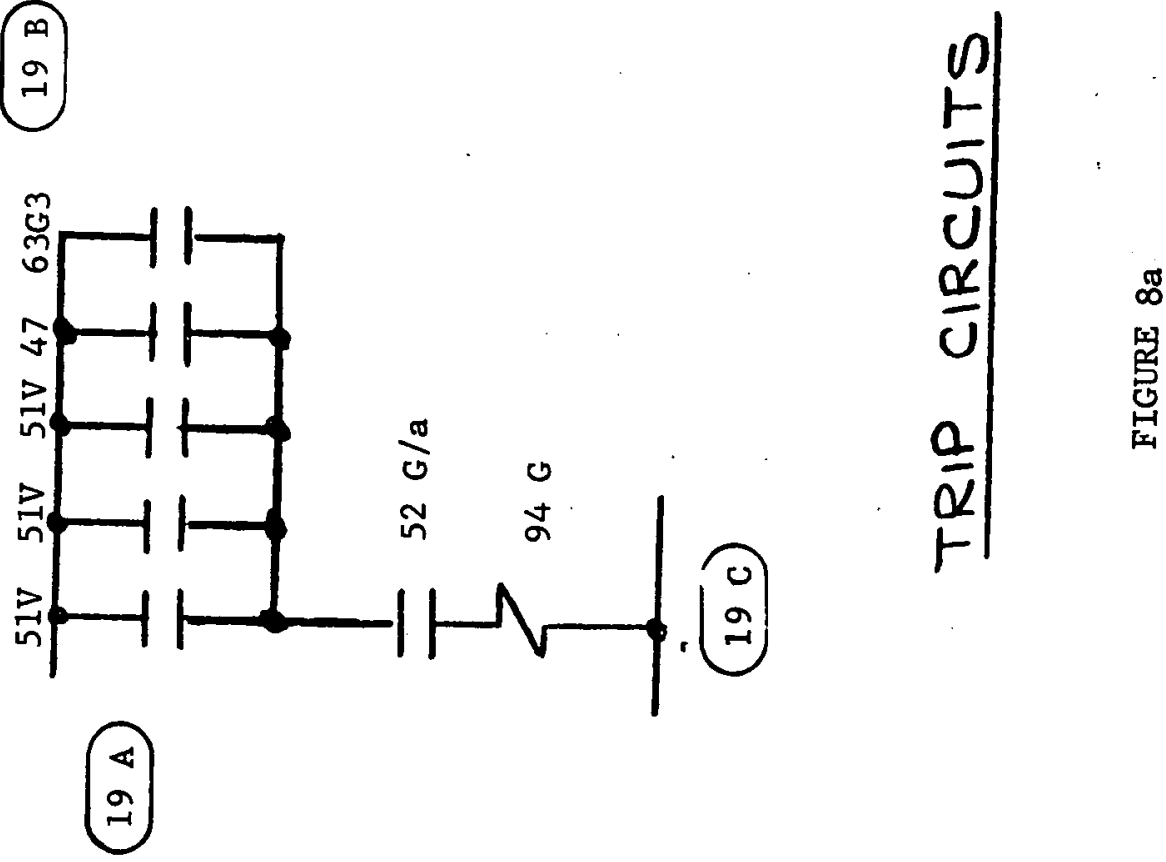
POWER GENERATION FMEA

FMEA DIAGRAM/DRAWING CROSS REFERENCE

\begin{tabular}{|c|c|c|c|}
\hline (1) & BLUE RIDGE ELECTRIC & MEMBERSHIP COF & RPORATION \\
\hline (2) & TRANSFORMER ASM & $273 A 6418$ & \\
\hline (3) & AUX SUPPLY & $273 A 6509$ & (PART) \\
\hline (4) & MAIN BREAKER & $273 A 6509$ & (PART) \\
\hline 5) & SLIP RING & $273 A 6519$ & \\
\hline (6) & GENERATOR & $273 A 6429$ & \\
\hline$\theta$ & EXCITATION & $273 A 6510$ & (REGUL. PART) \\
\hline & STABILIZER & $265 A 7087$ & \\
\hline & RELAYING & $273 A 6510$ & (PART) \\
\hline & SYNC & $273 A 6510$ & (PART) \\
\hline & MOTOR CONTROL & $273 A 6431$ & \\
\hline & GND. C.P. & $848 E 893$ & \\
\hline (a) & NAC . C.B. & $132 D 6390$ & \\
\hline 3b) & BATTERY ASM & $273 A 6432$ & \\
\hline & WARN LAMP & $273 A 6690$ & \\
\hline & LIFT REEL & $132 D 6046$ & \\
\hline & CONTROL ENCLOSURE & $273 A 6507$ & \\
\hline 7 & $\begin{array}{l}\text { TRIP CIRCUIT RELAYS } \\
\text { ONE-LINE DIAGRAM }\end{array}$ & $298 E 475$ & REV. 3 \\
\hline
\end{tabular}




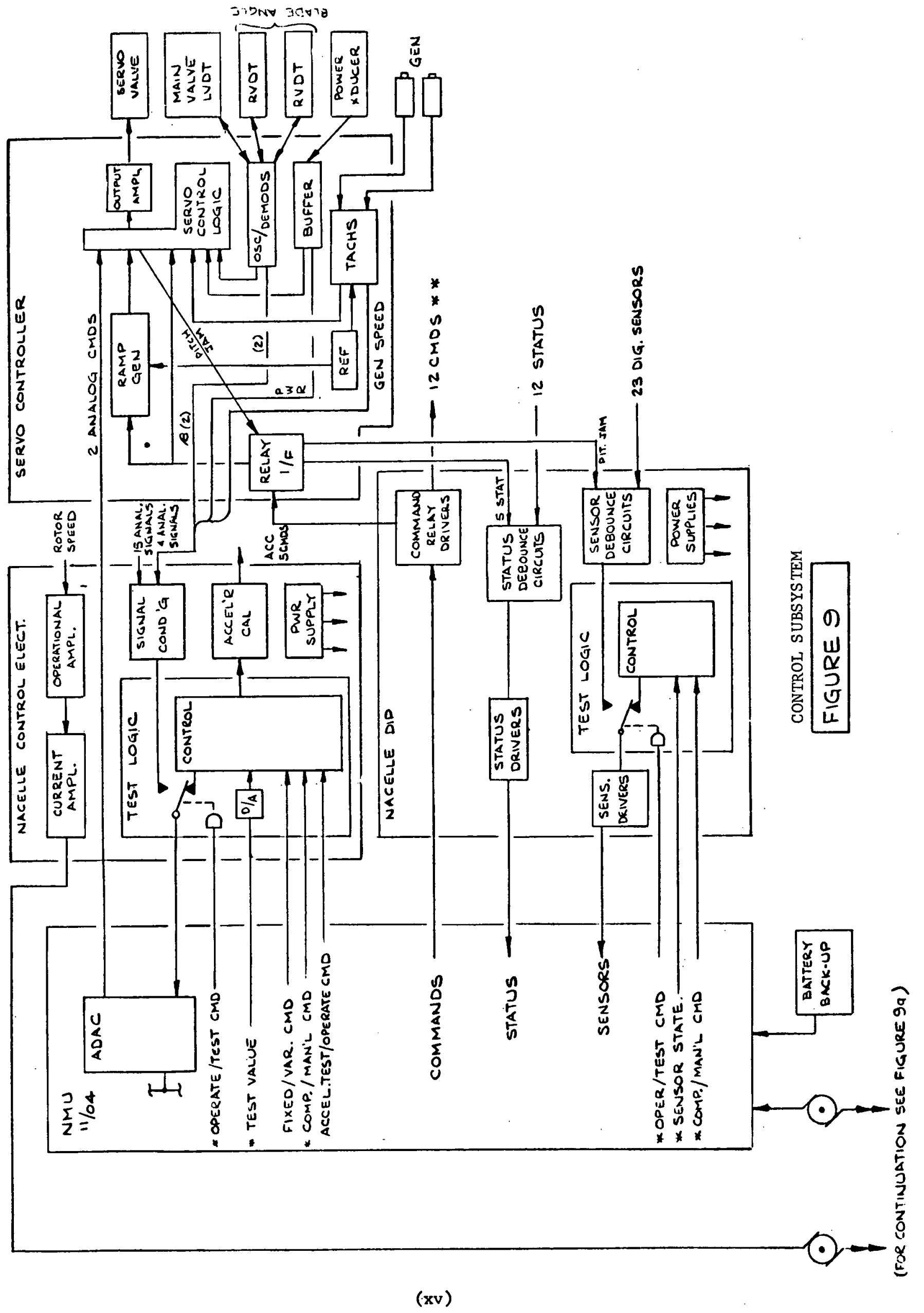




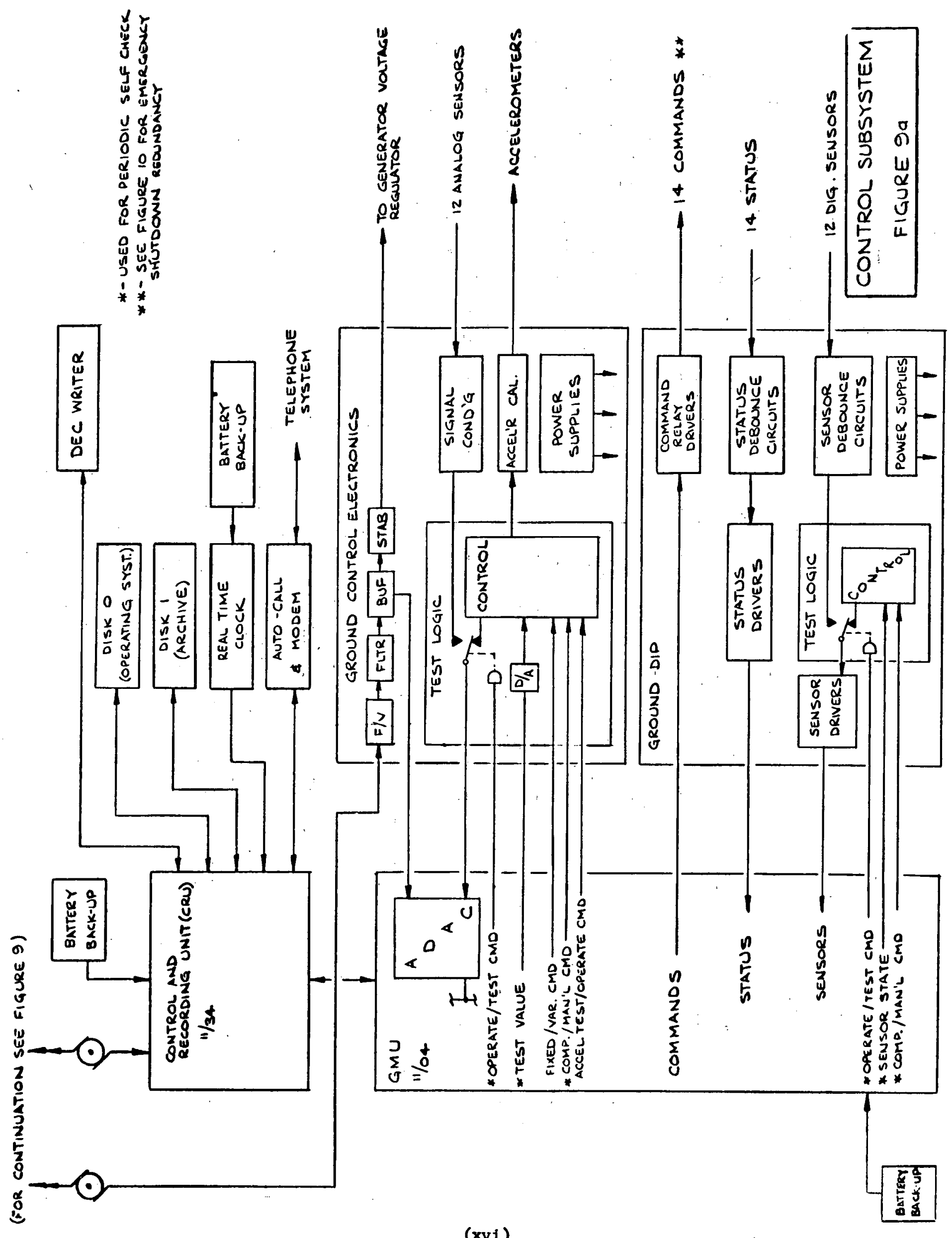

(xvi) 


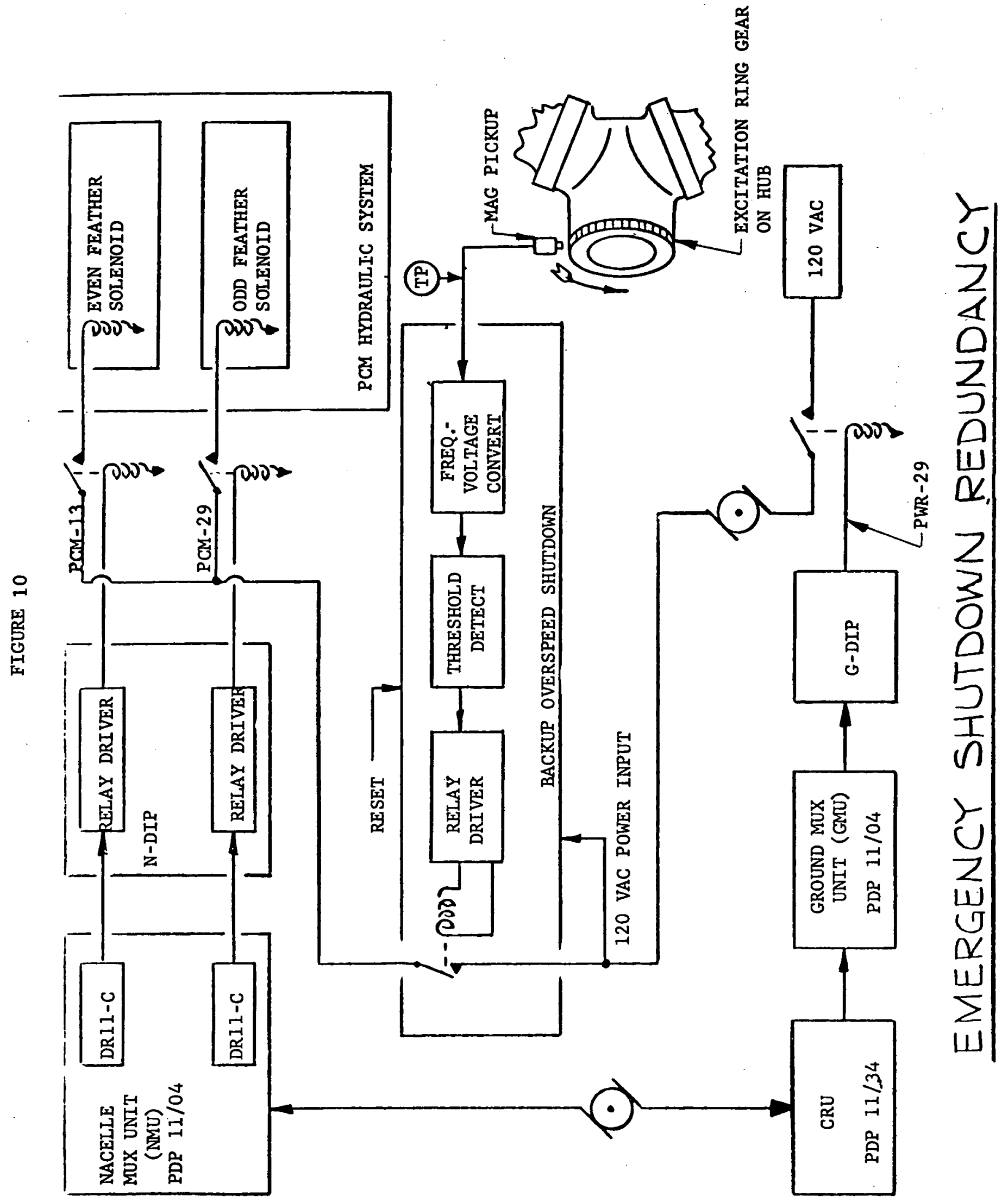




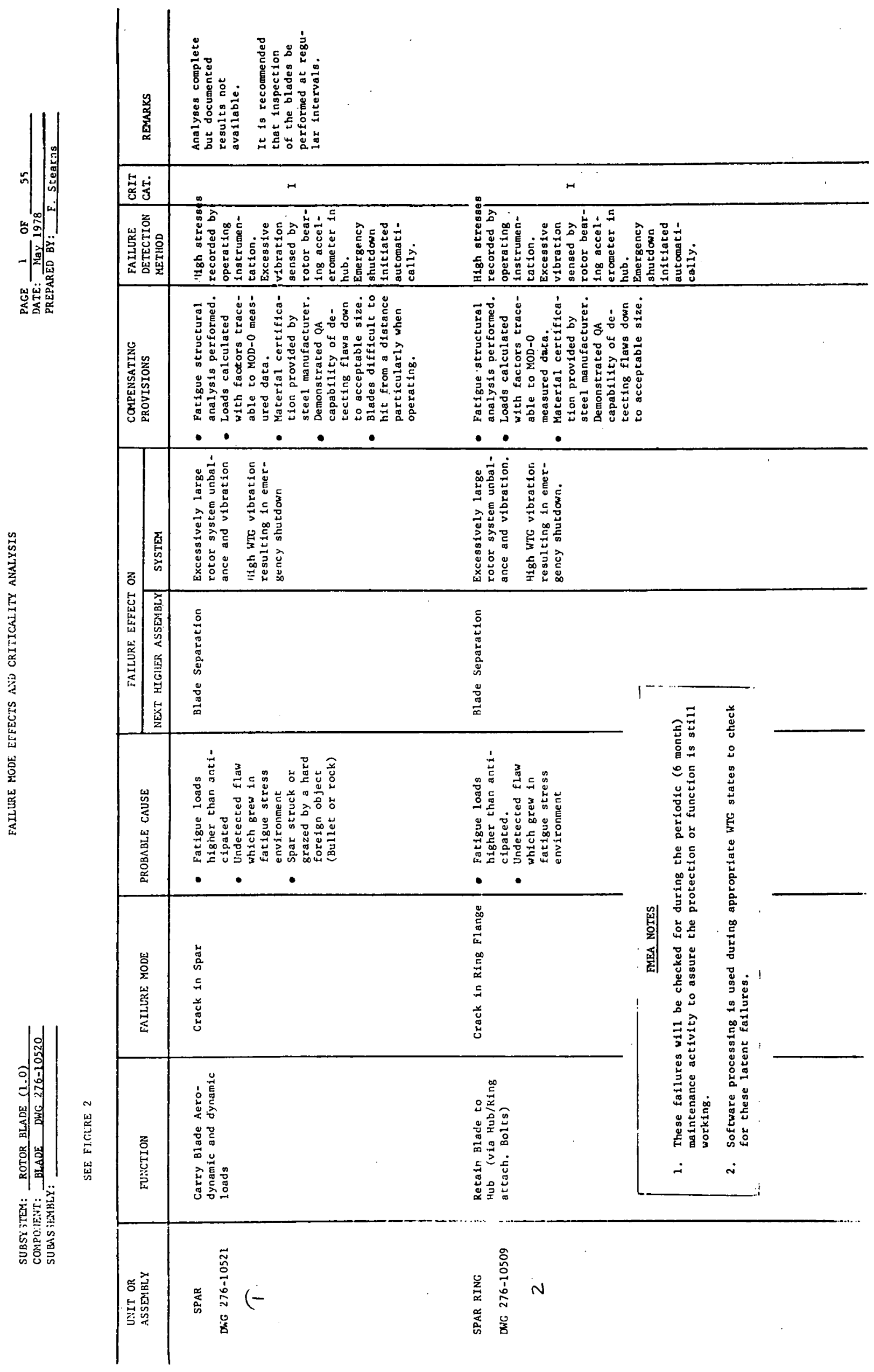




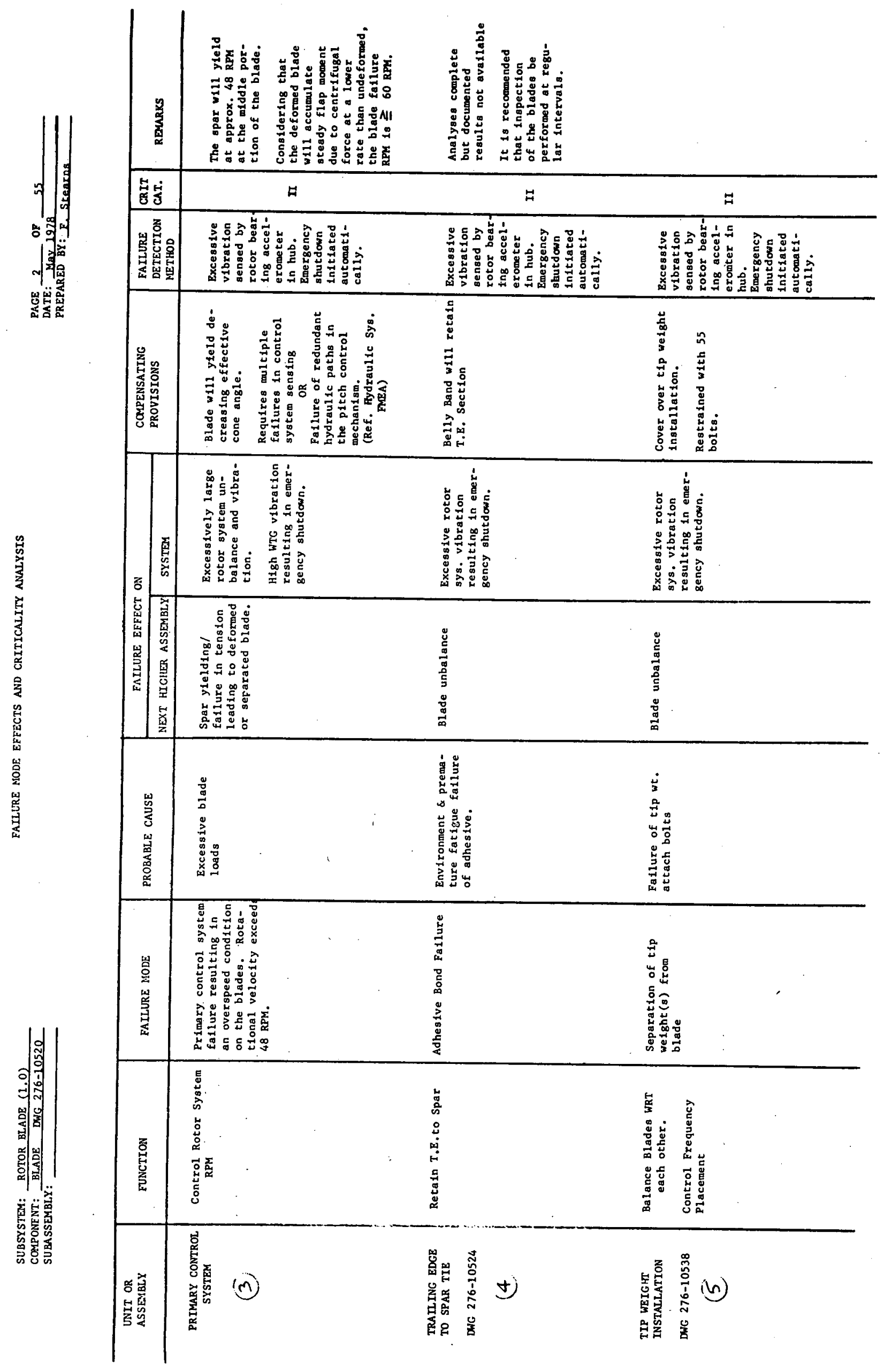




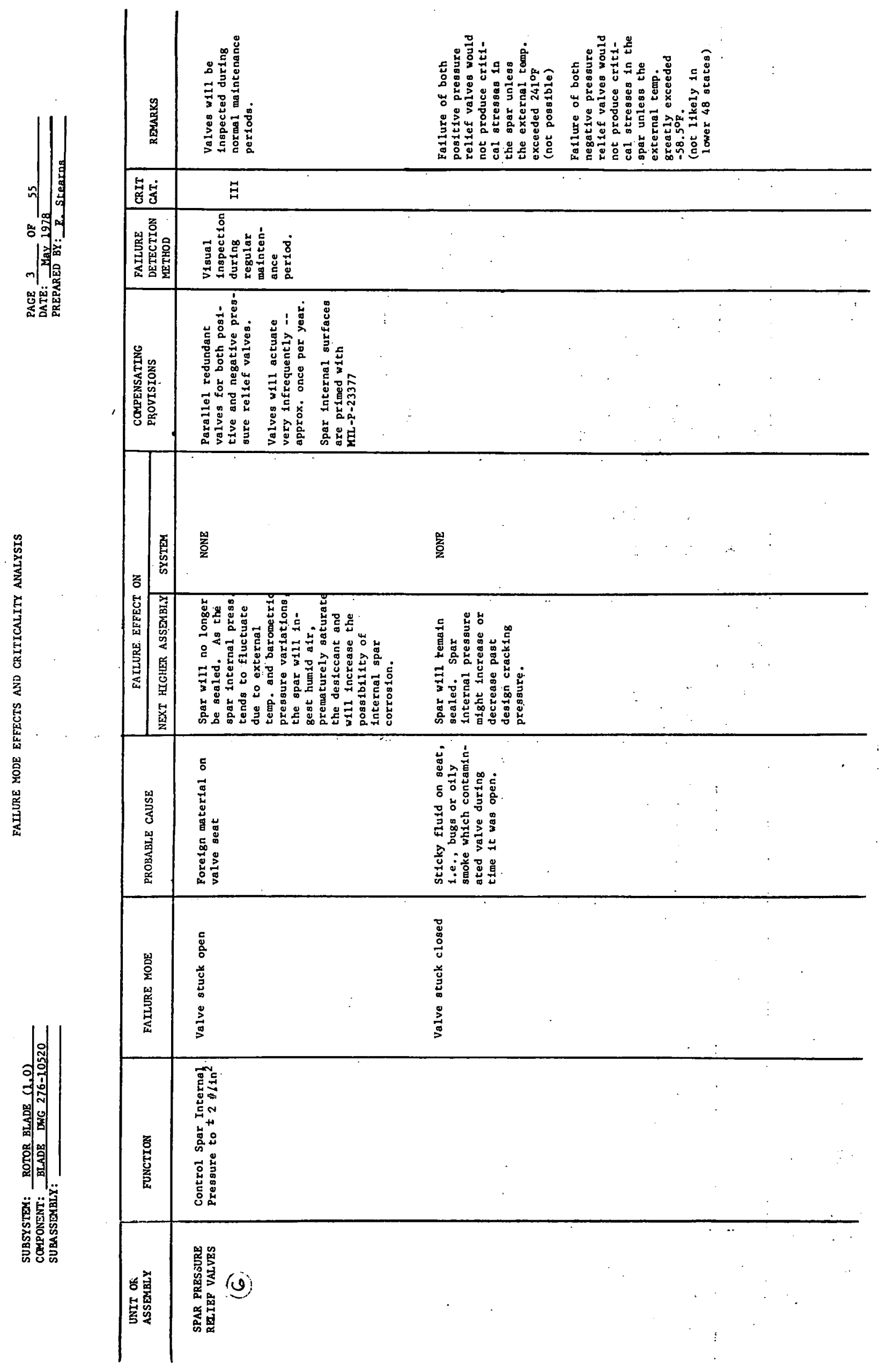




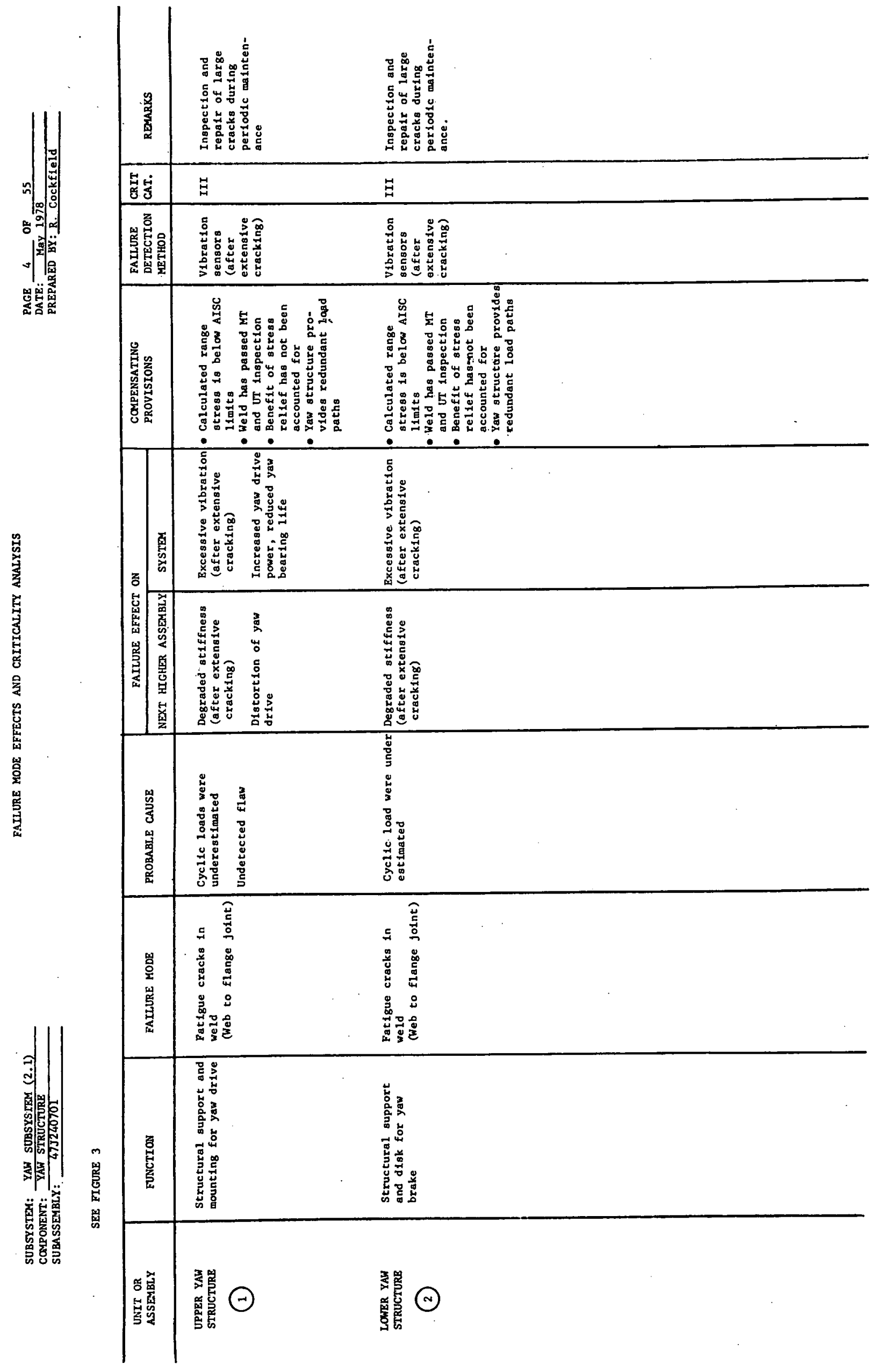




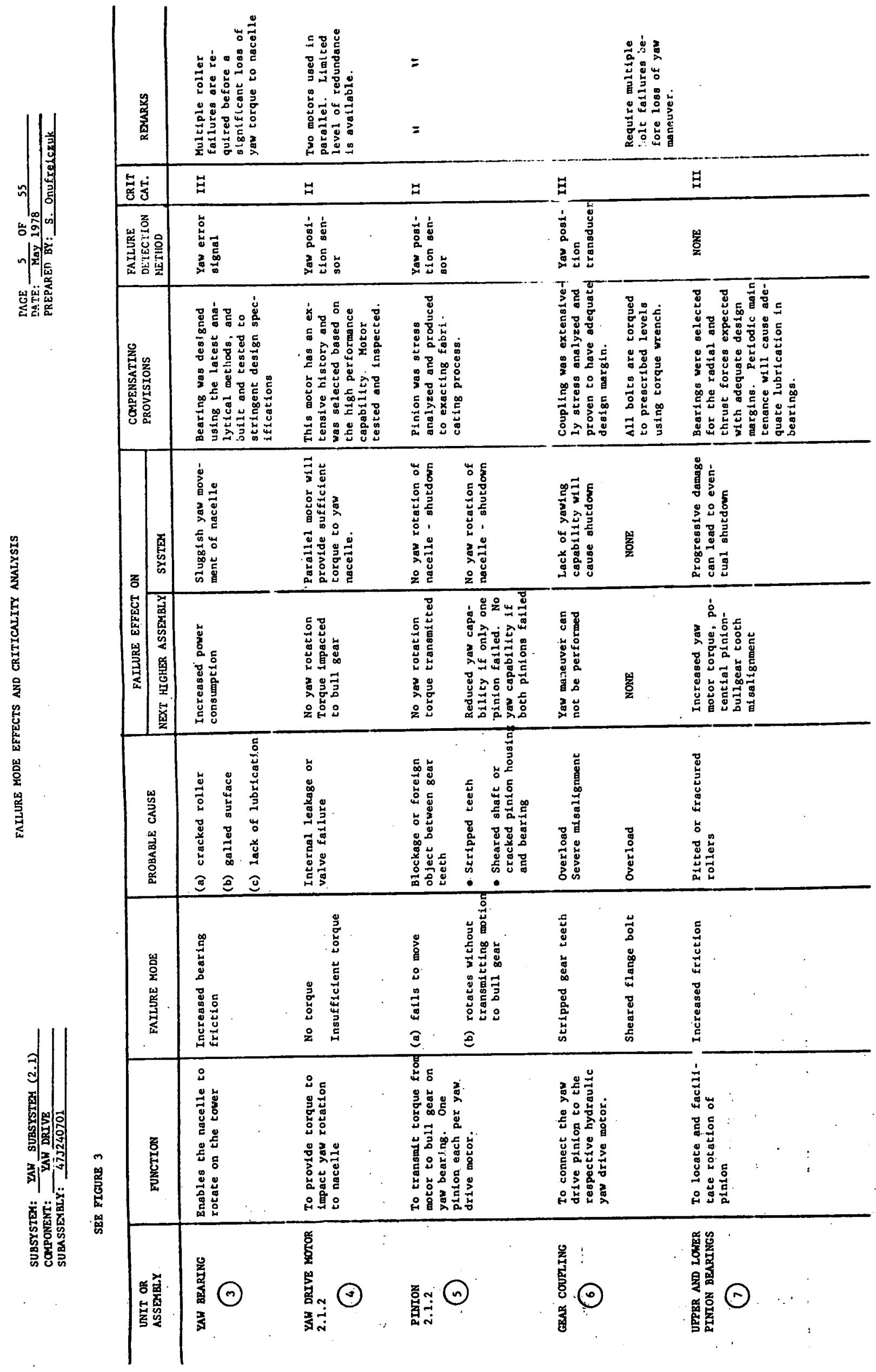




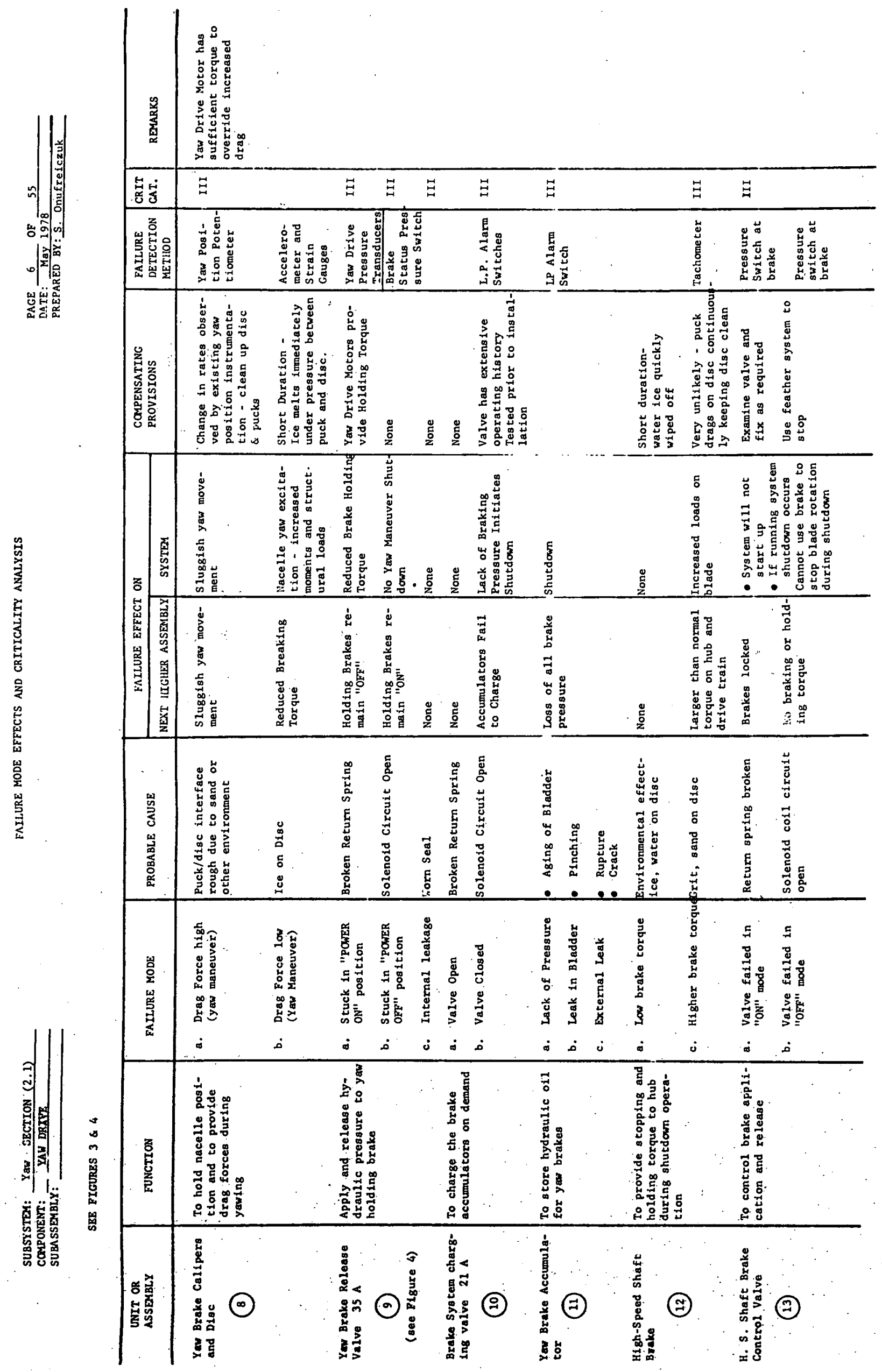




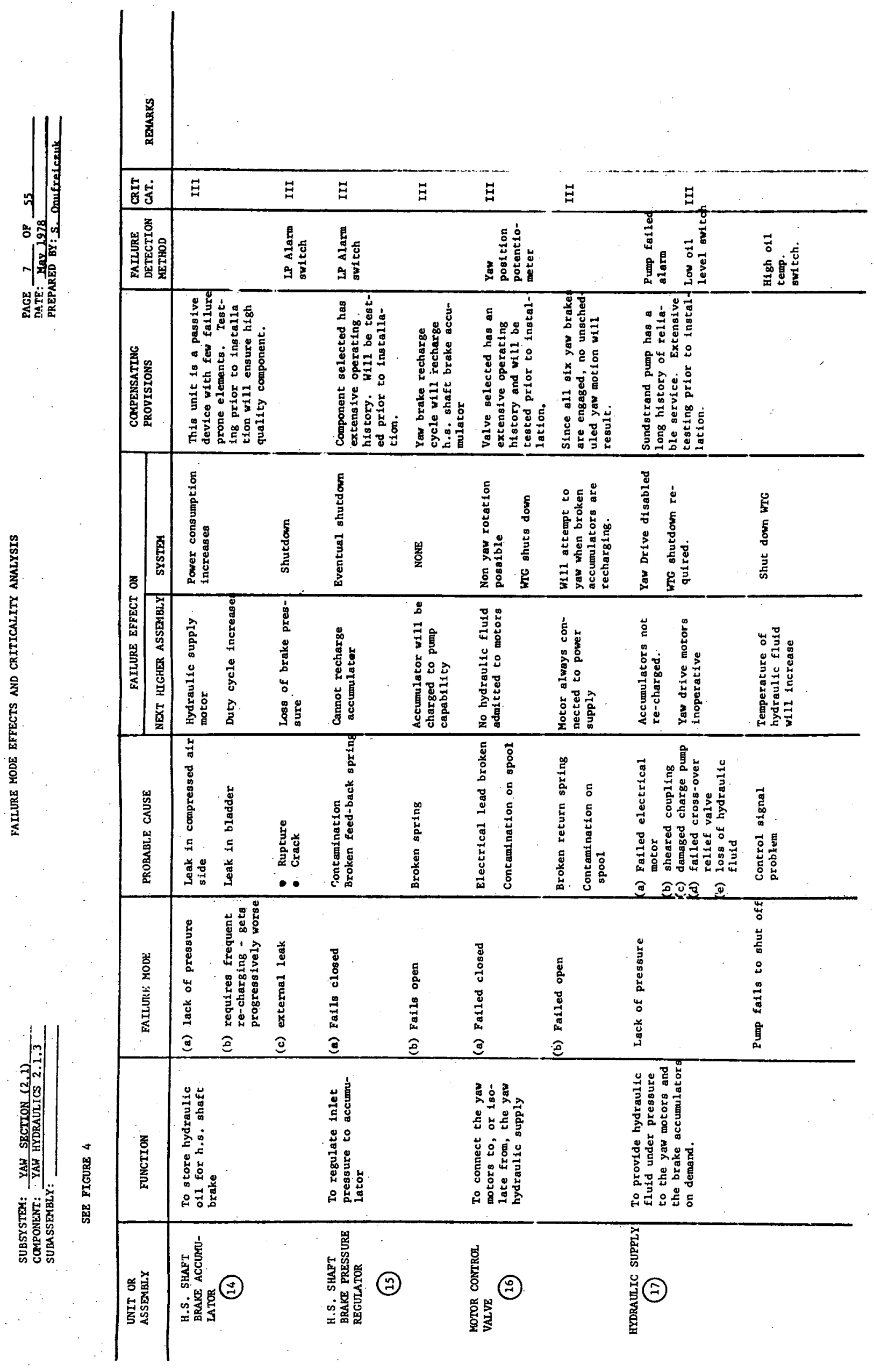




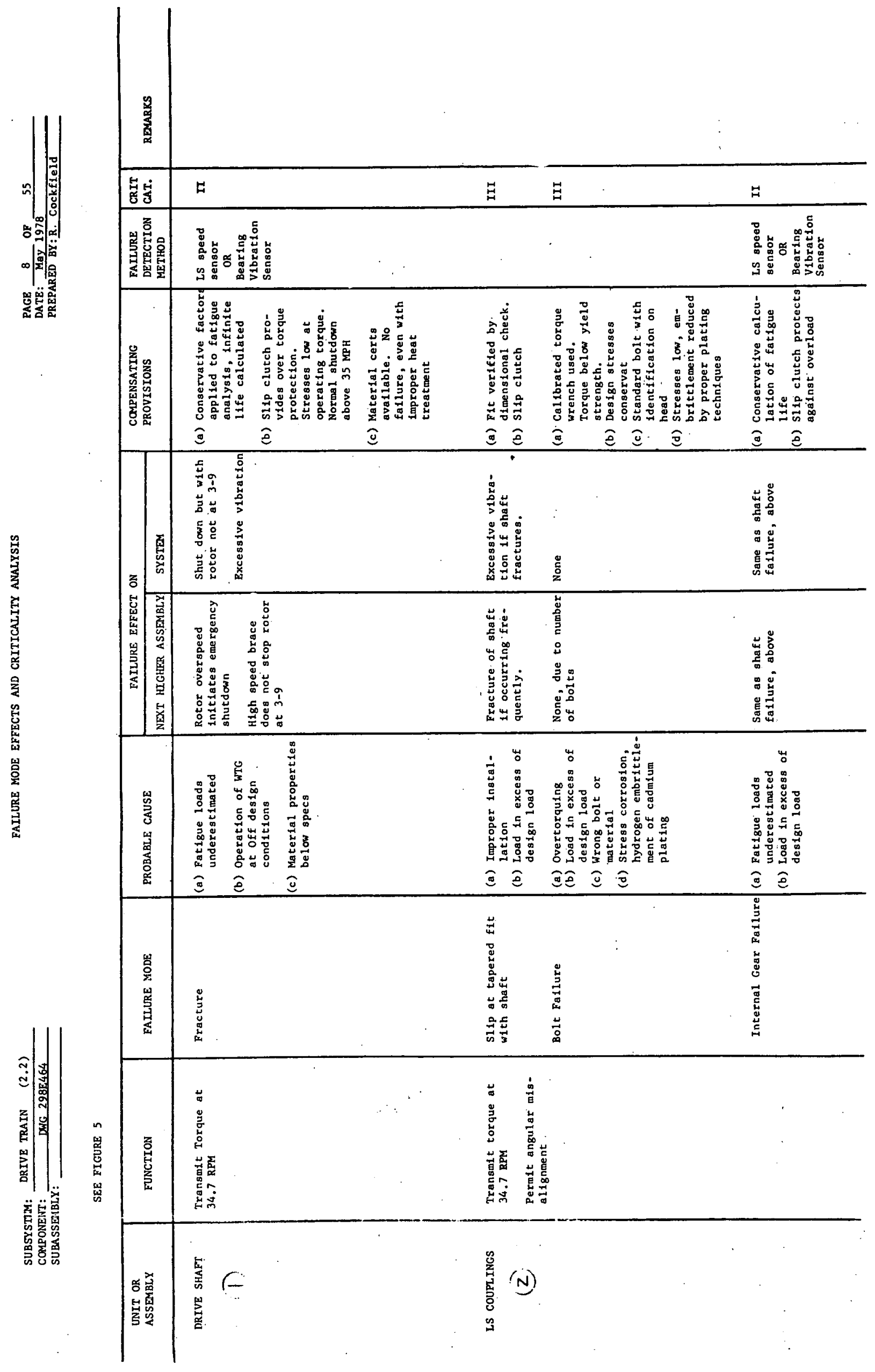




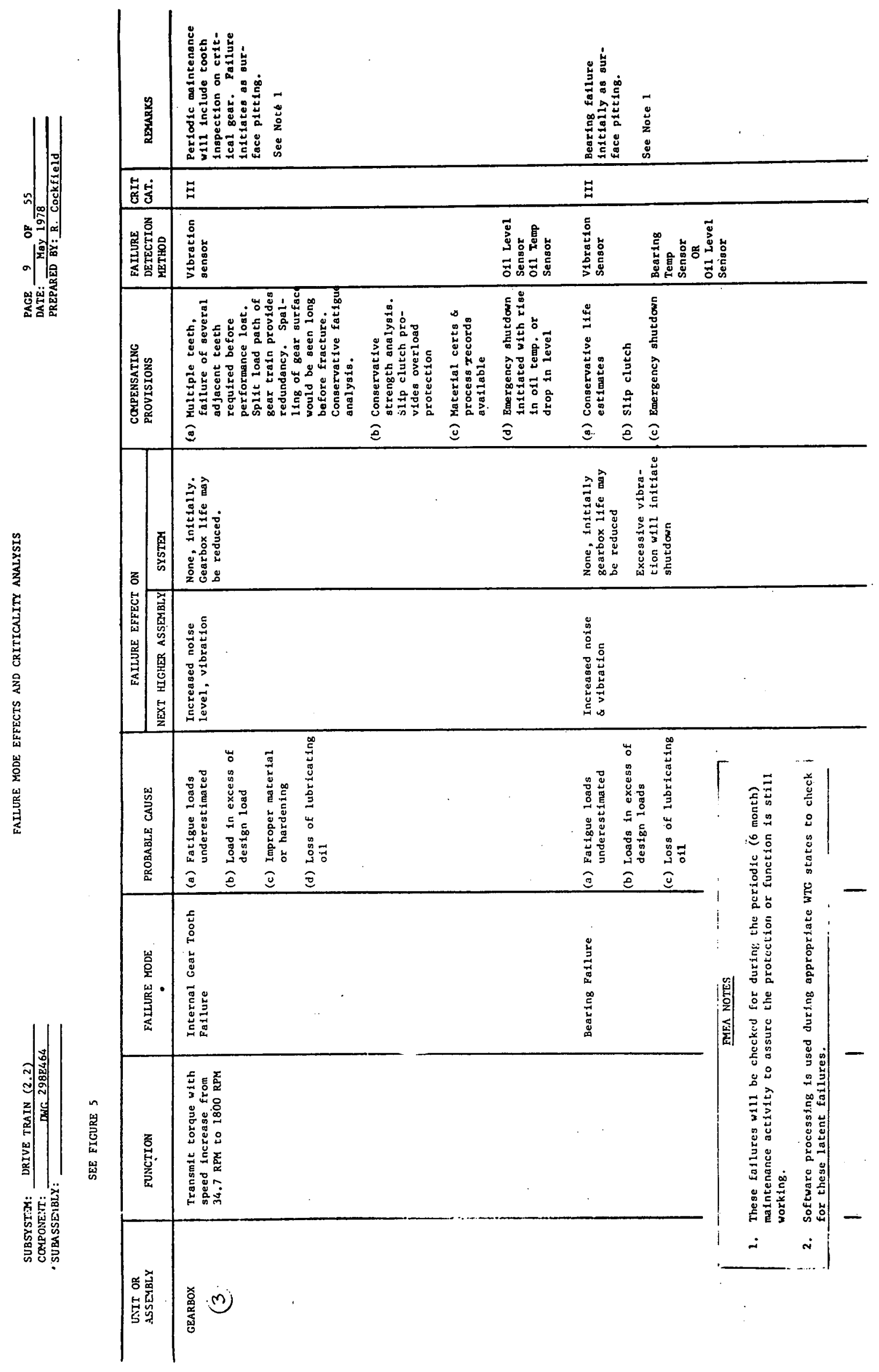




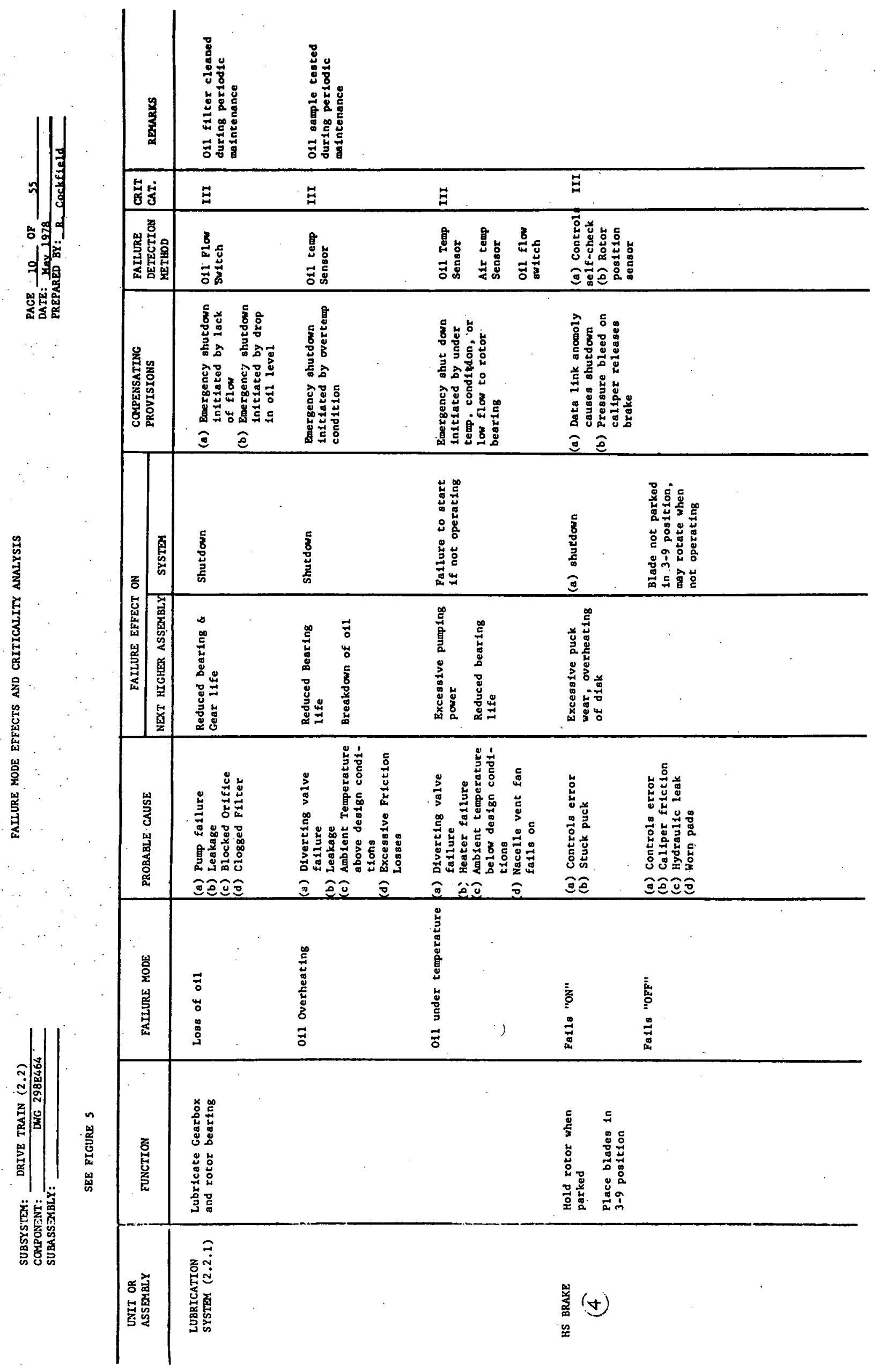




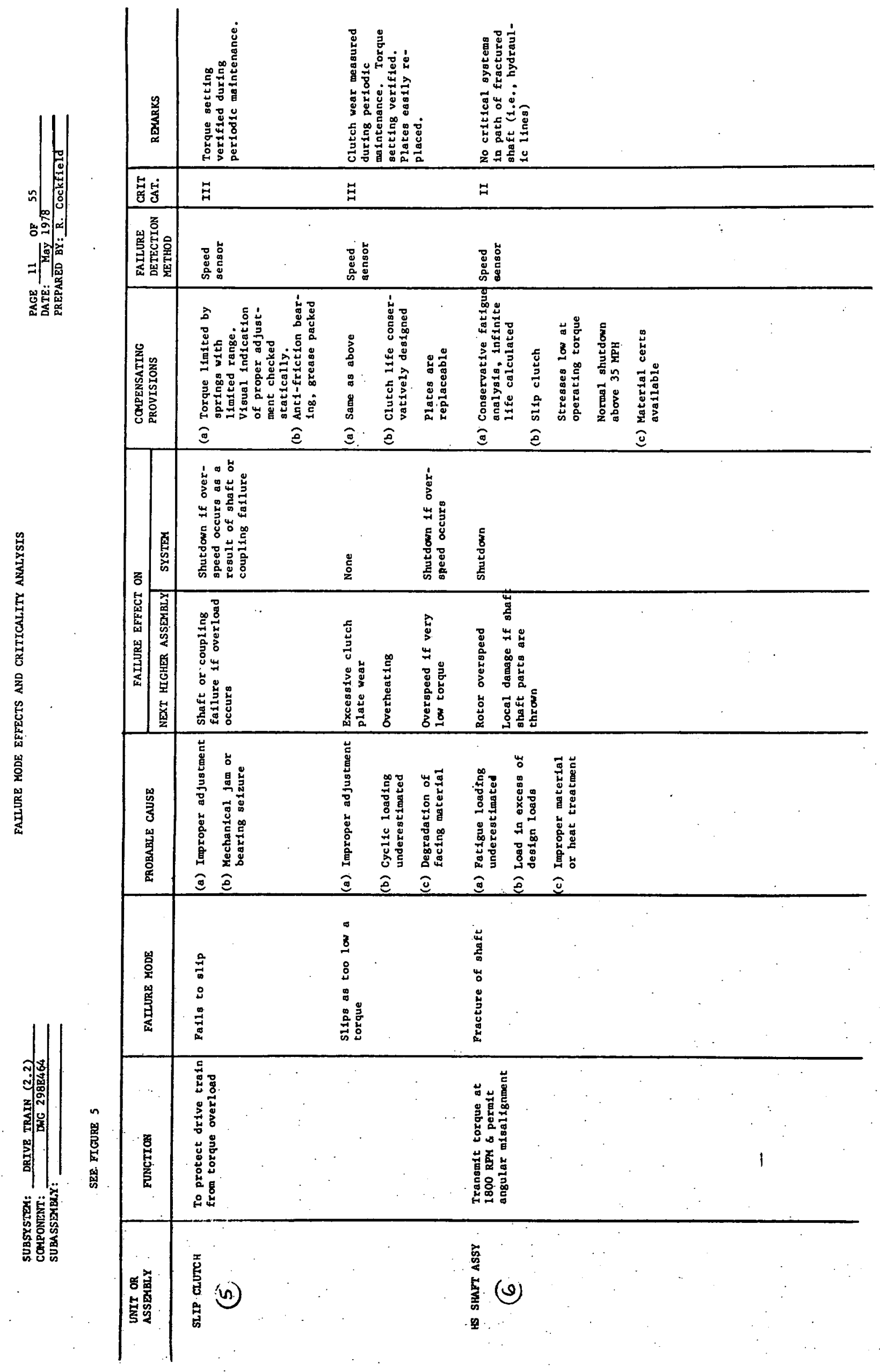




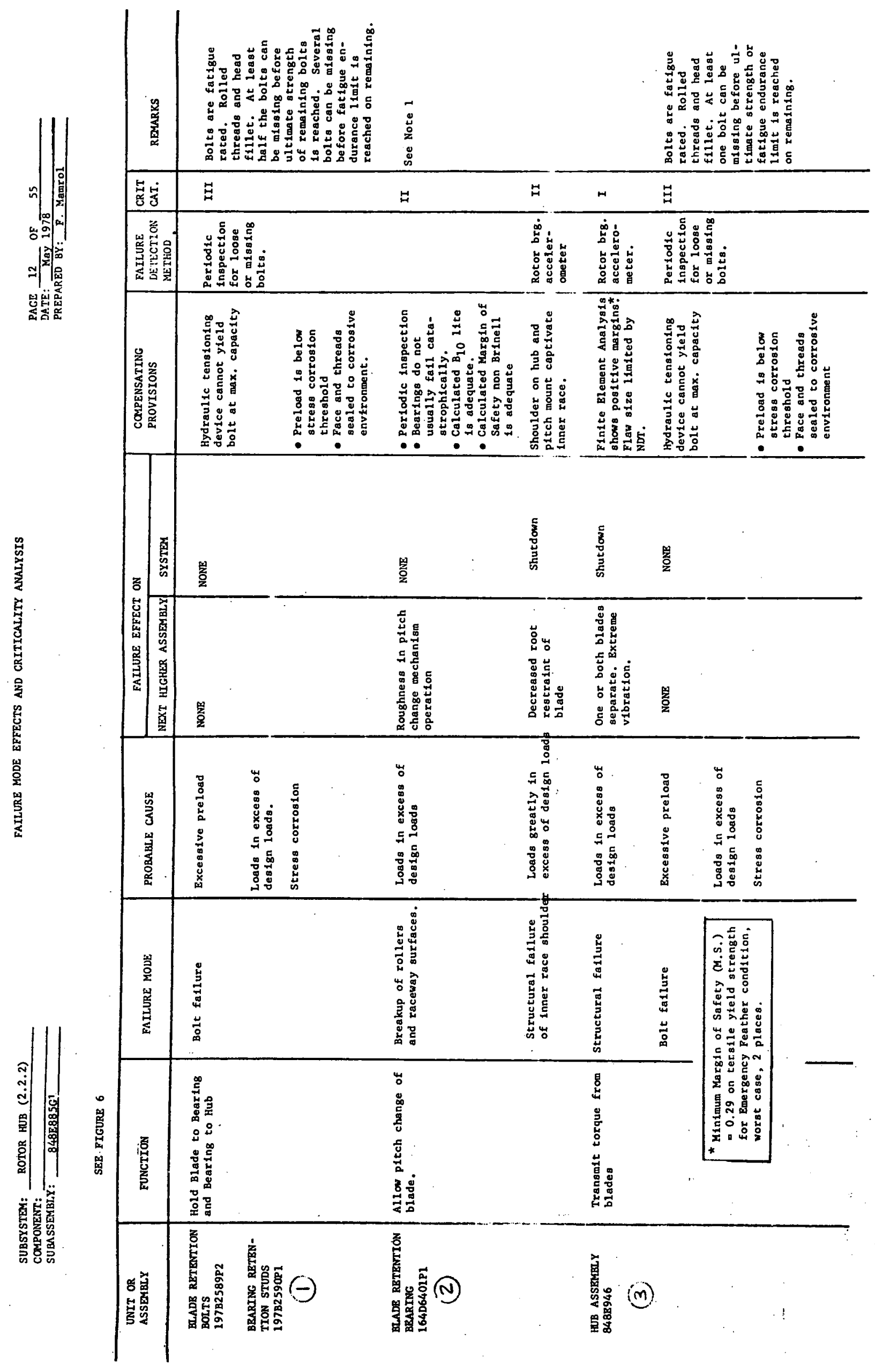




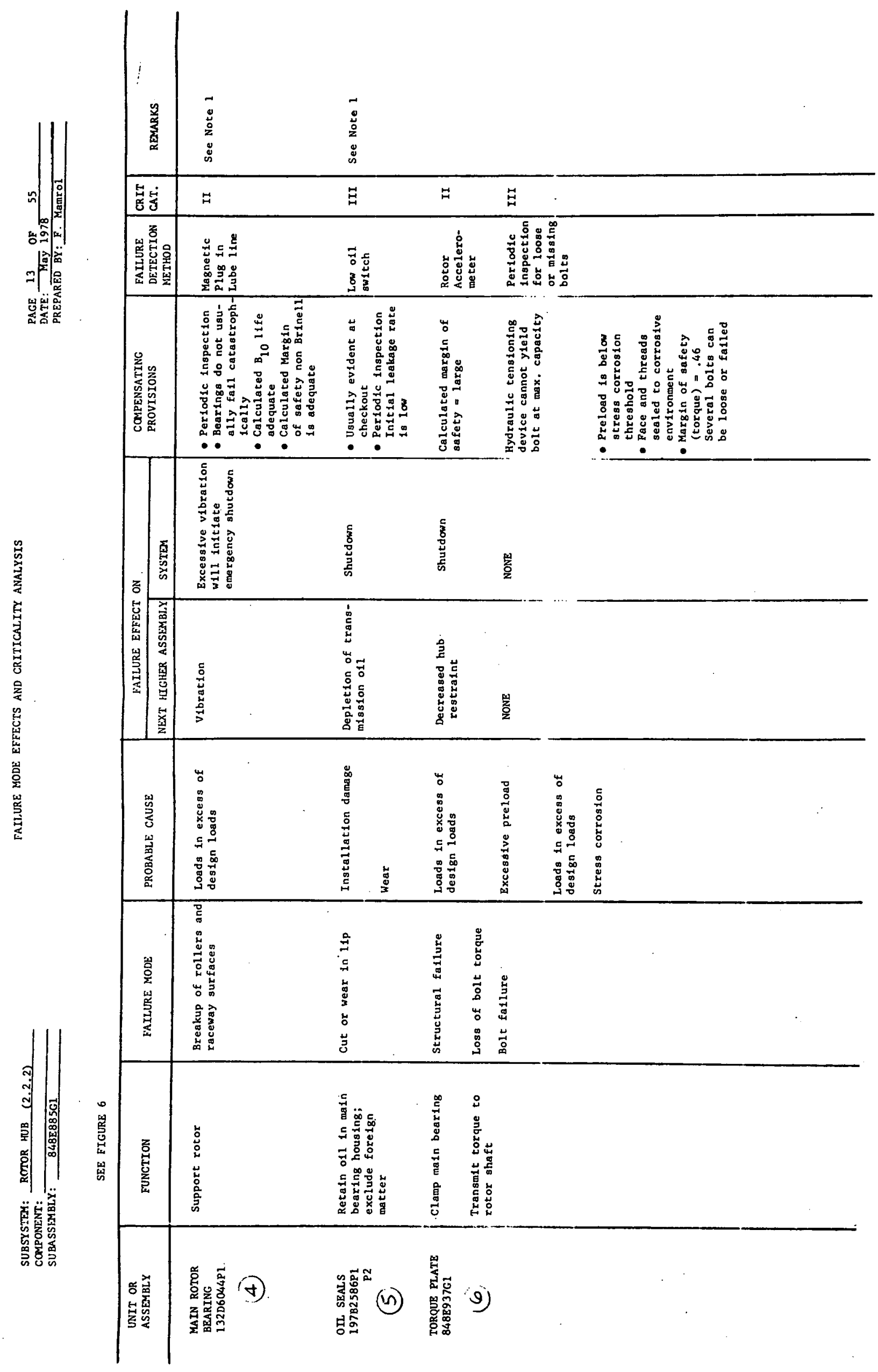




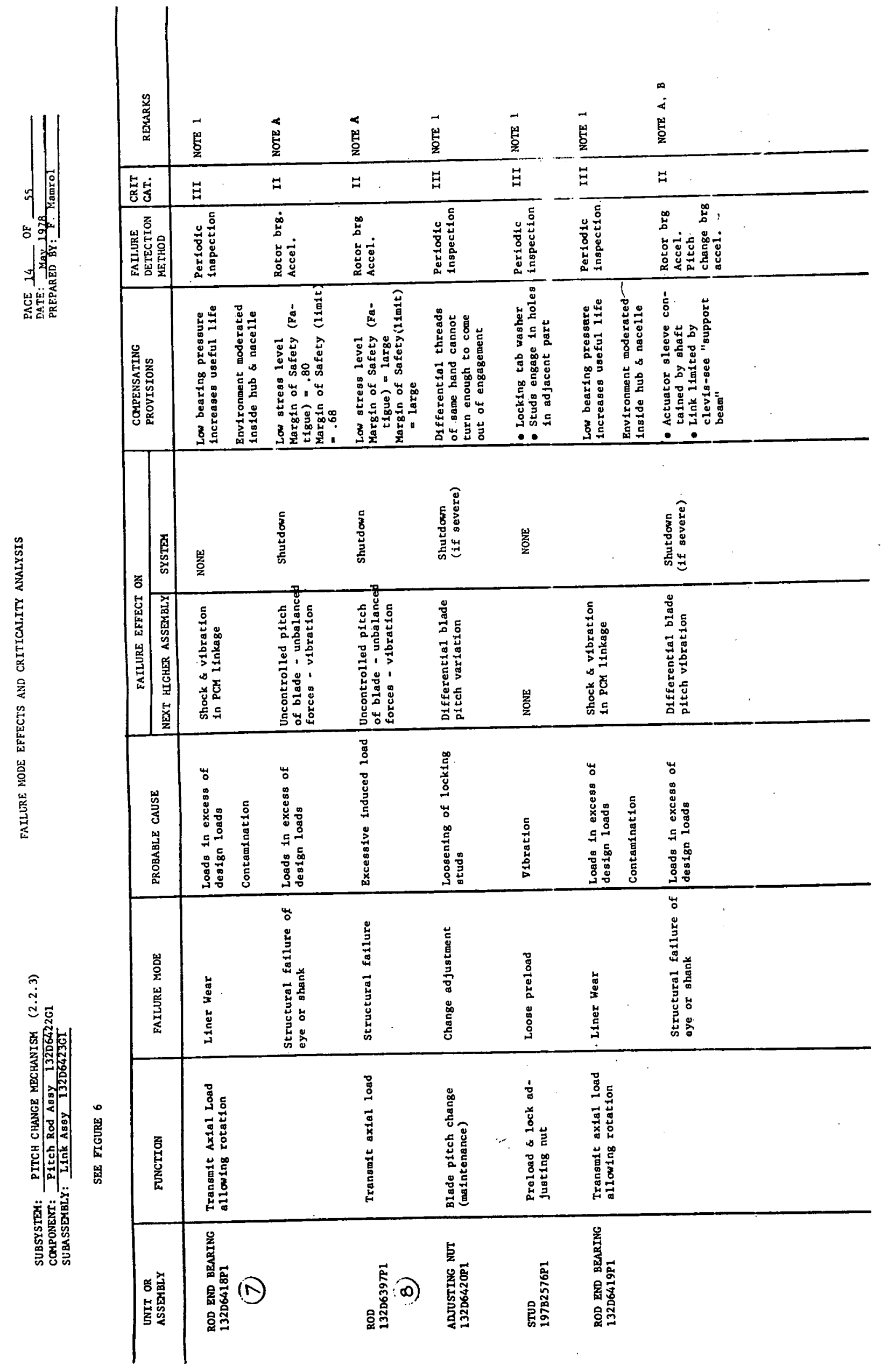




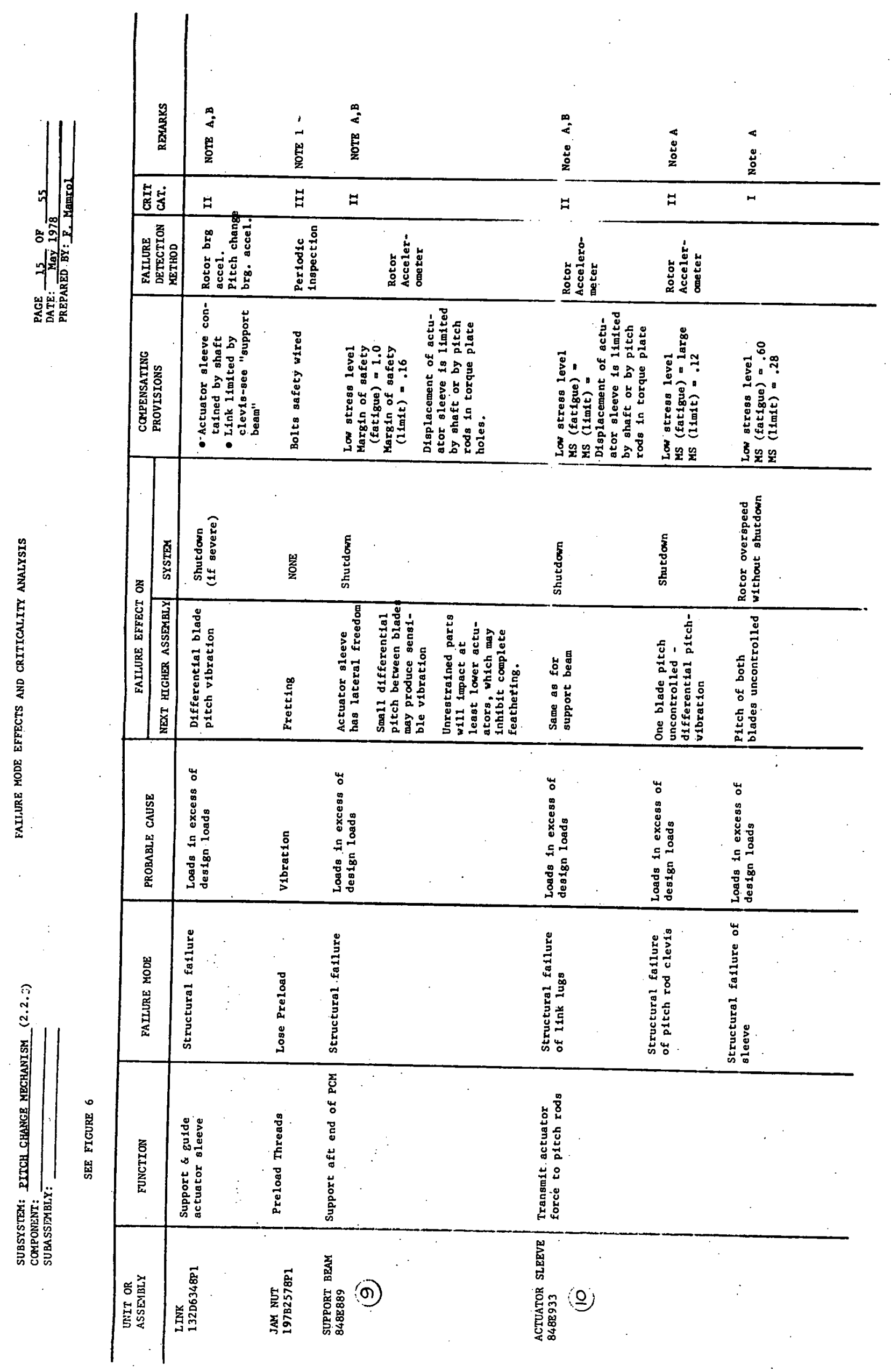




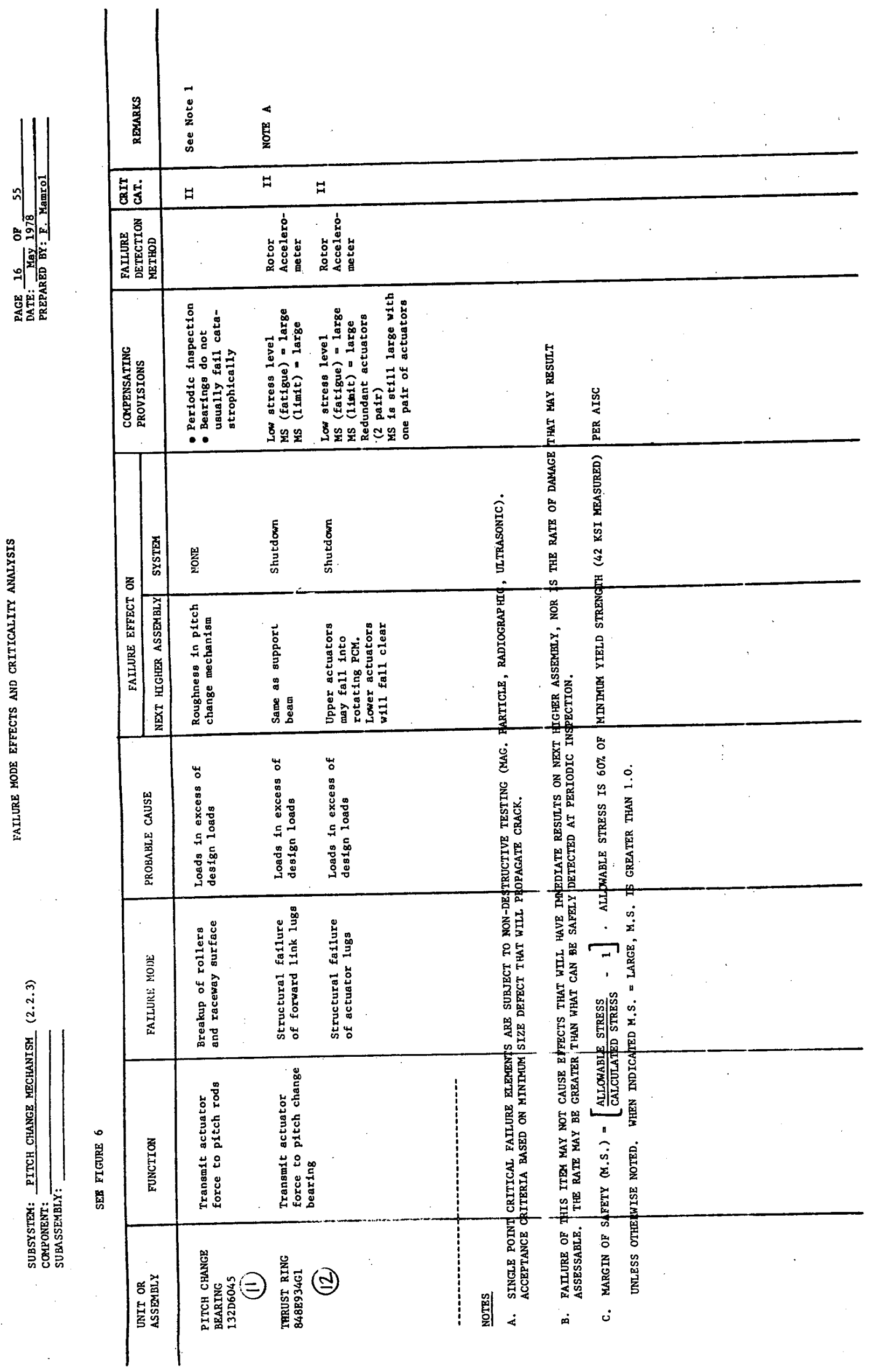




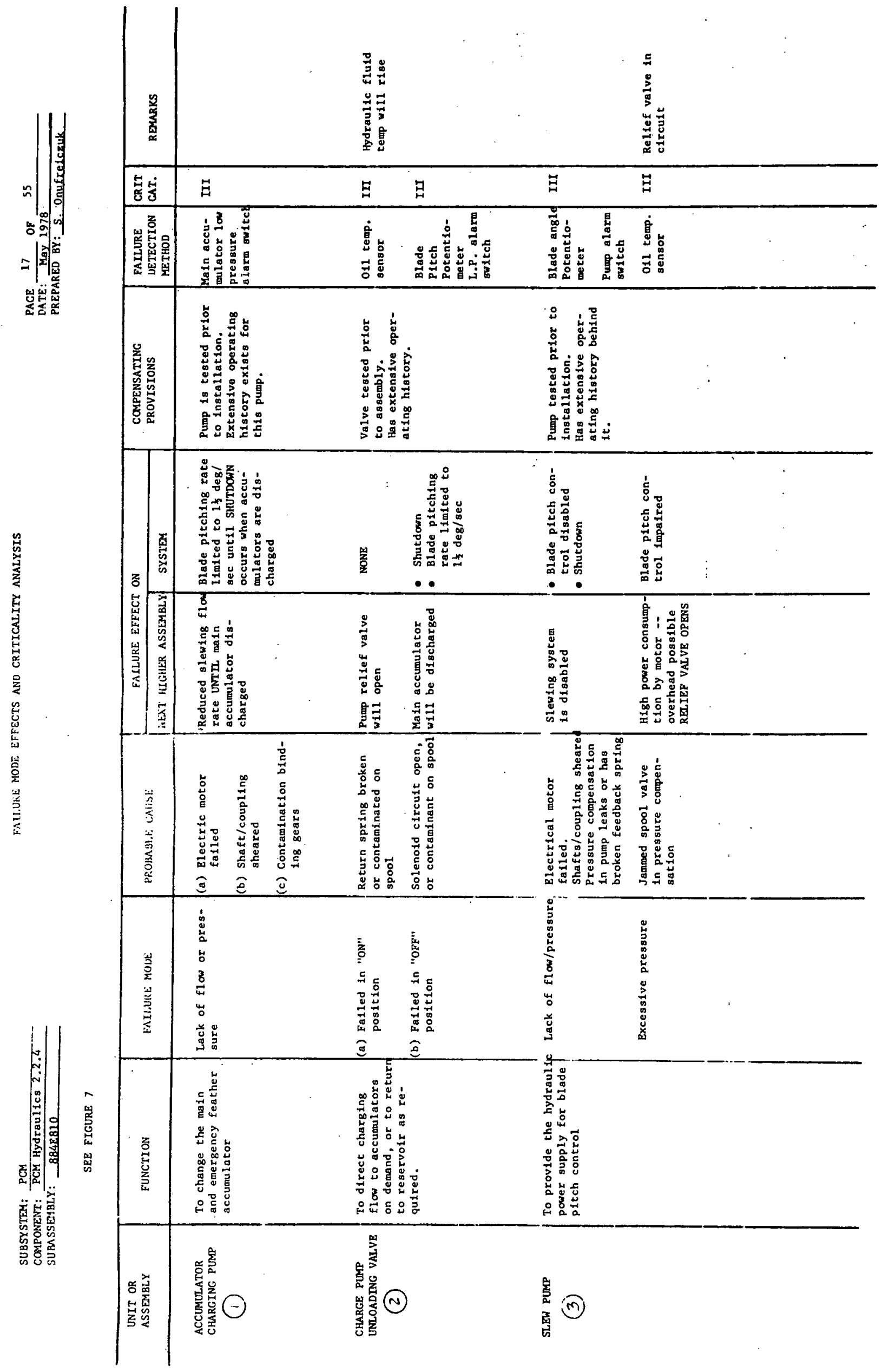




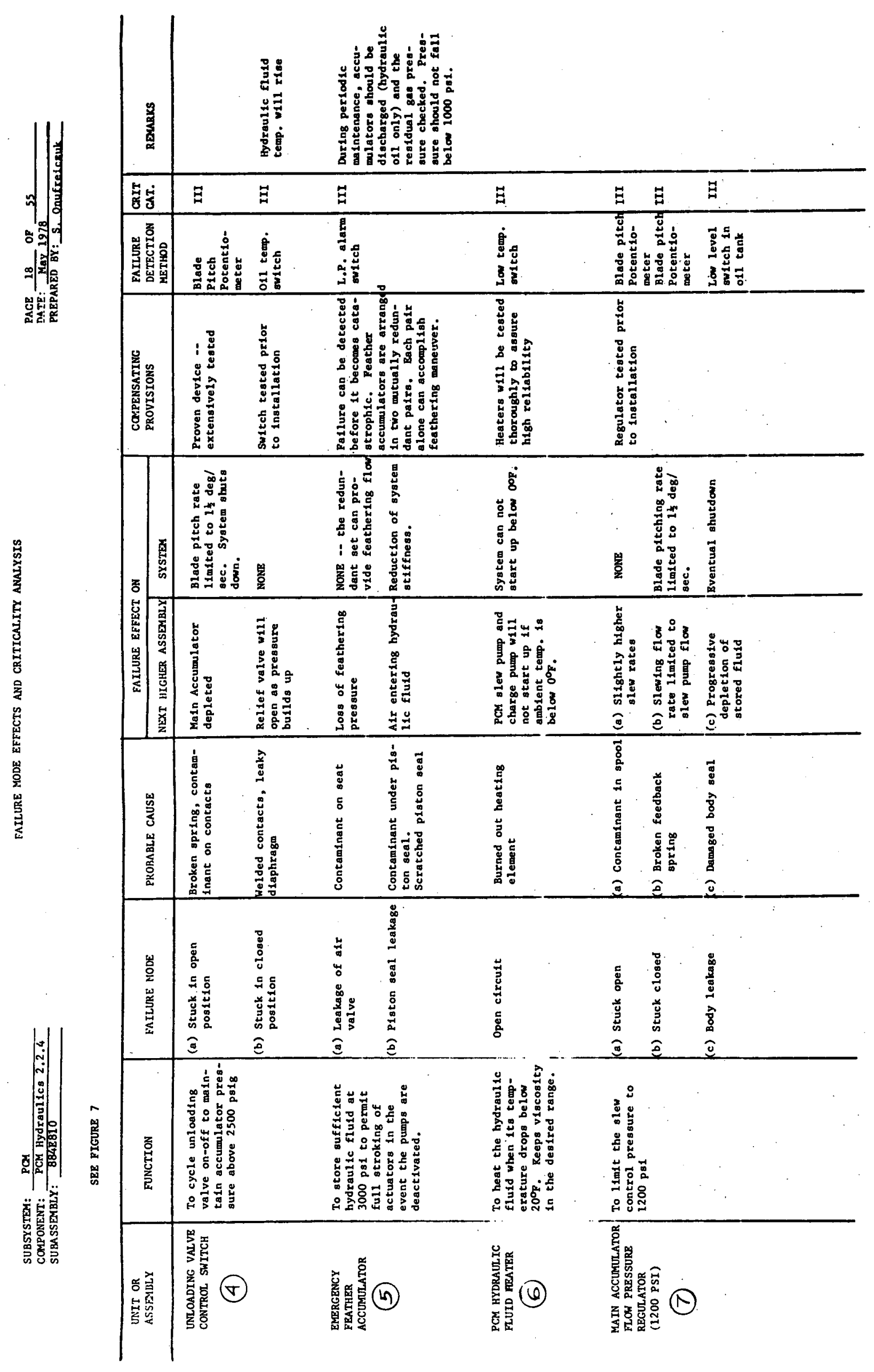




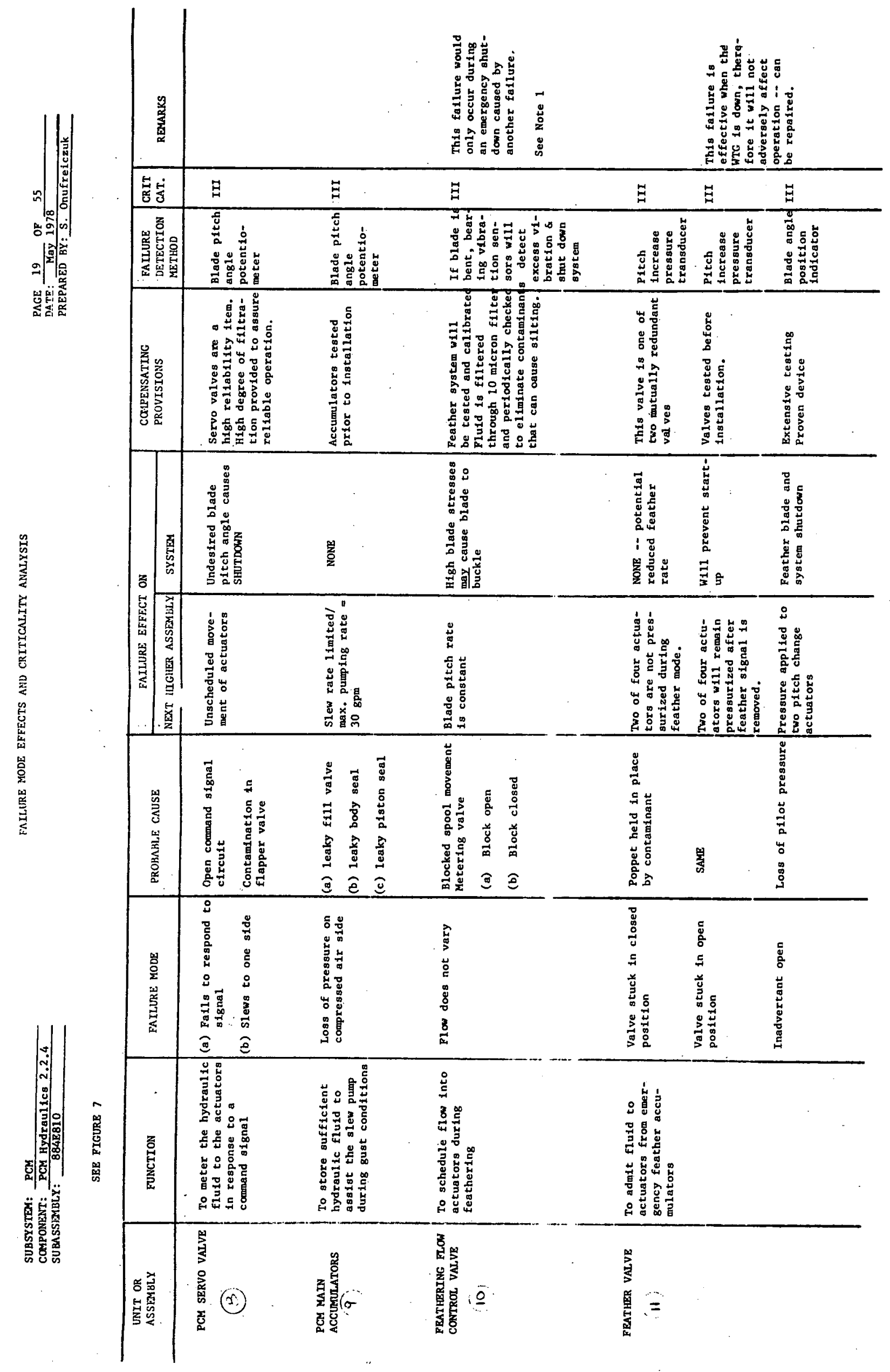




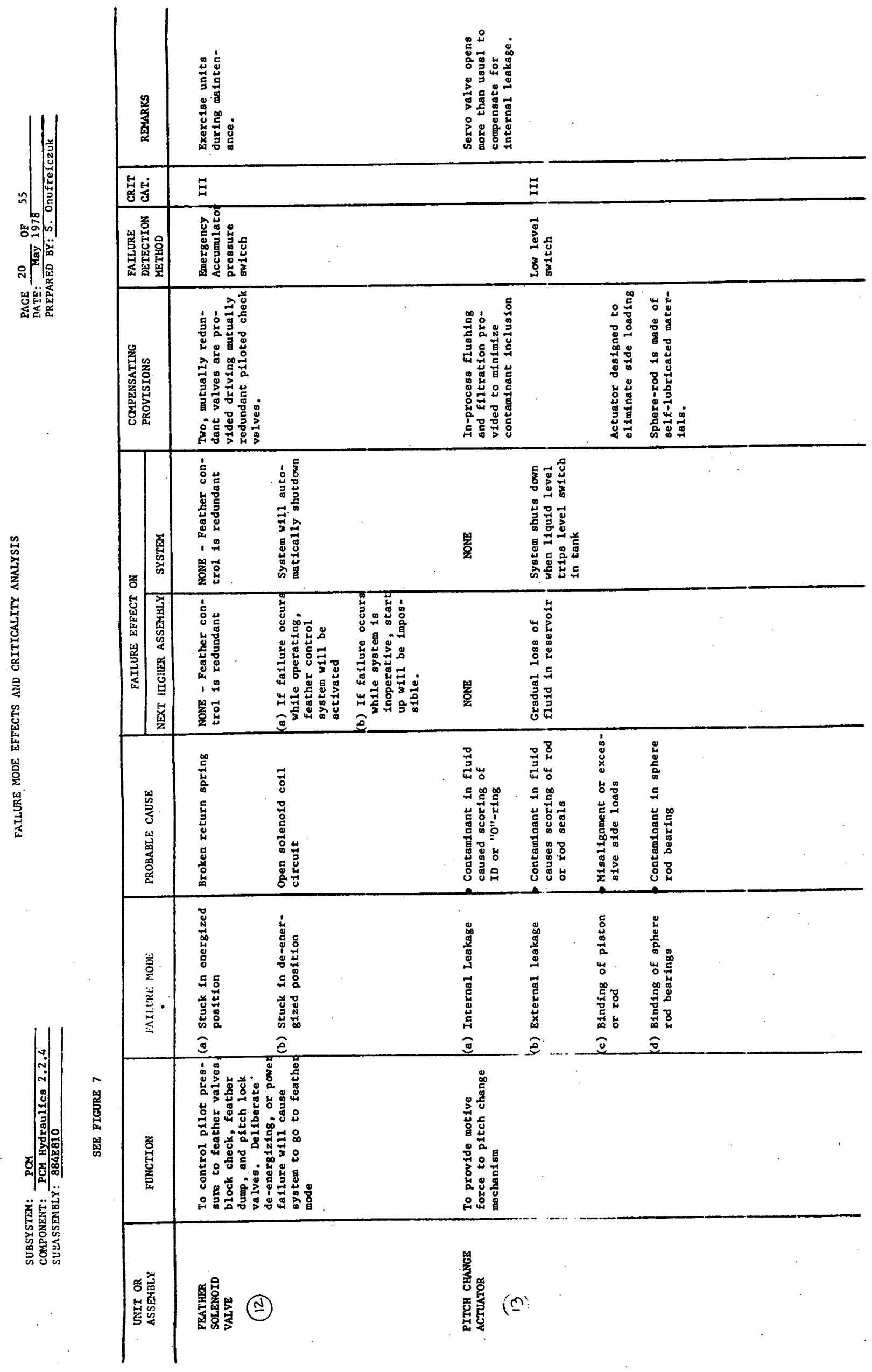




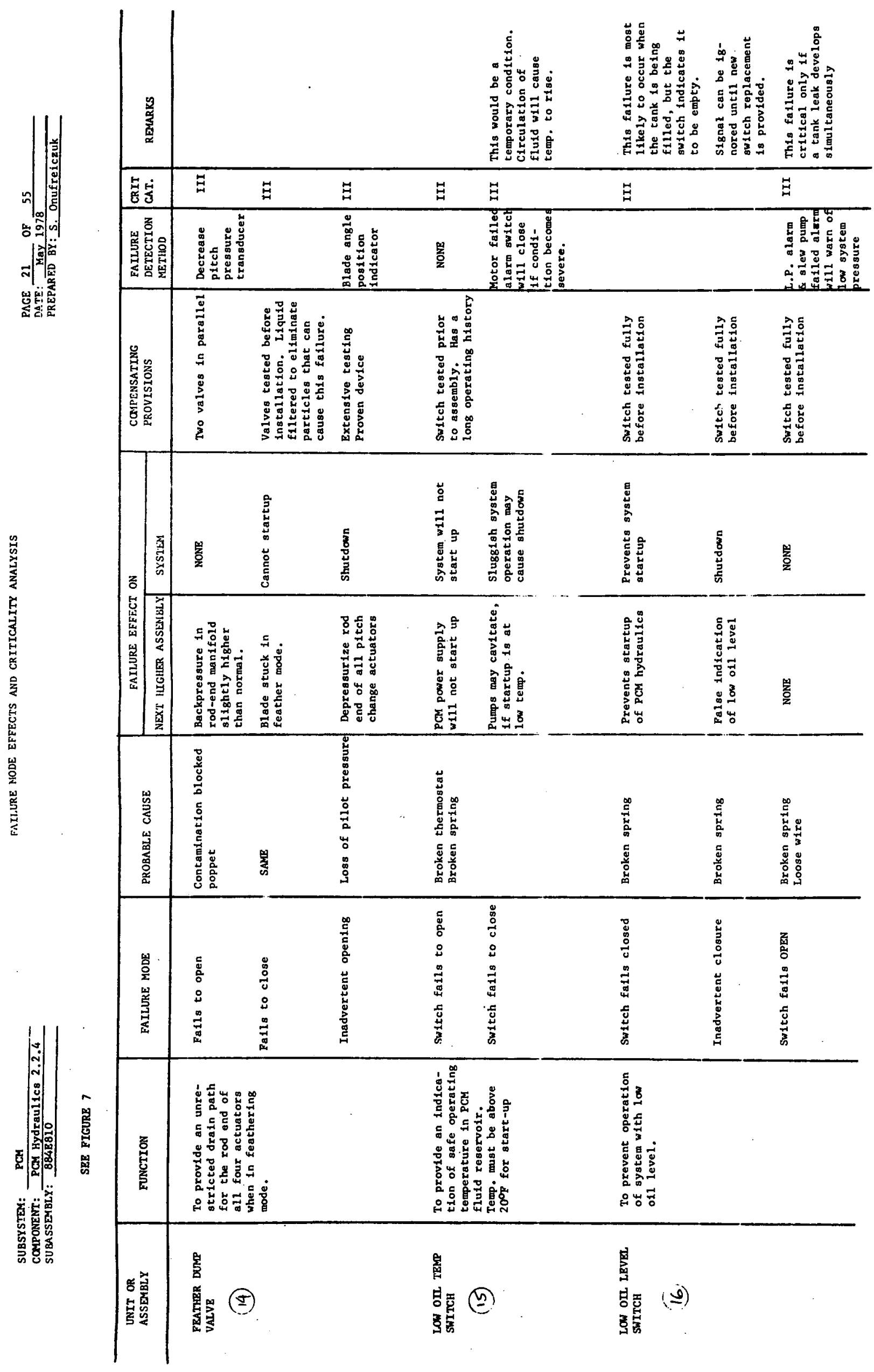




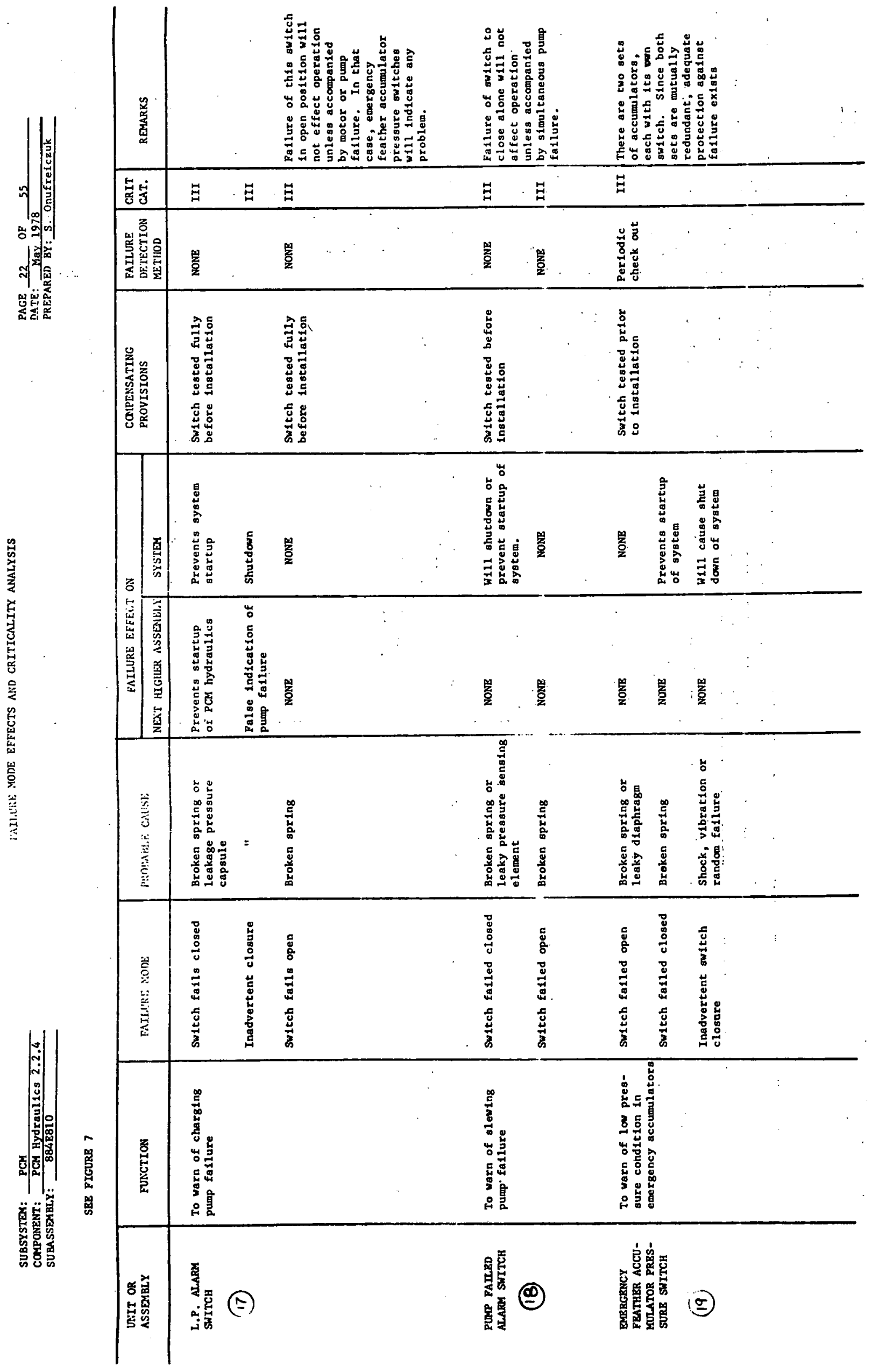




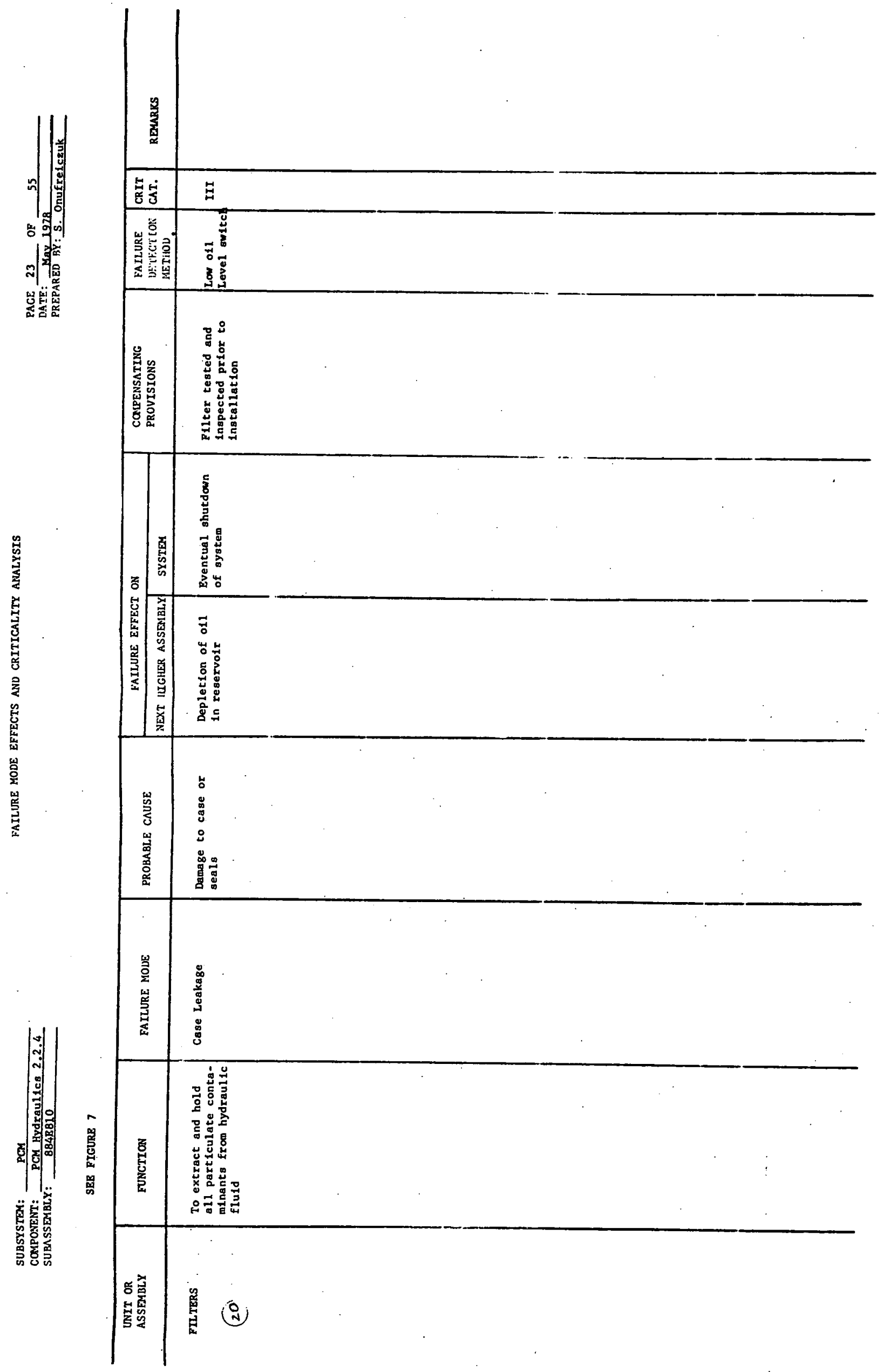




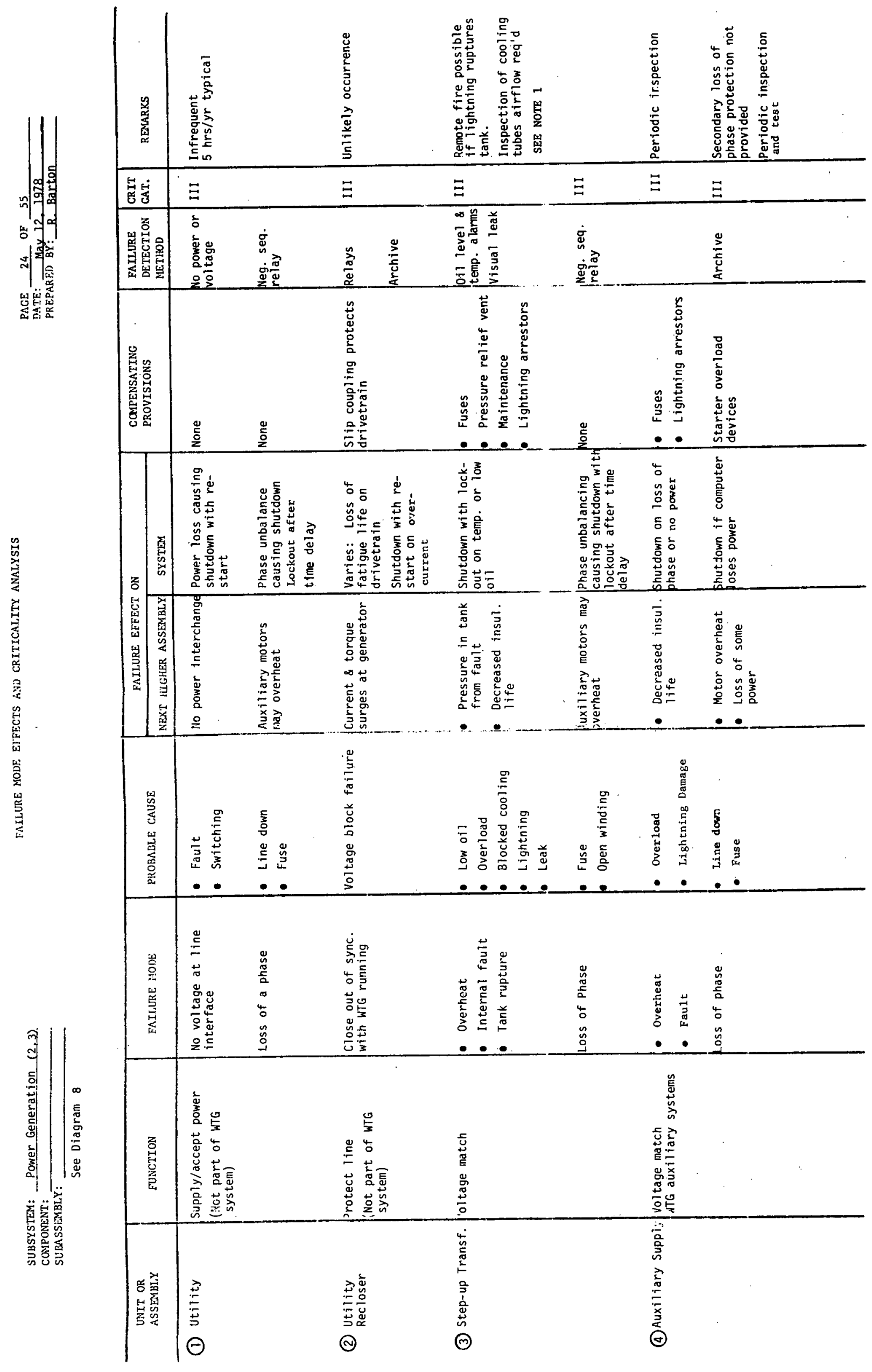




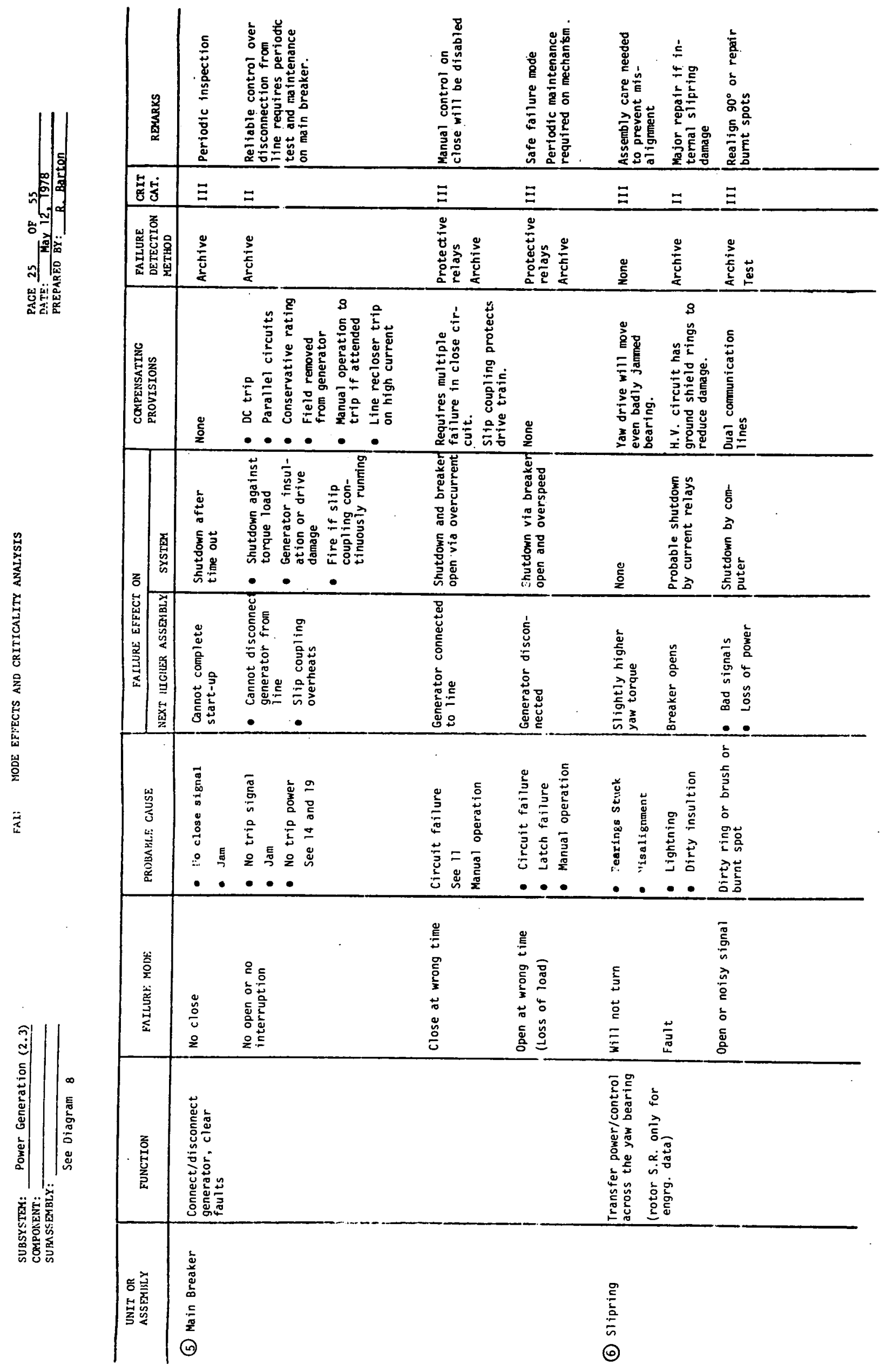




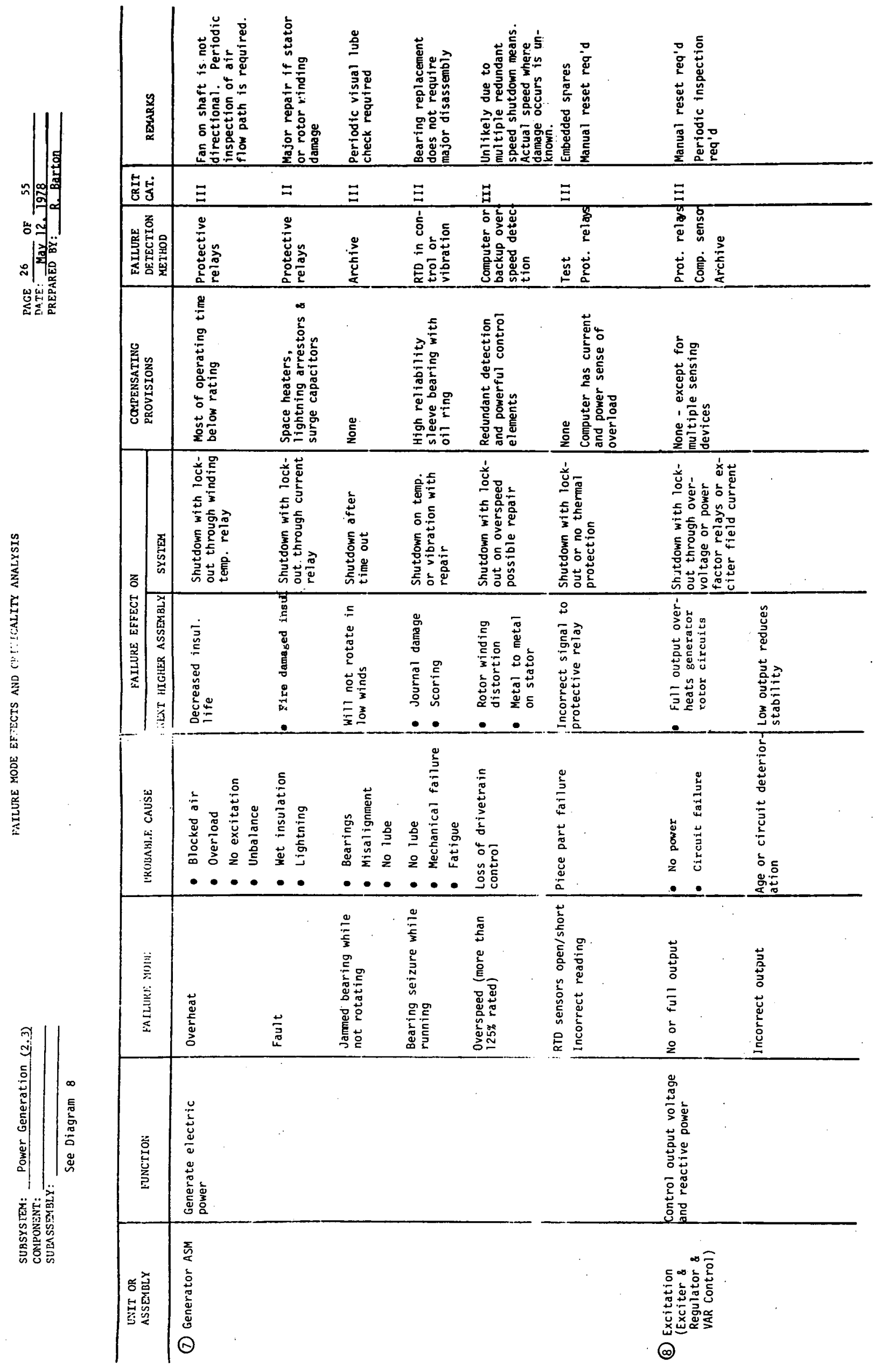




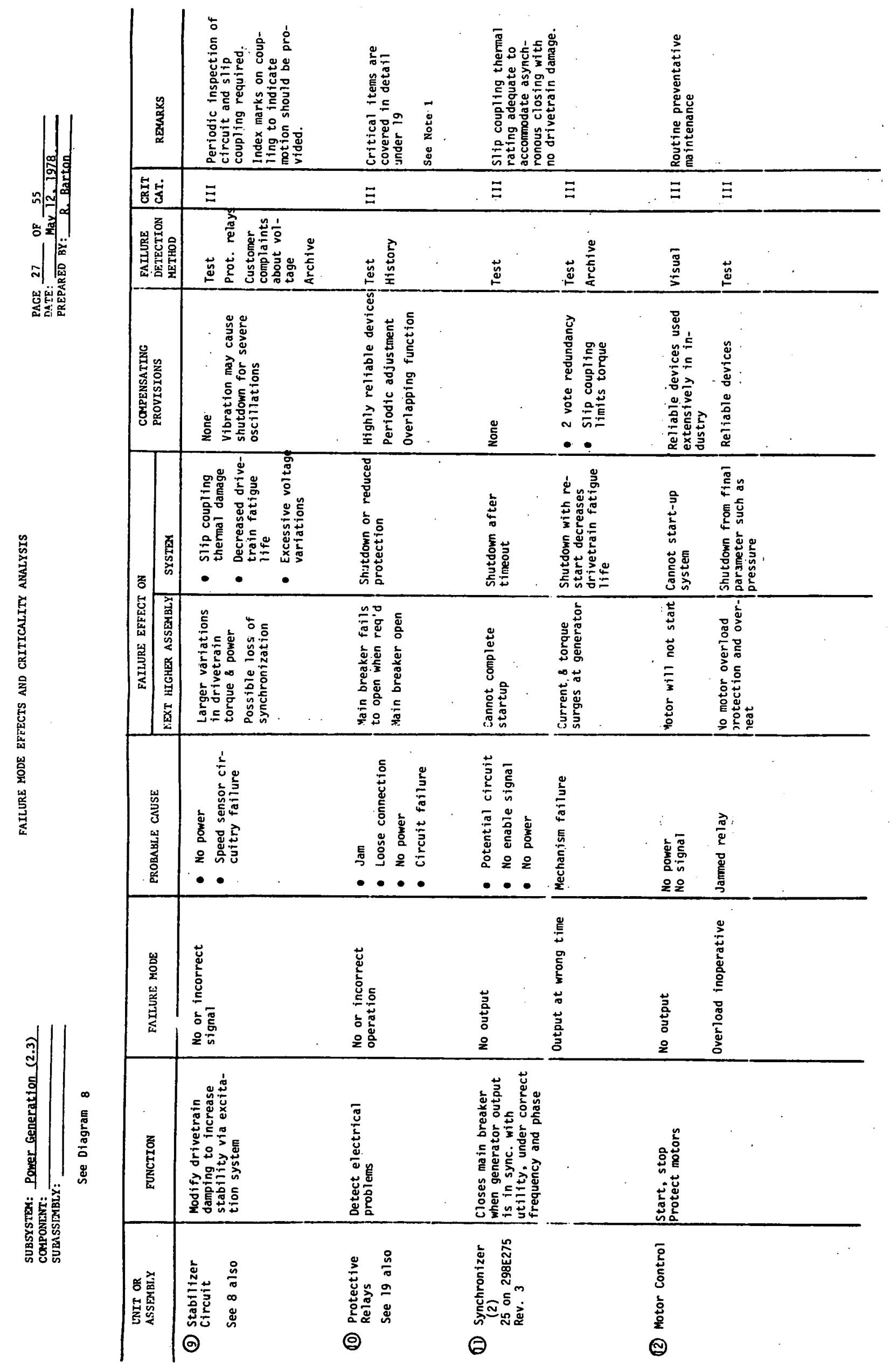




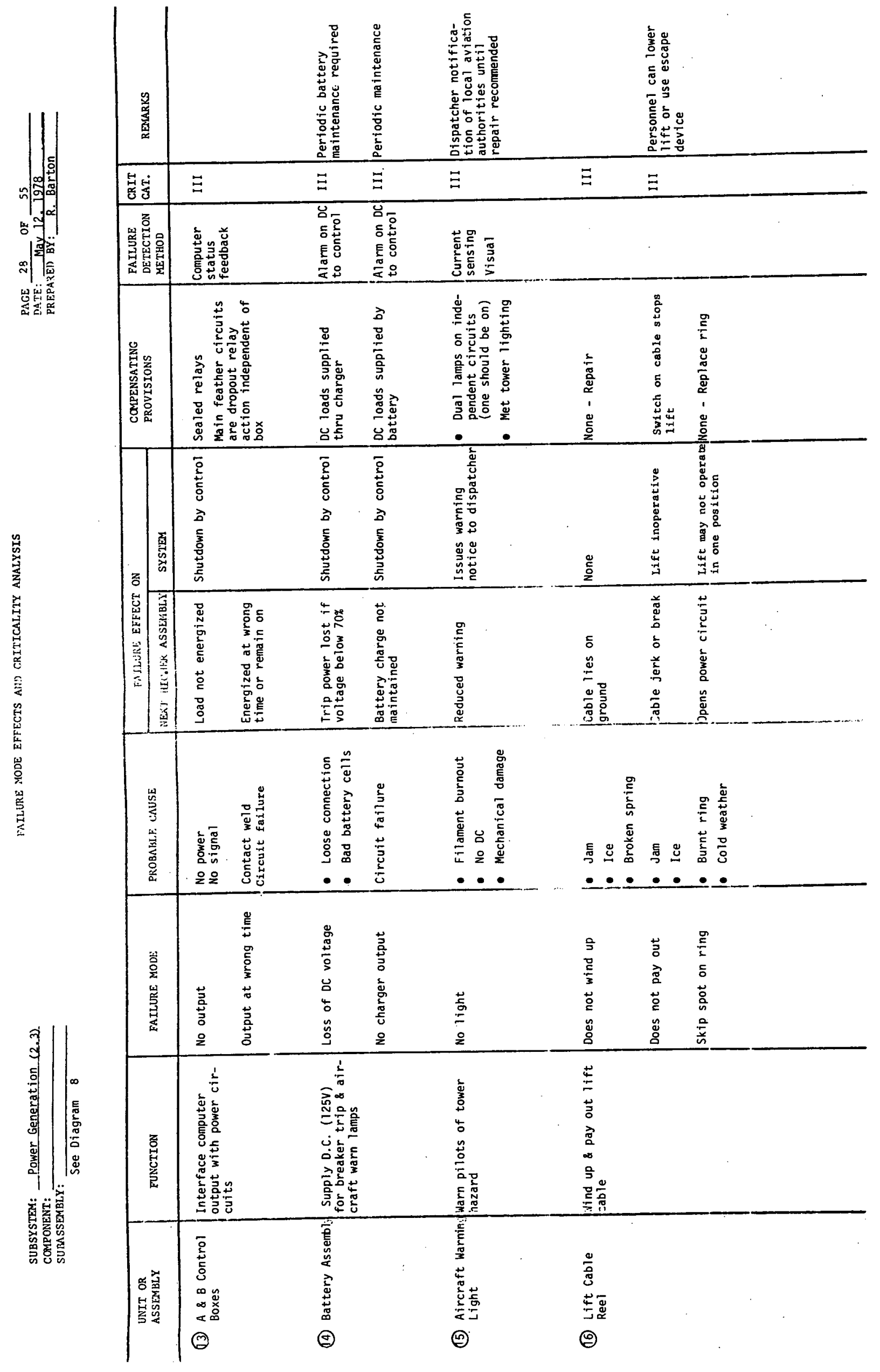




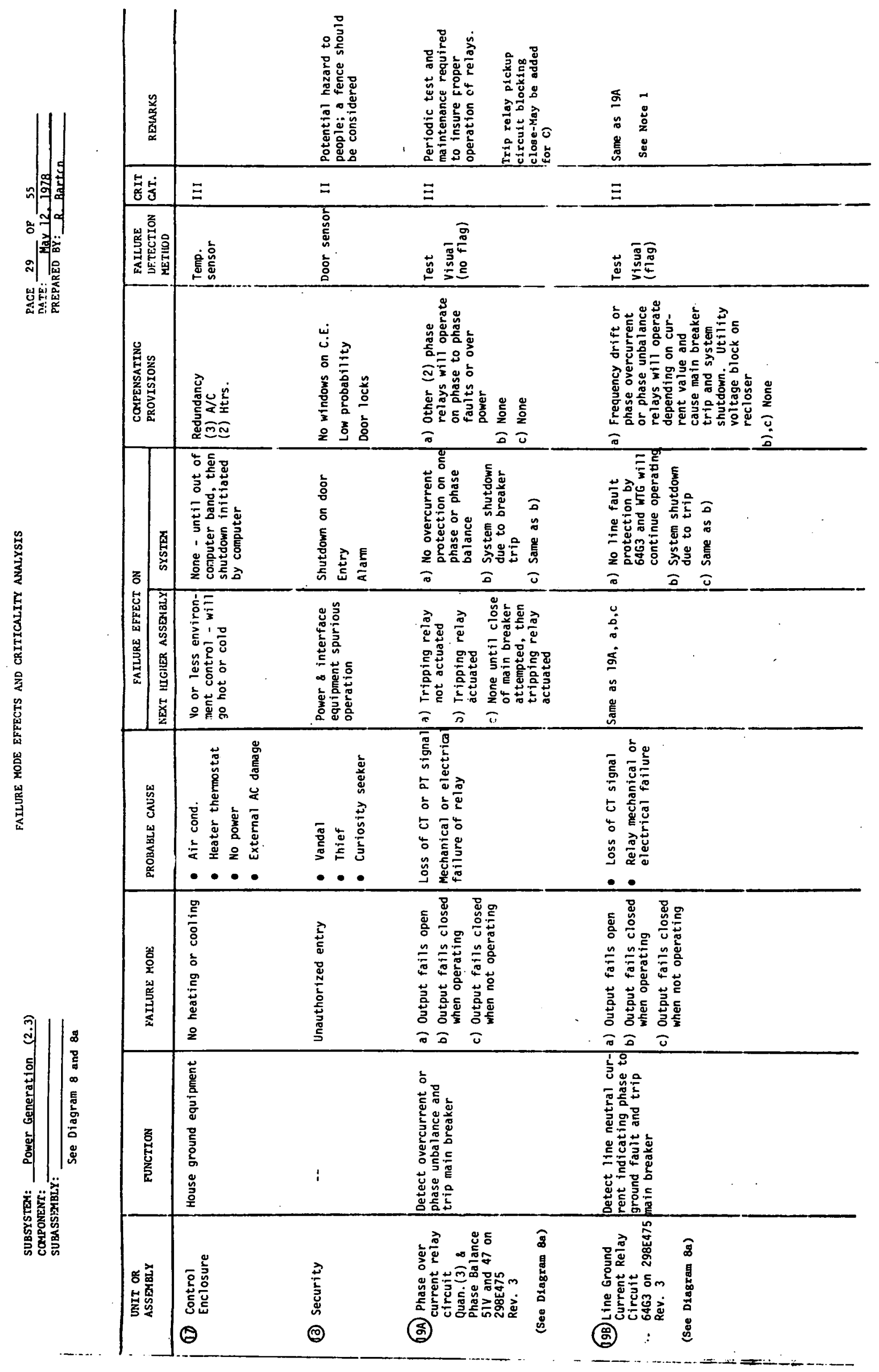




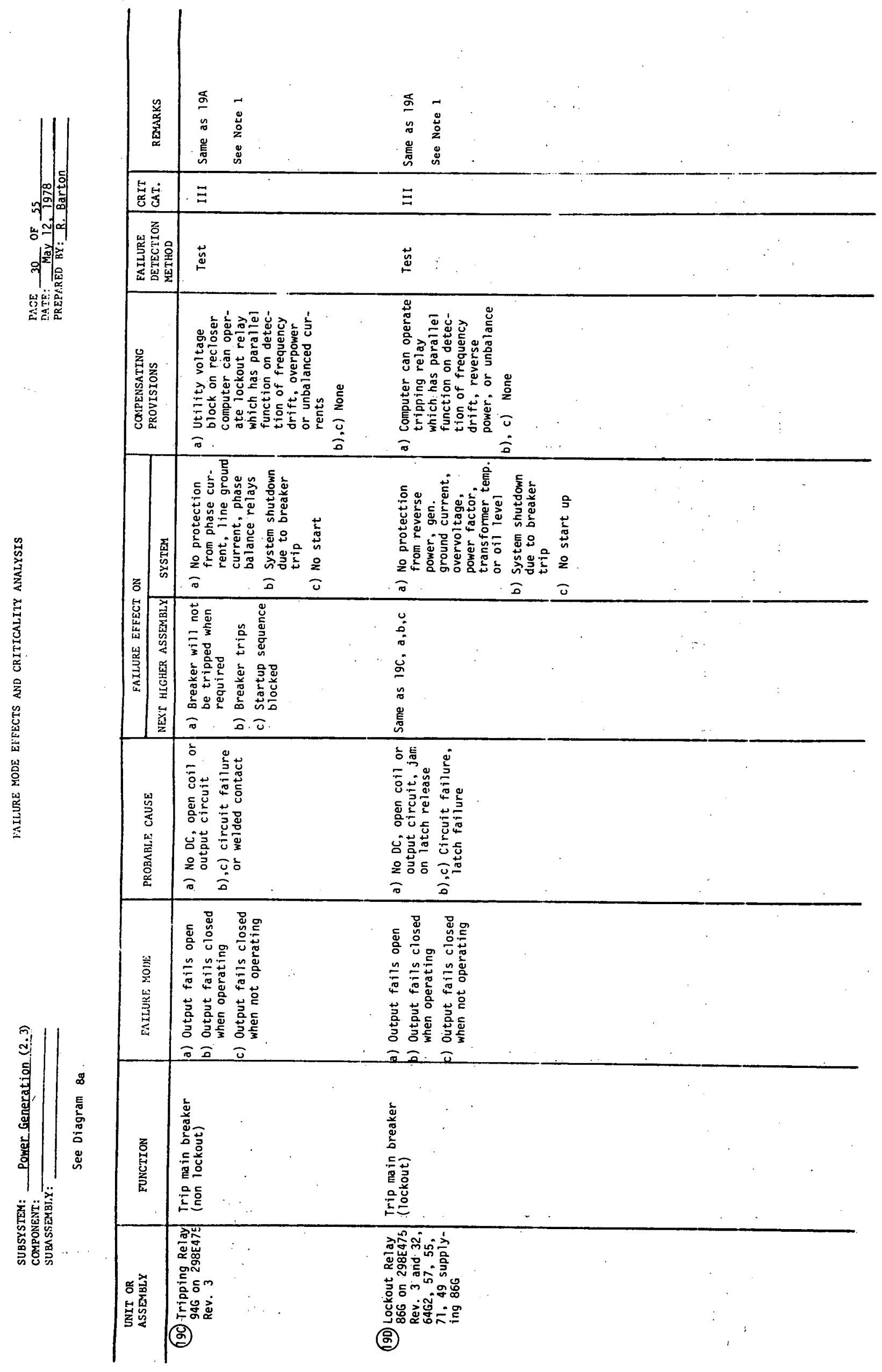




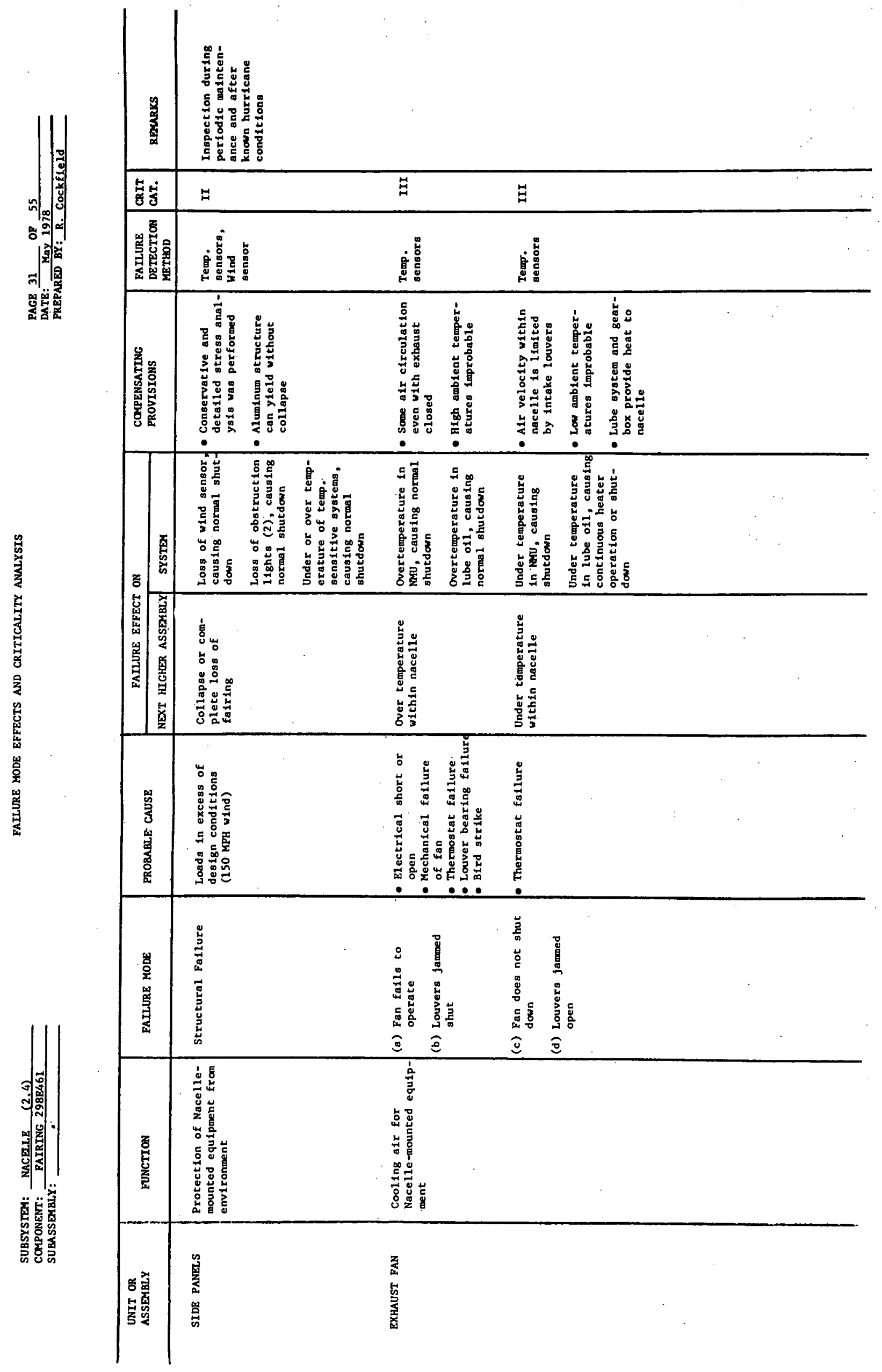




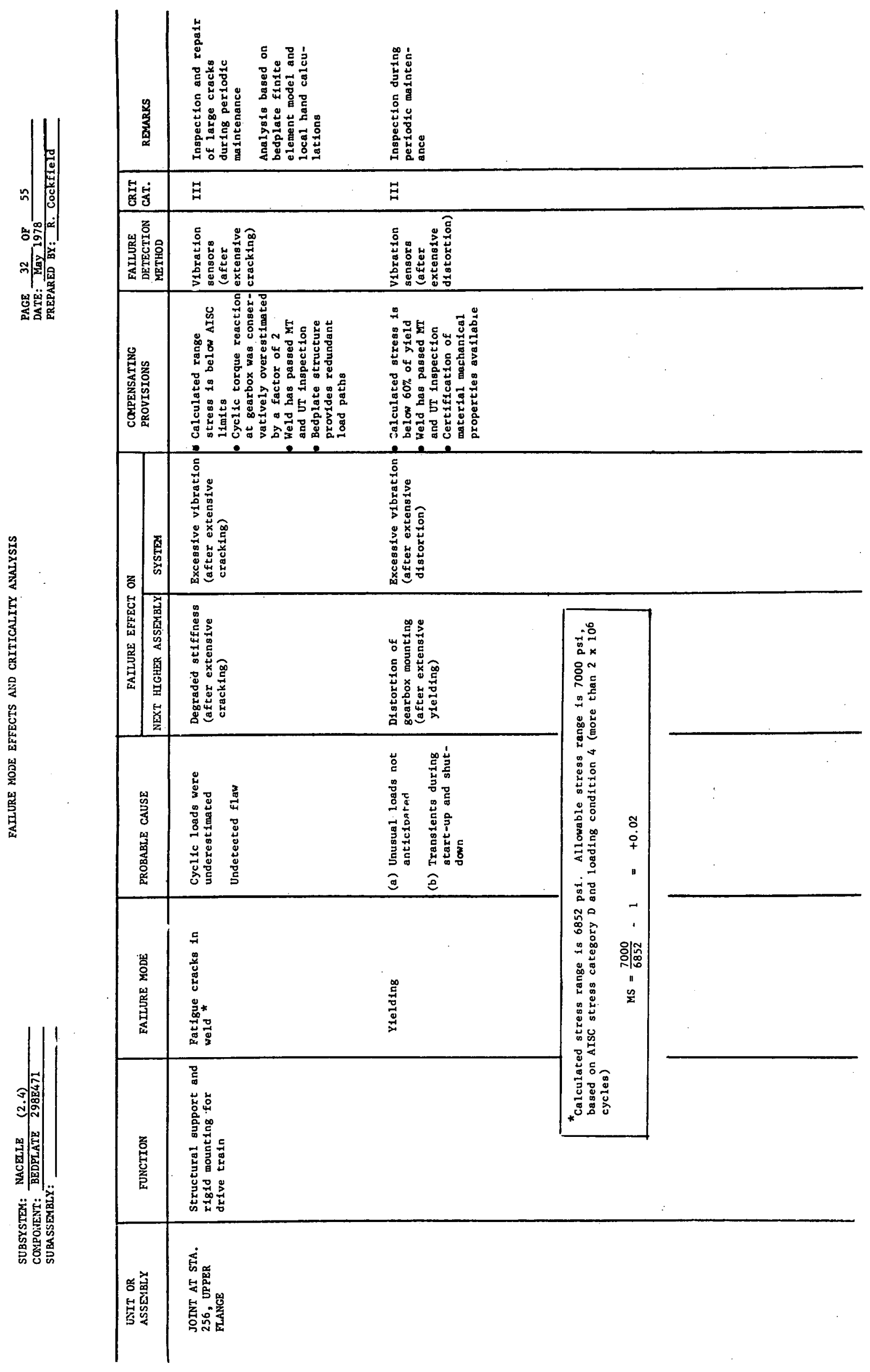




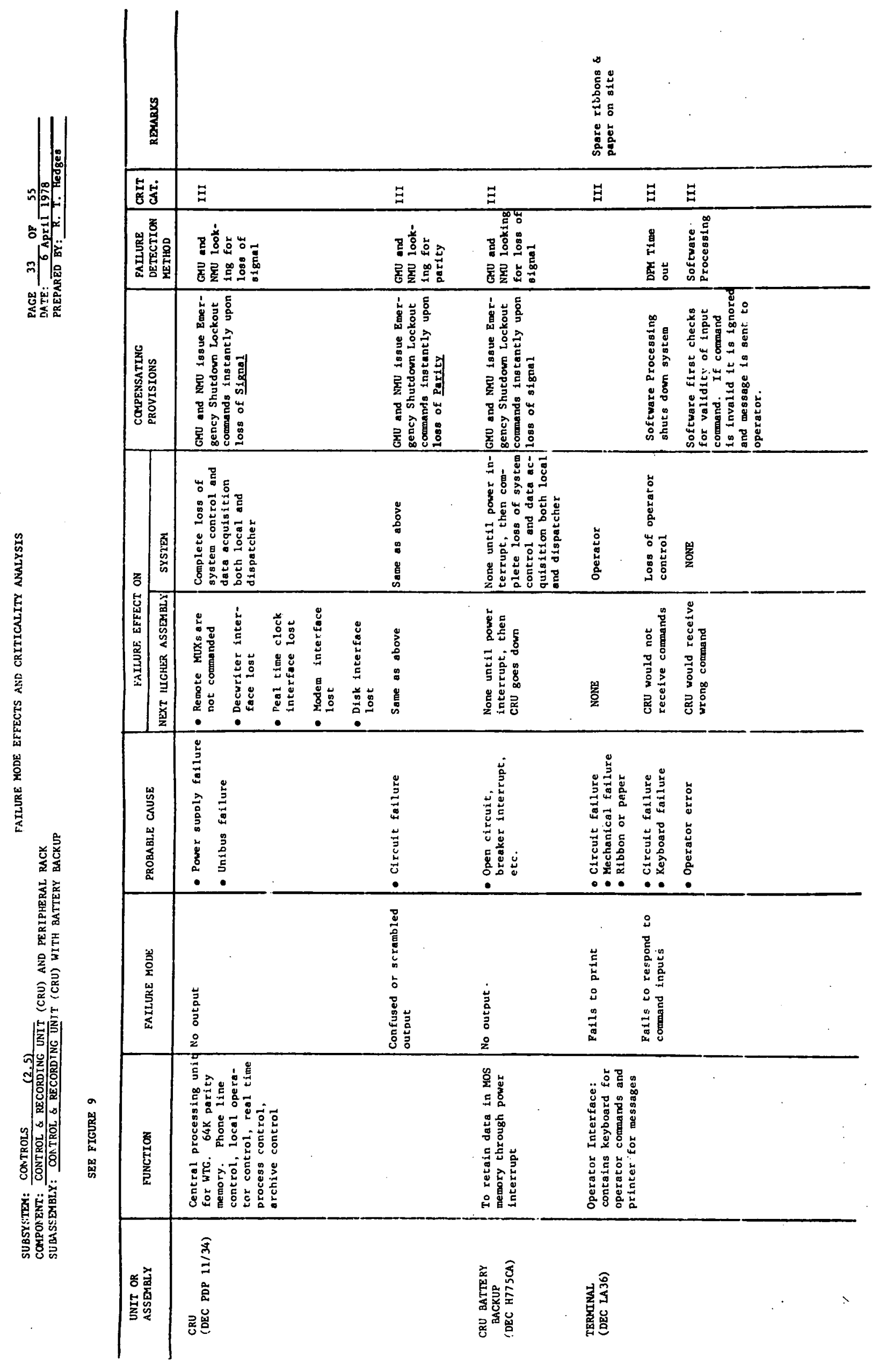




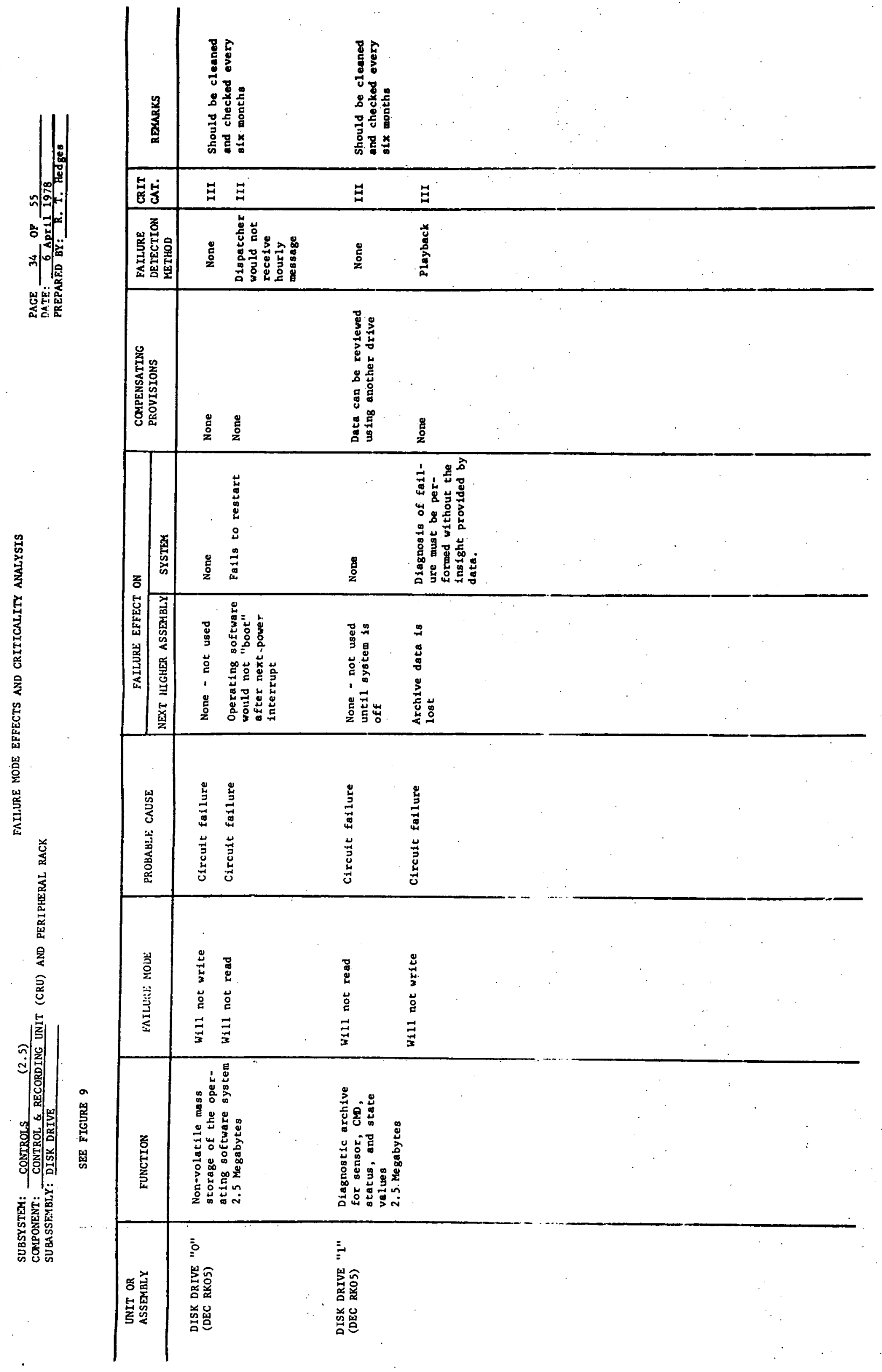




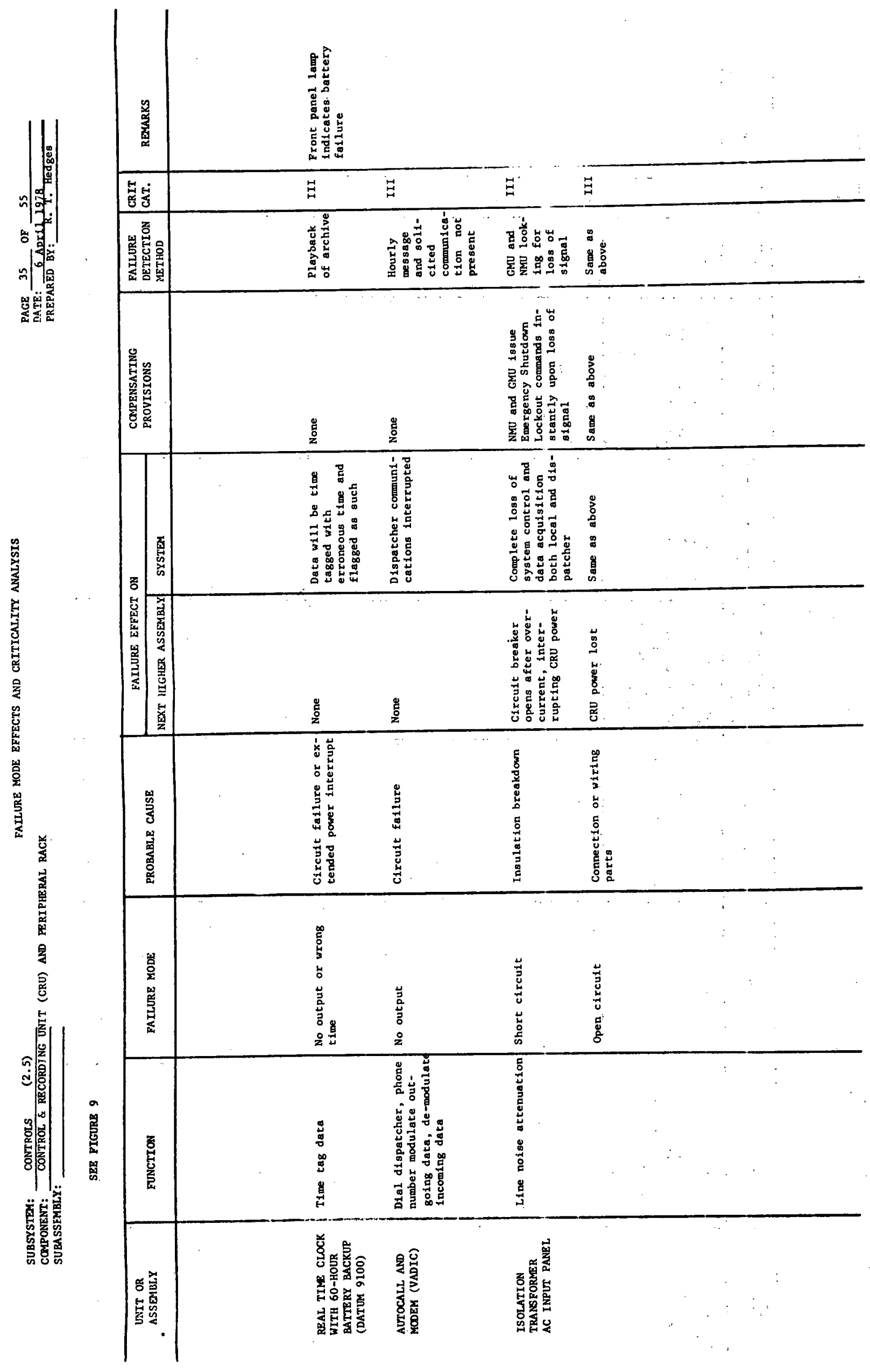




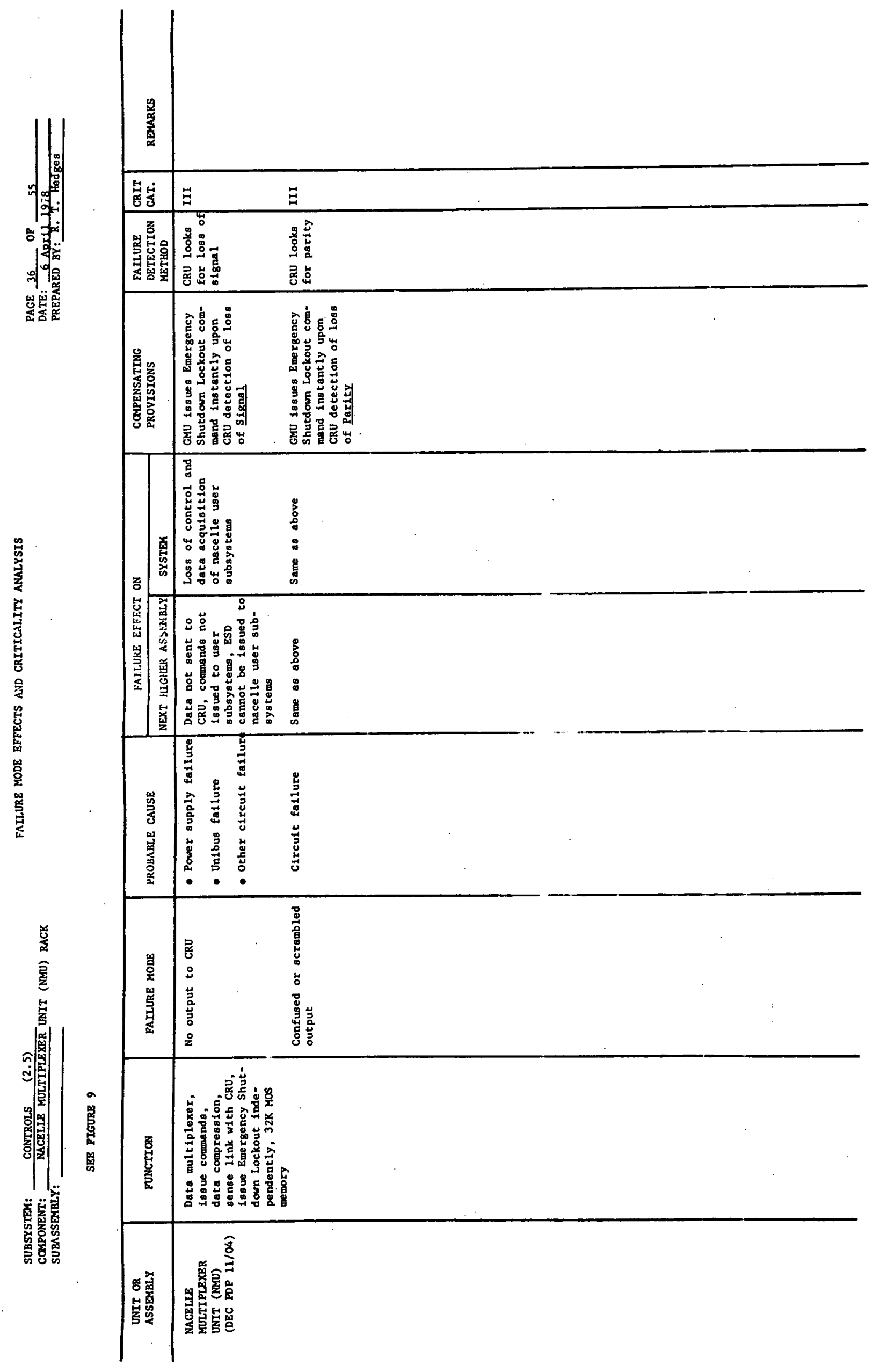




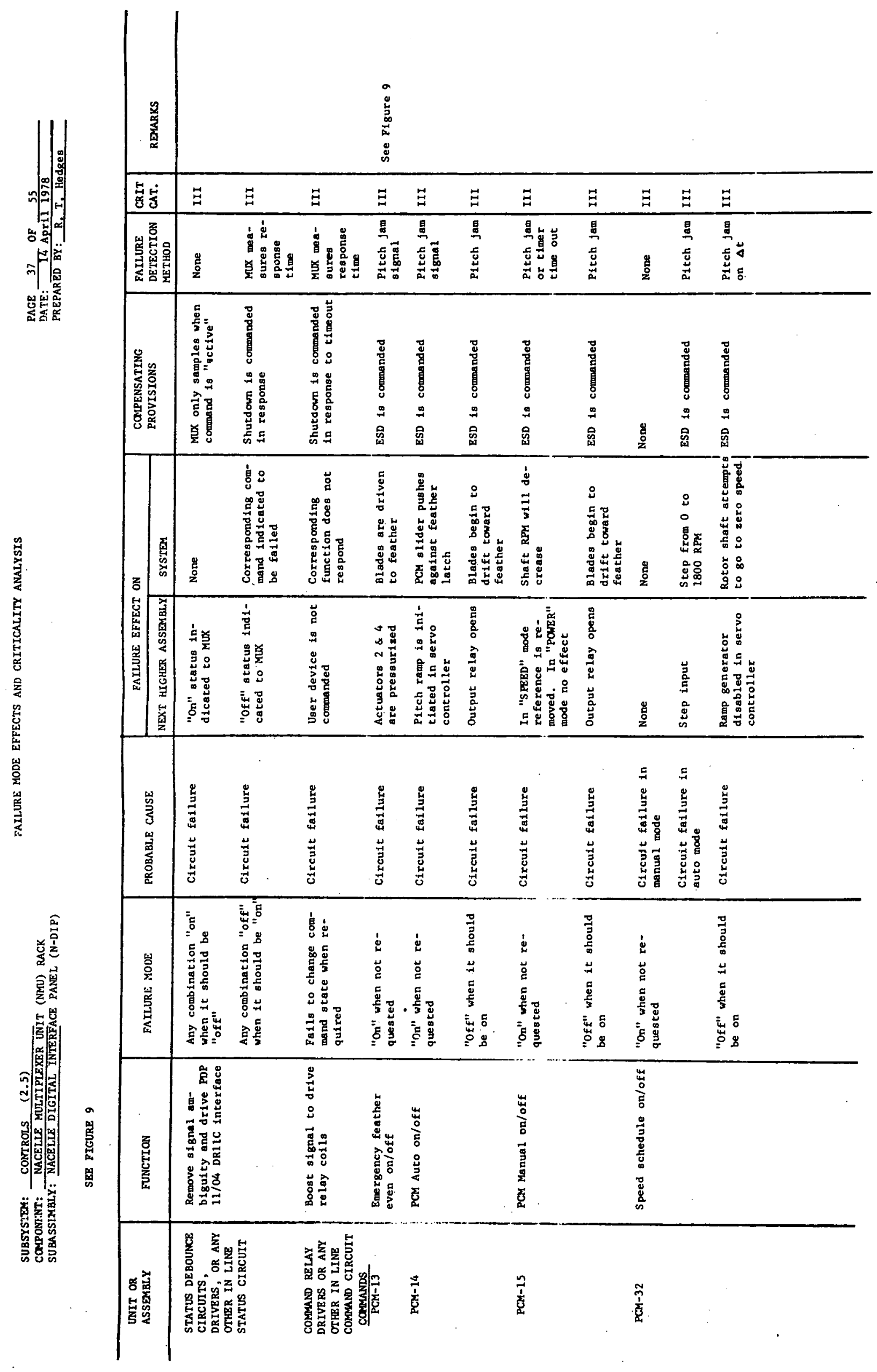




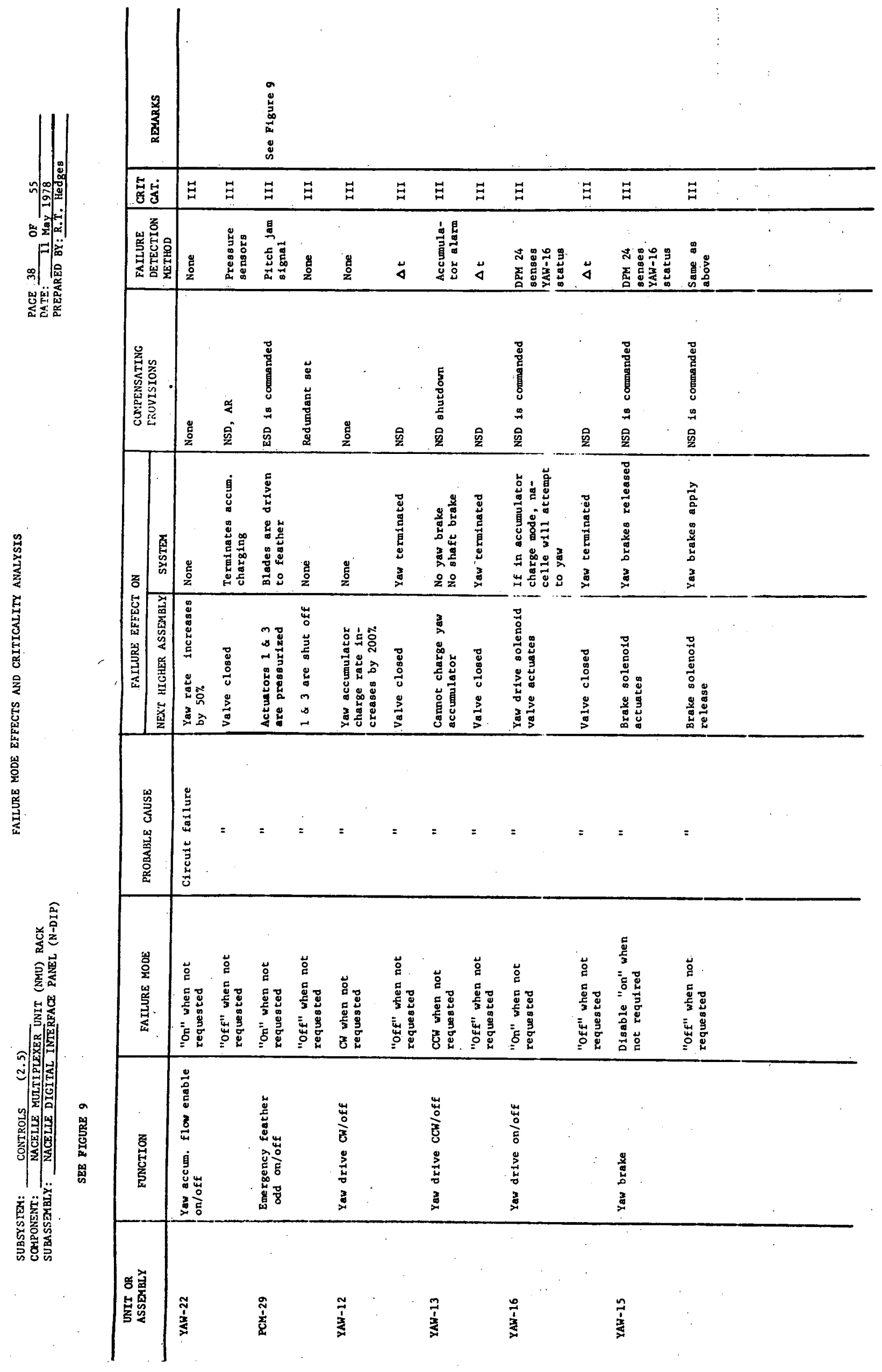




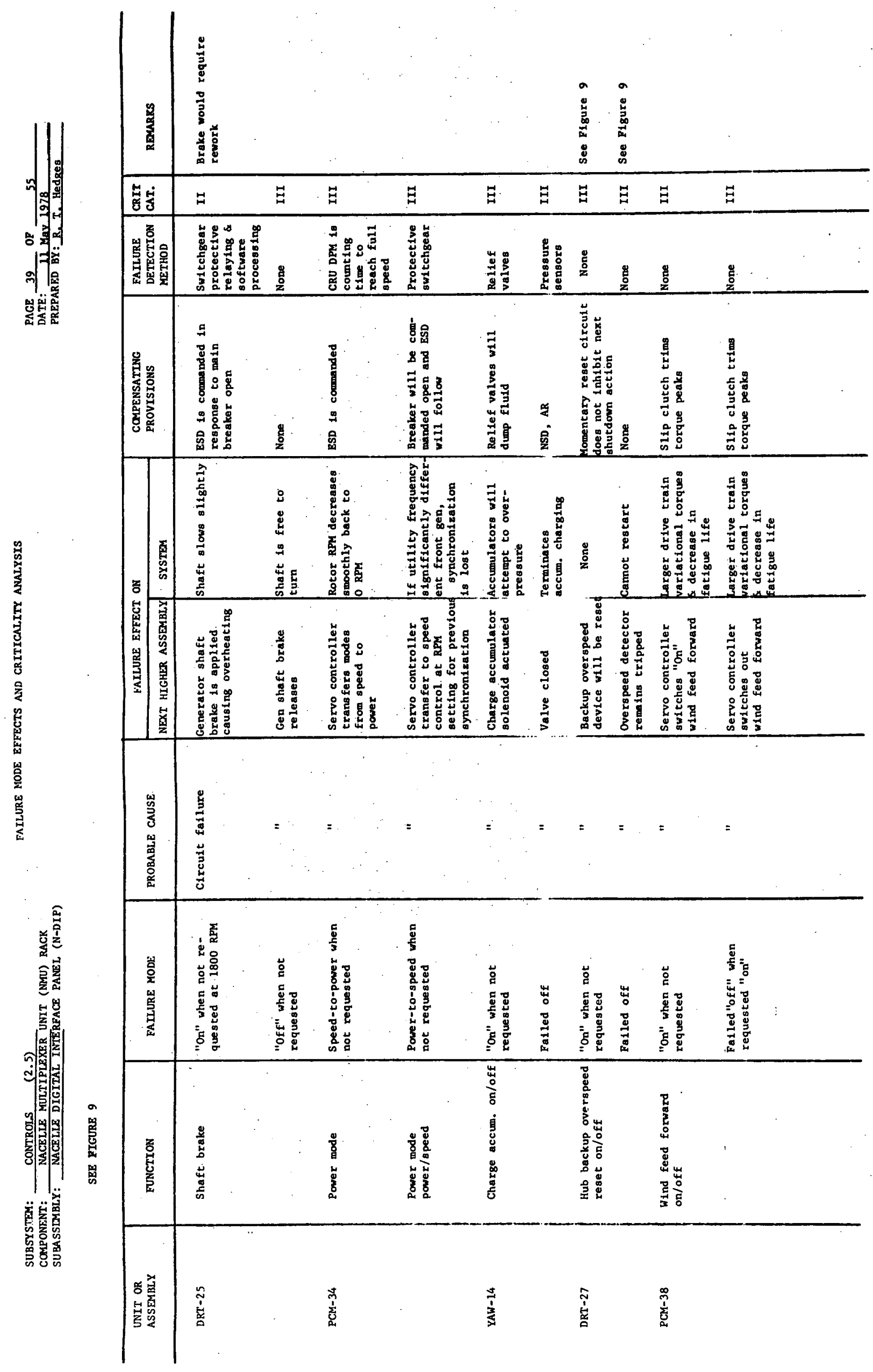




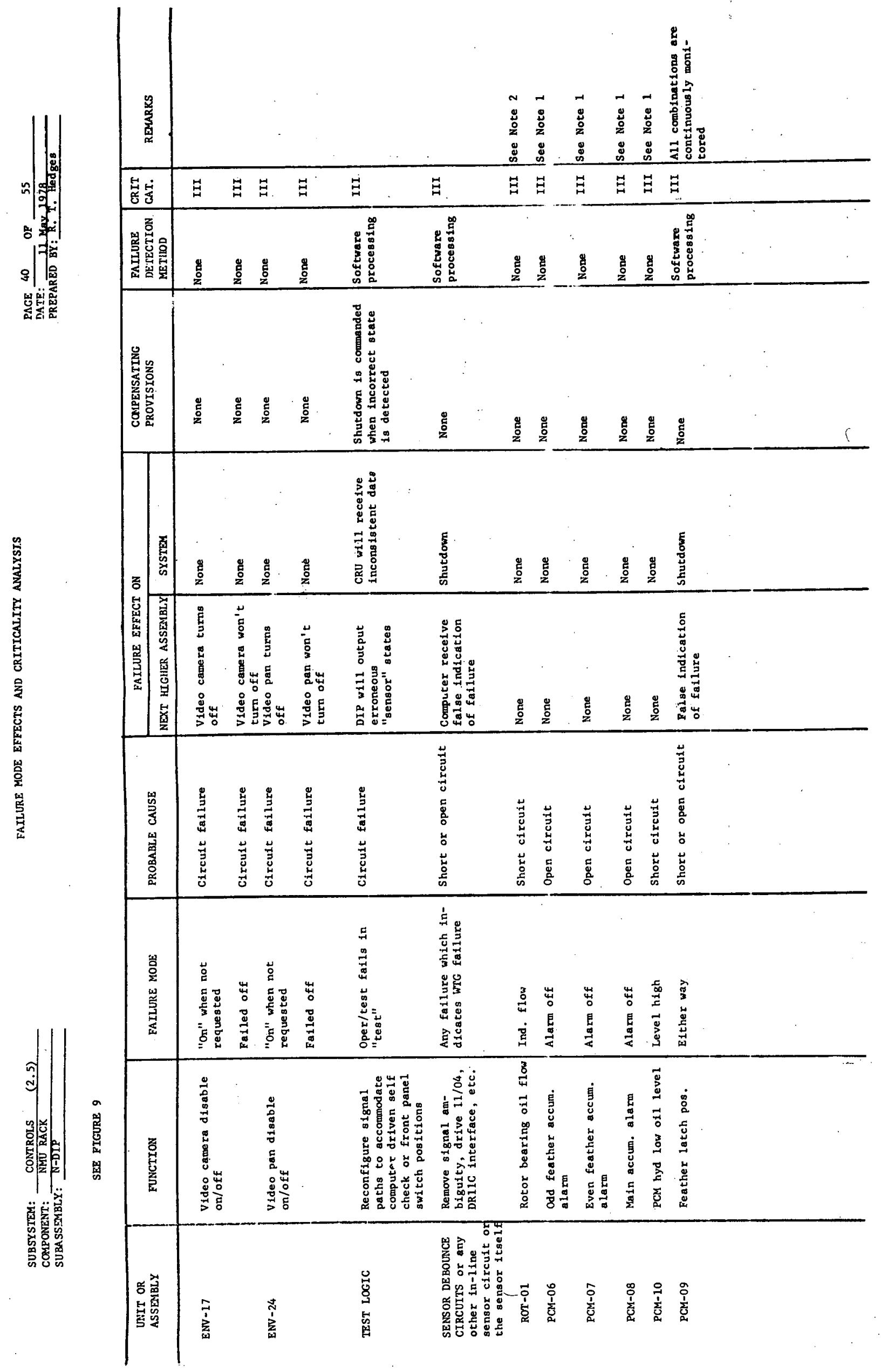




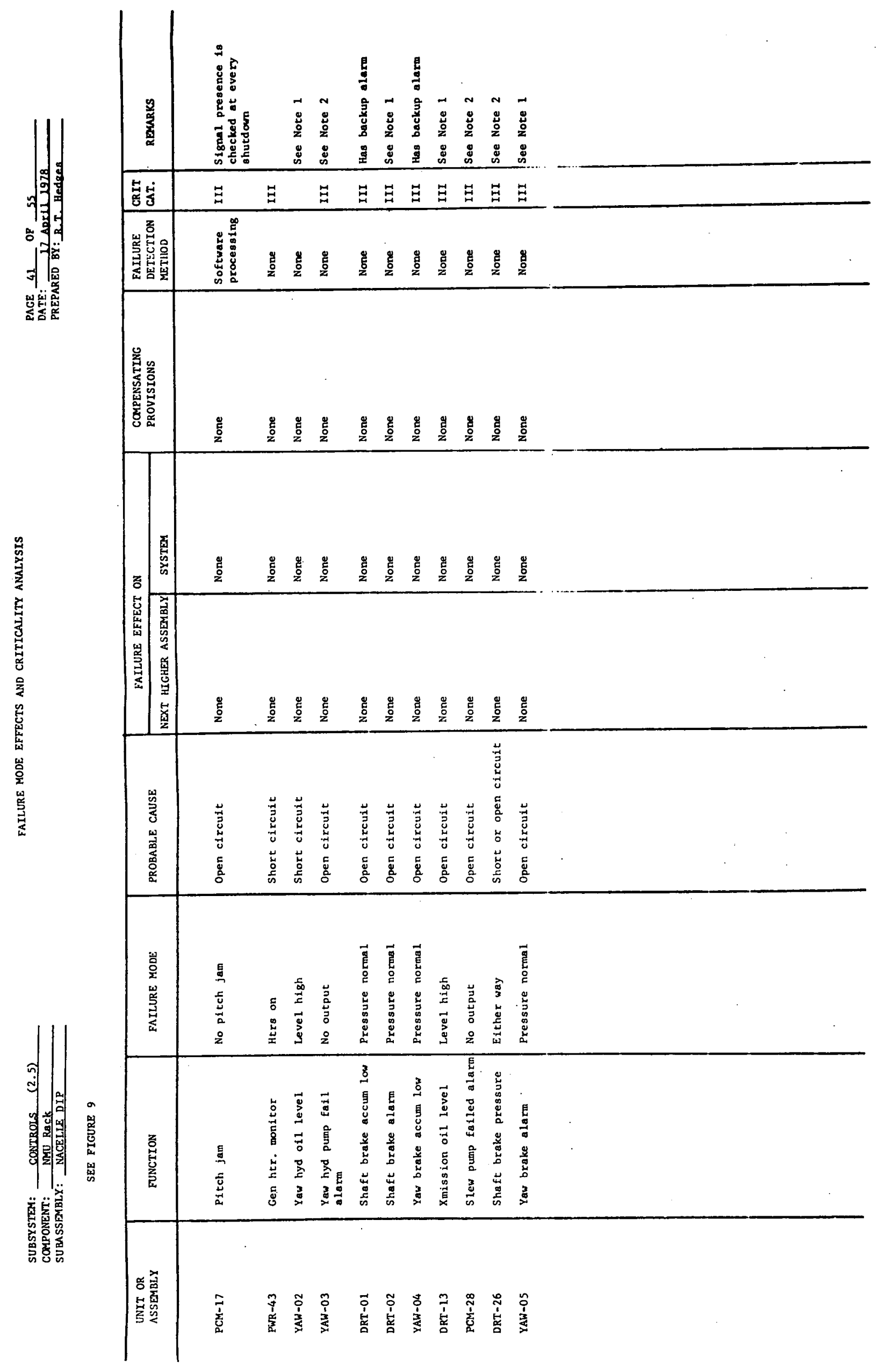




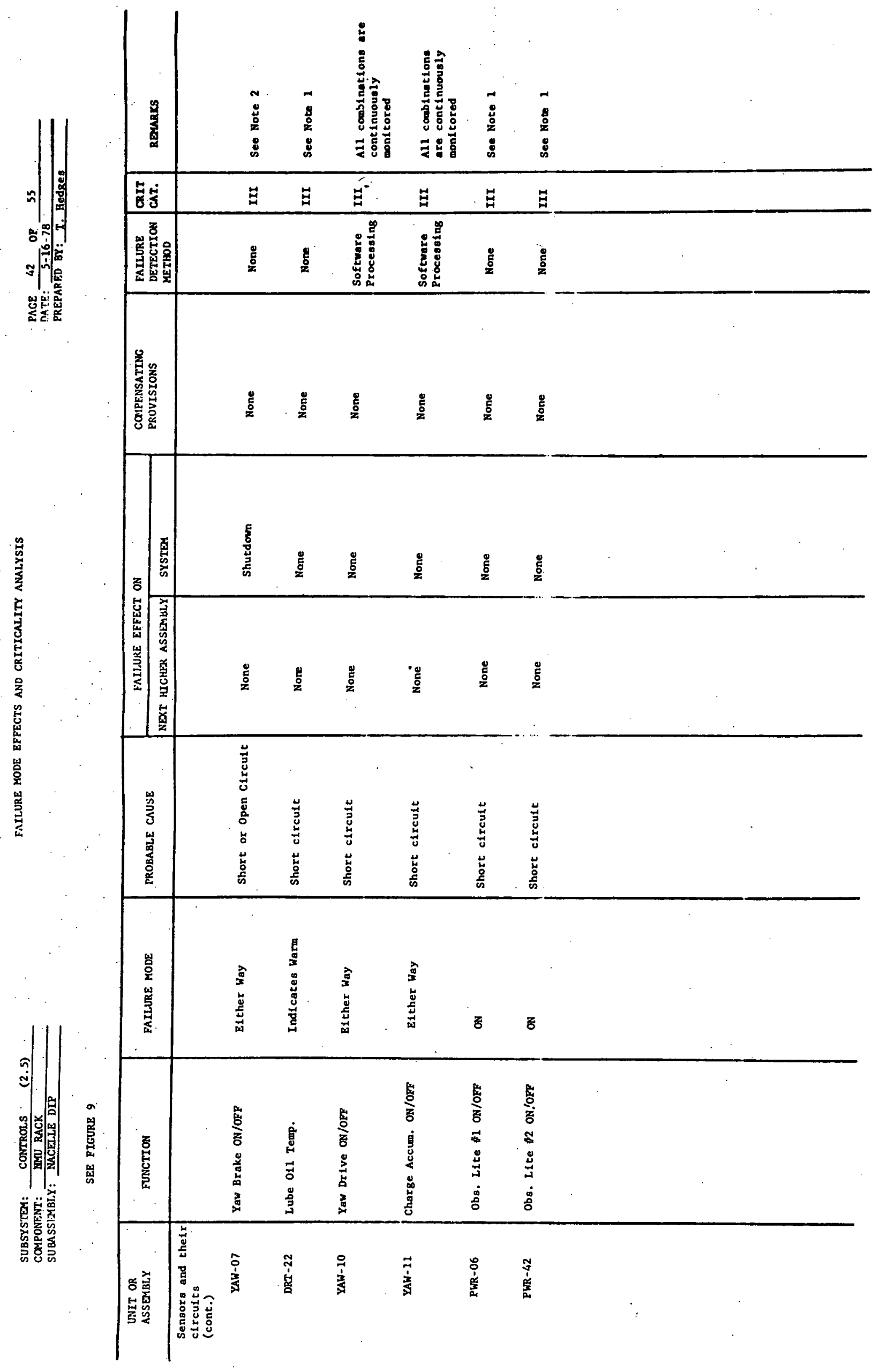




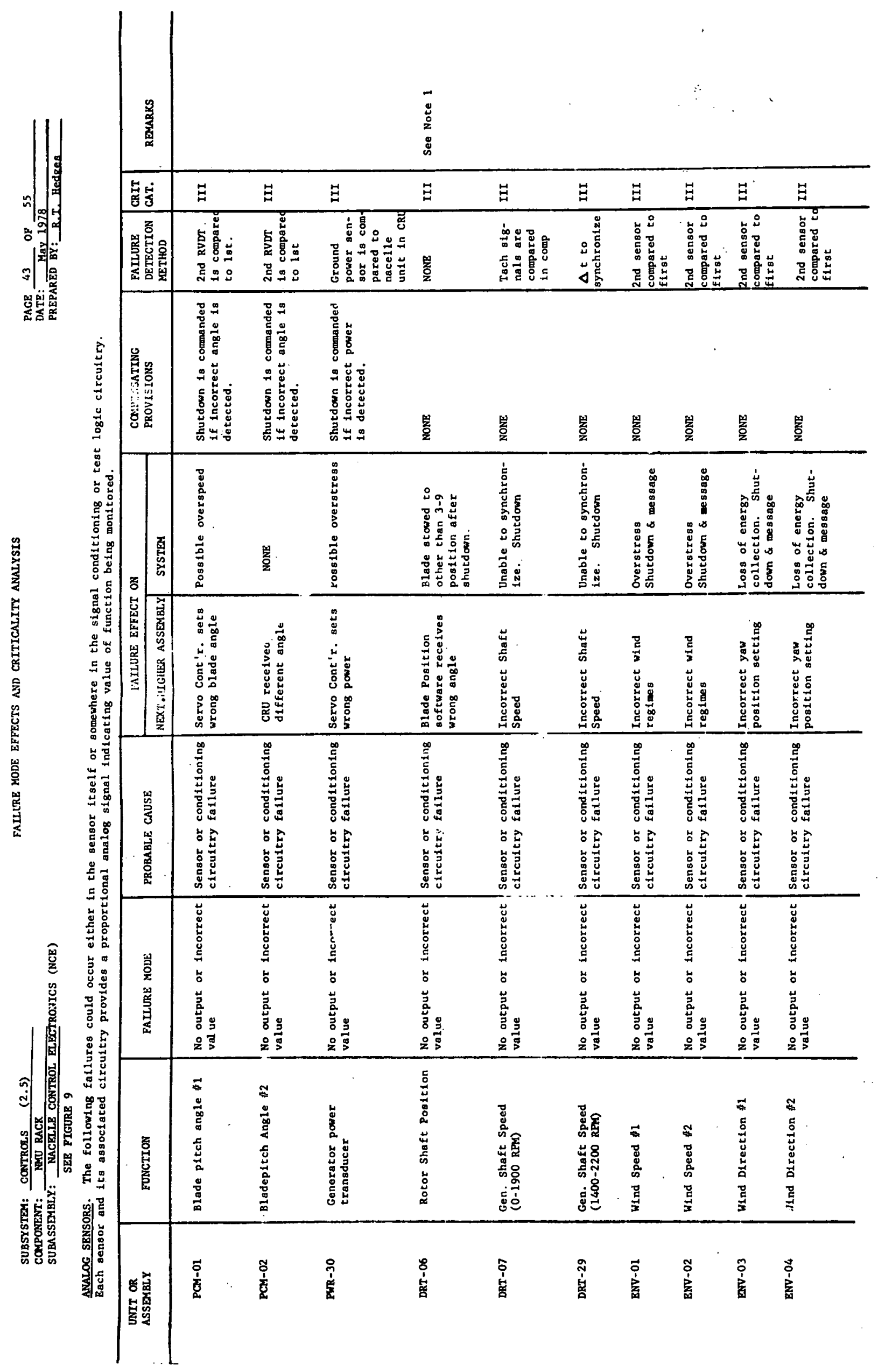




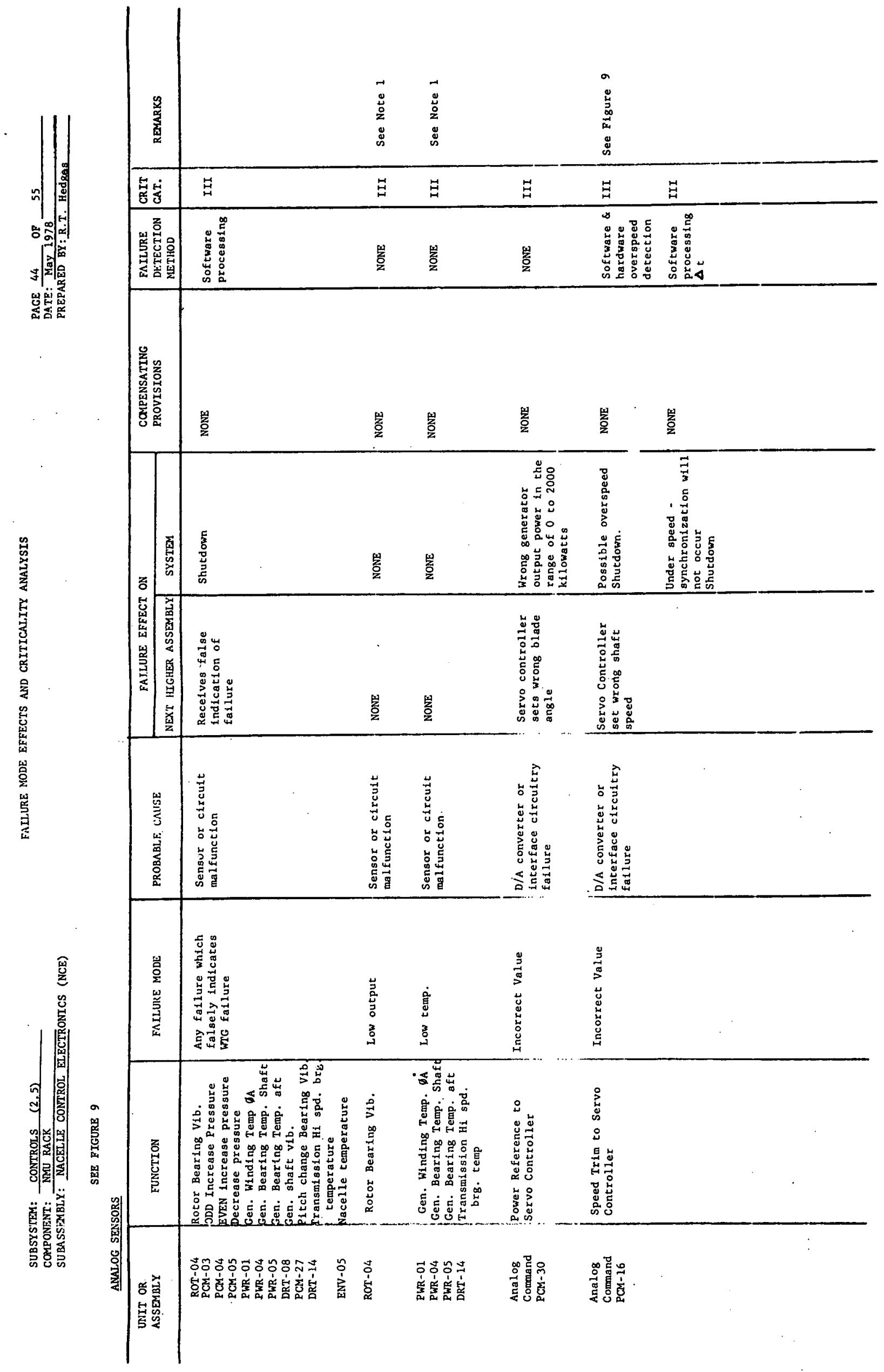



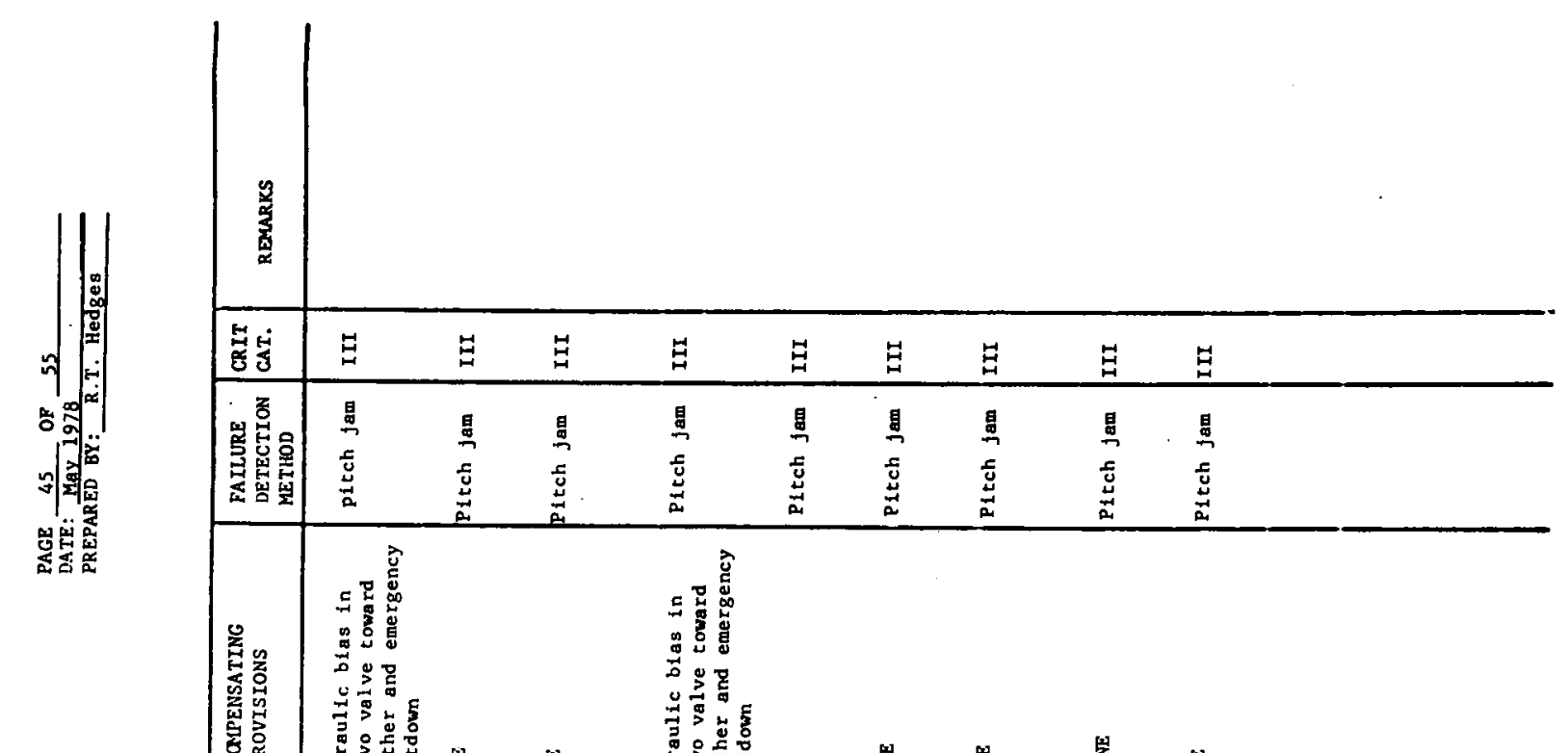

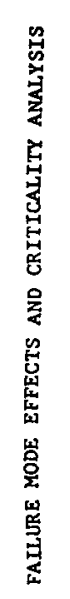

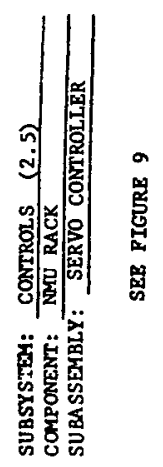




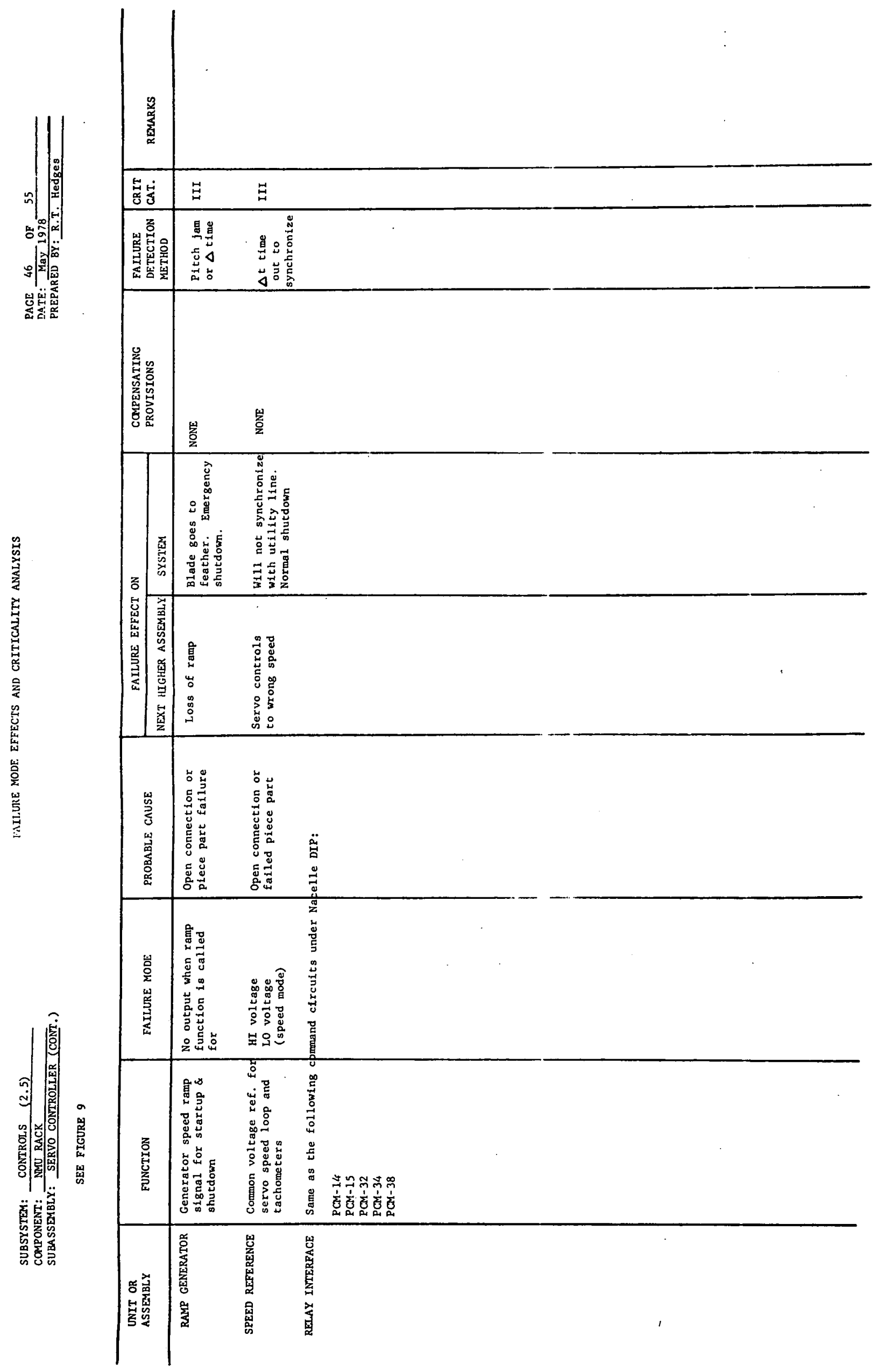




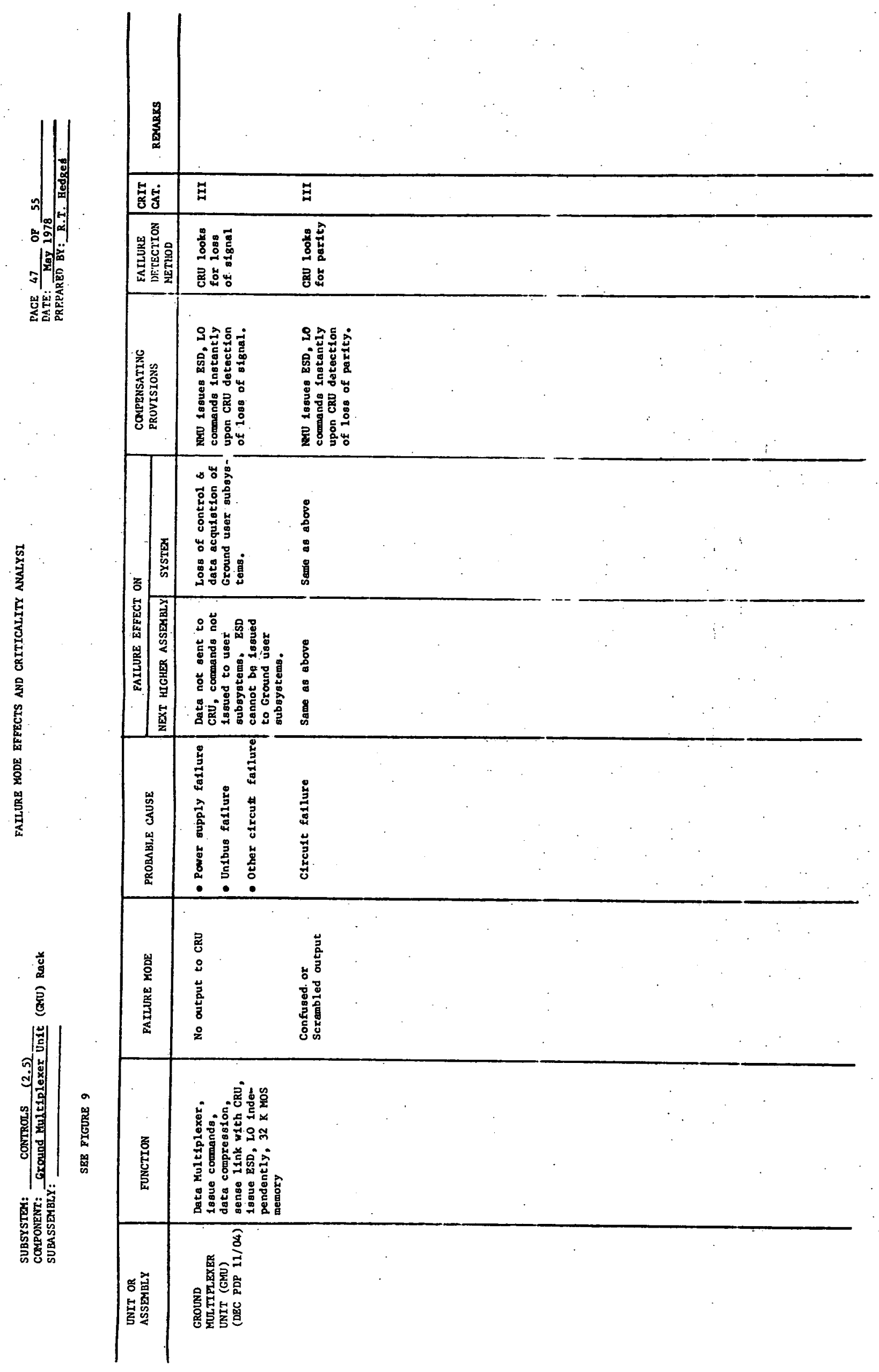




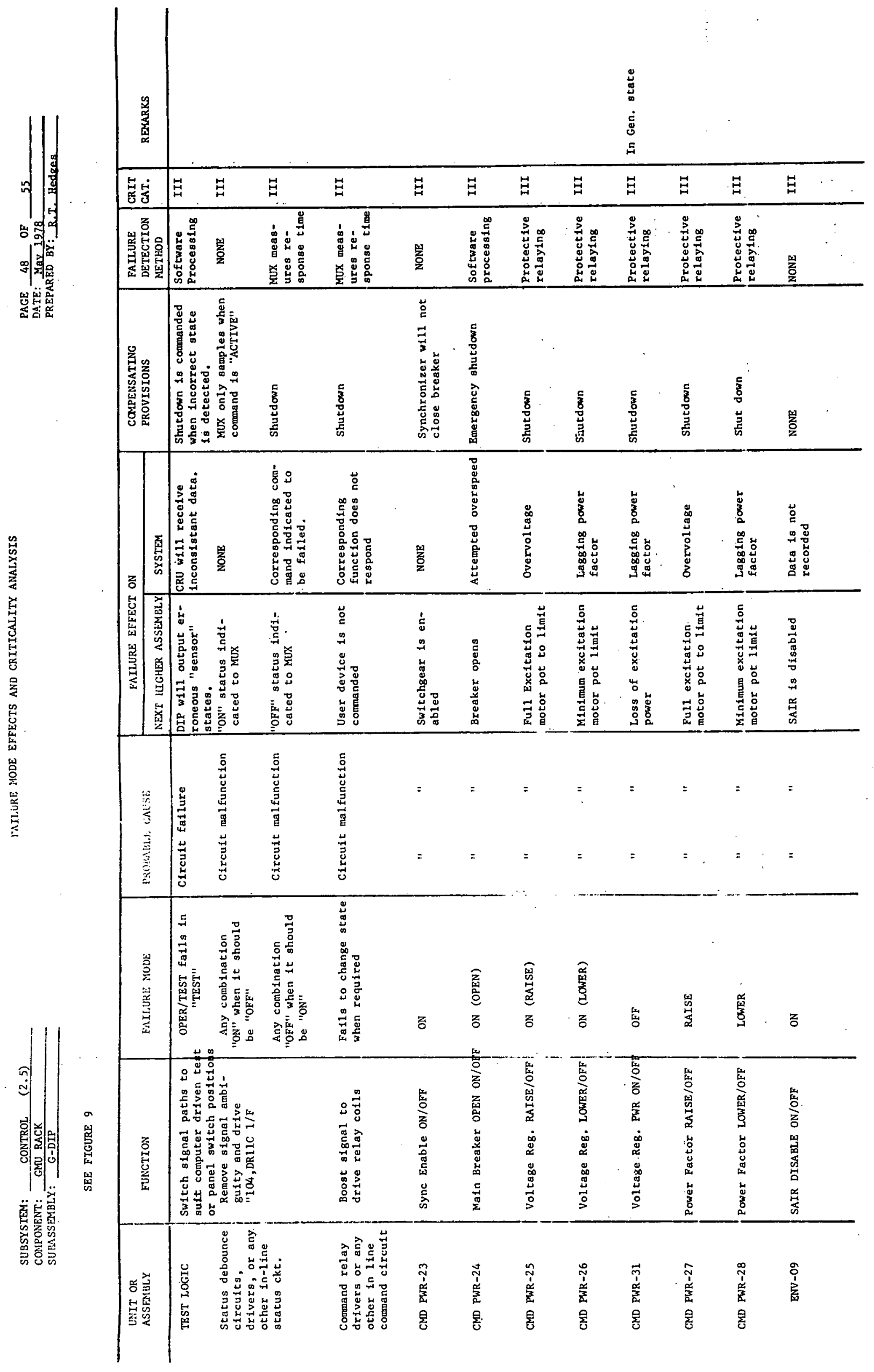




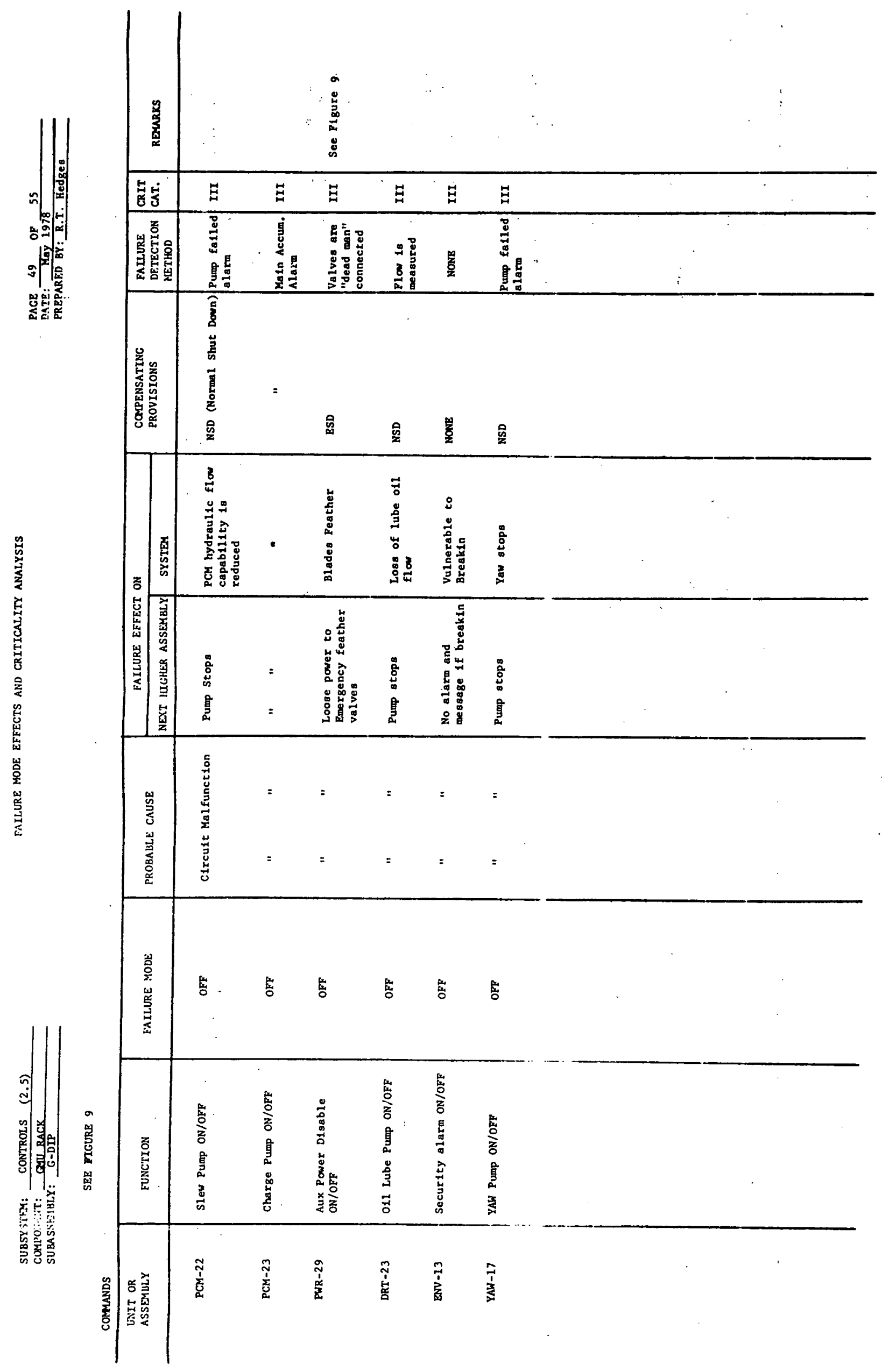




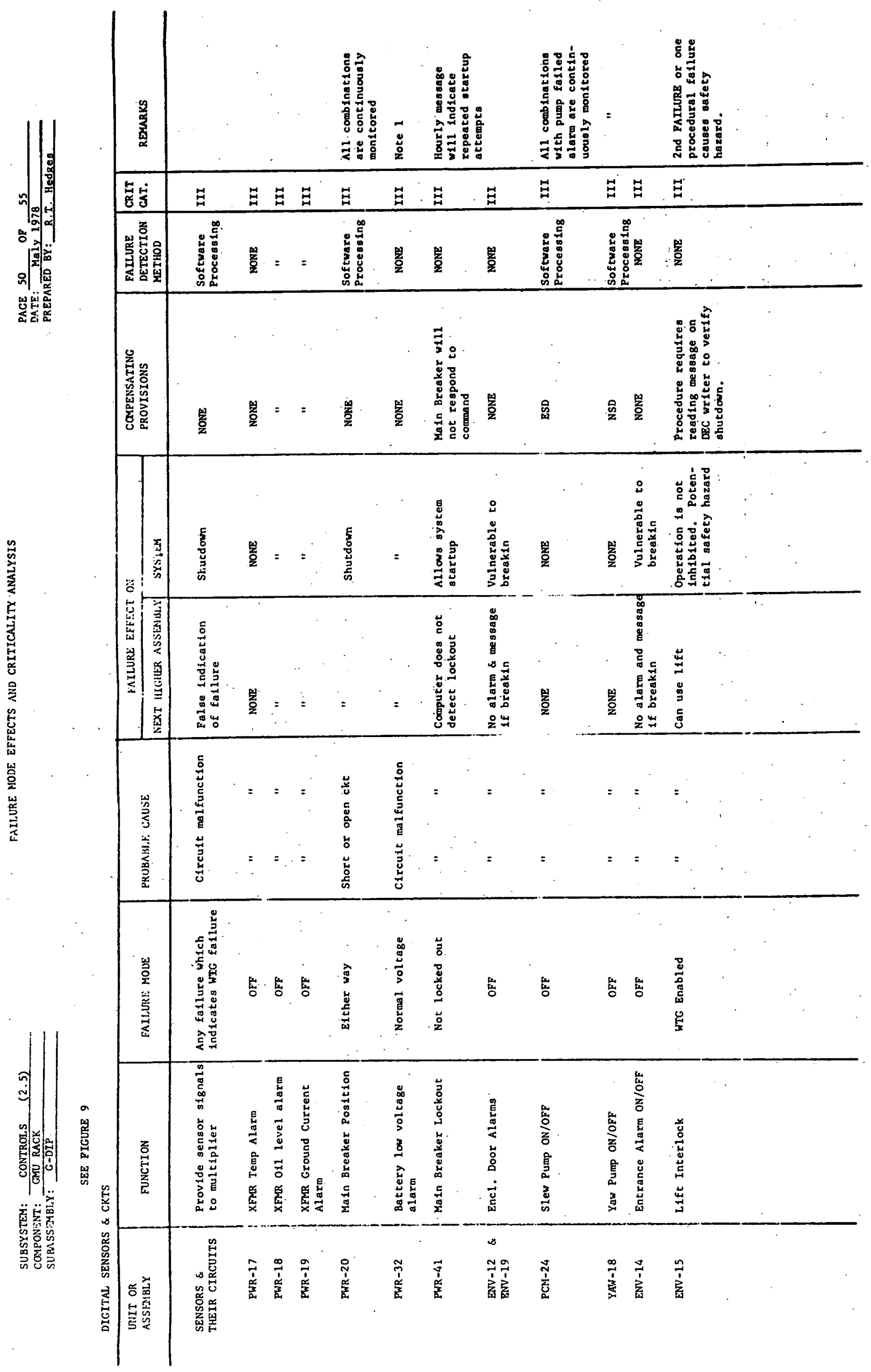




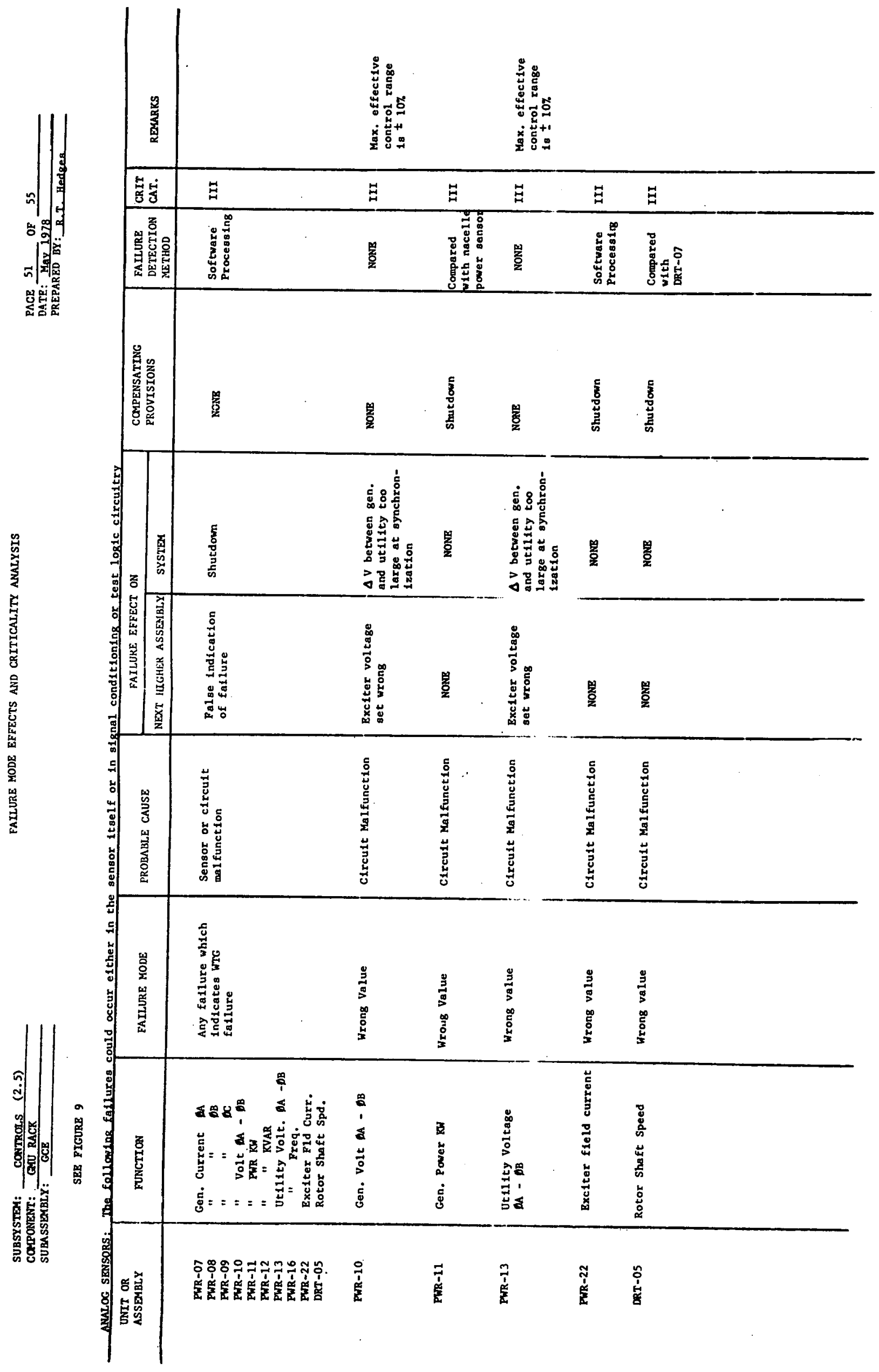




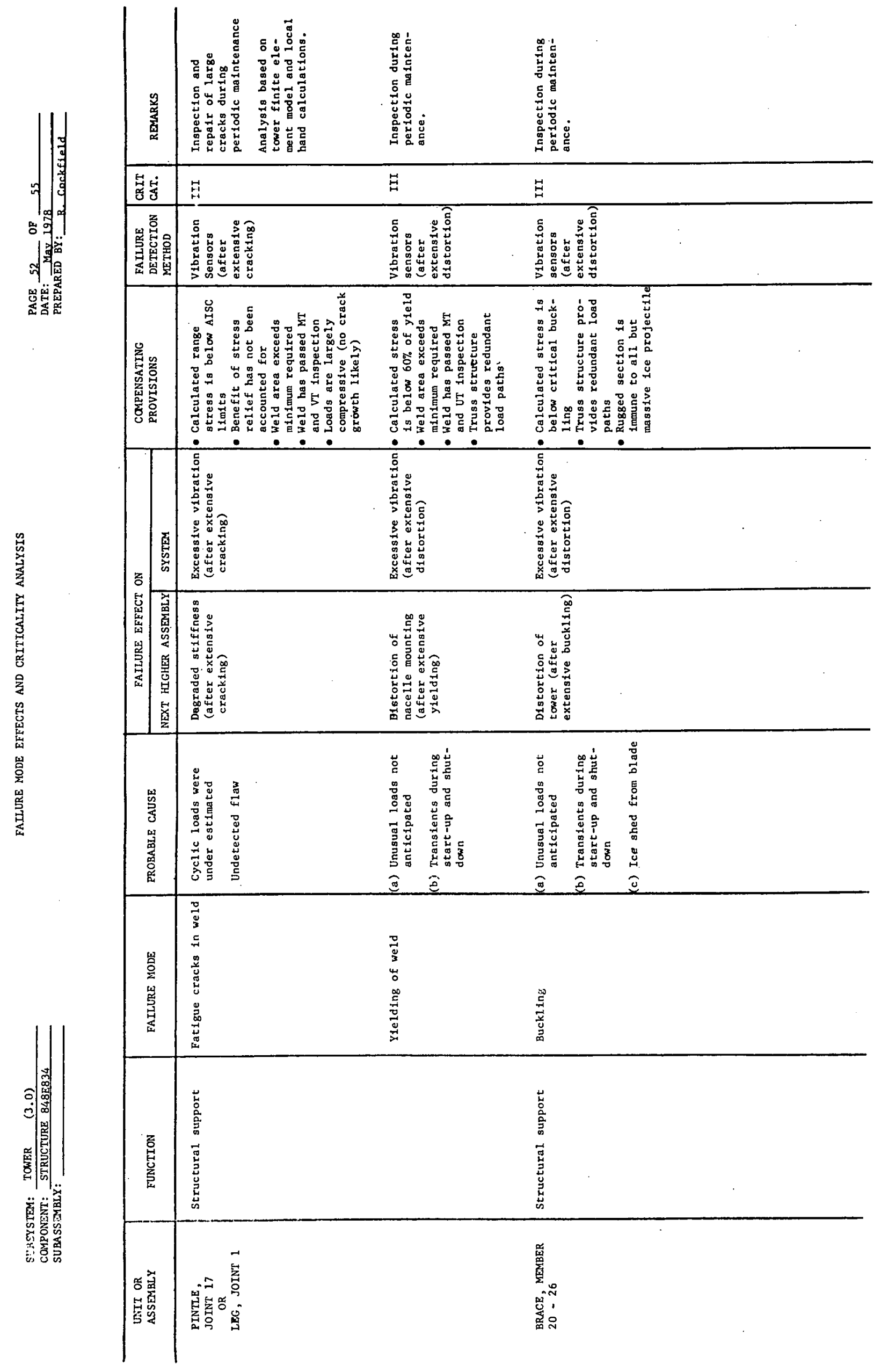




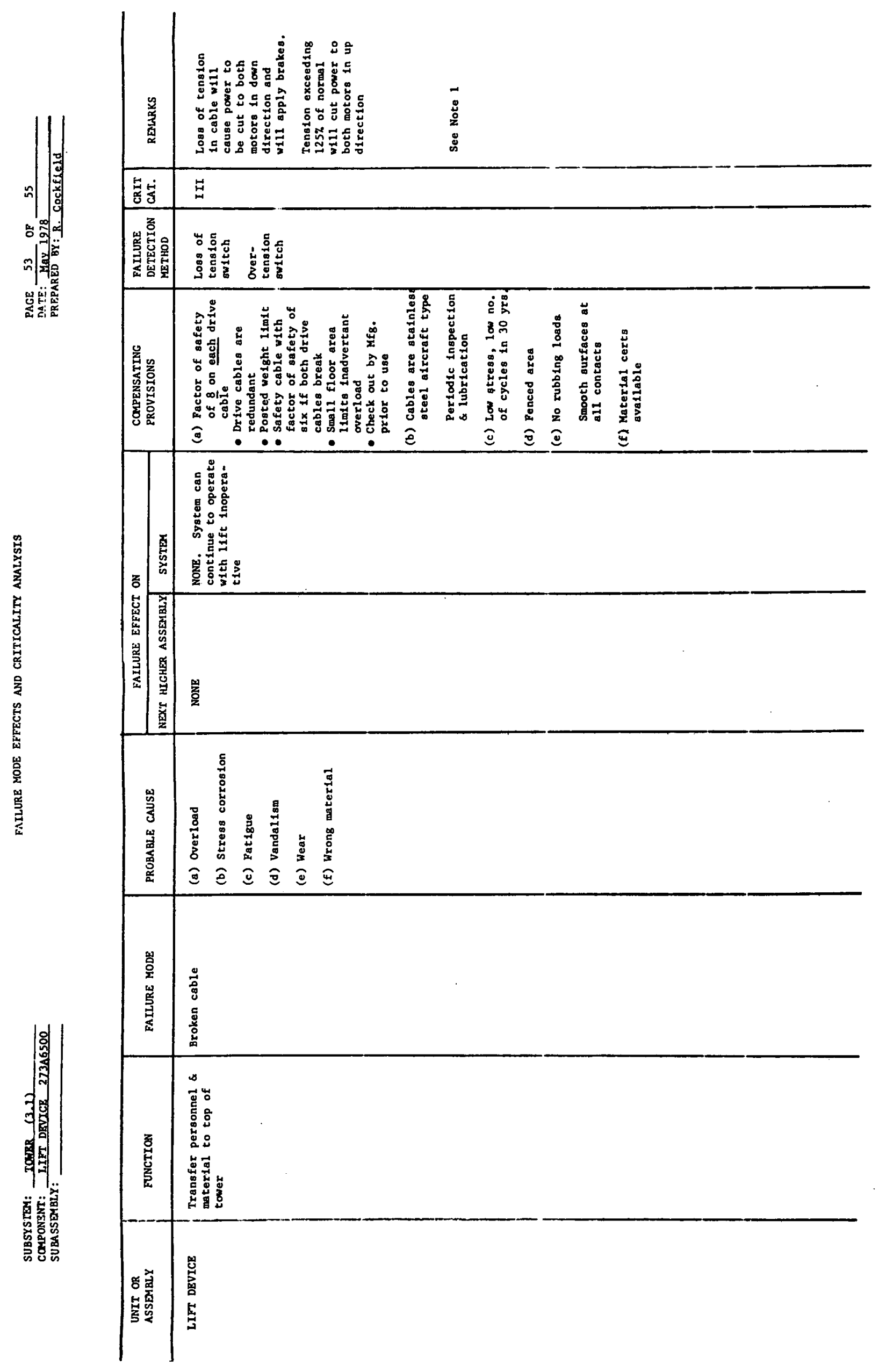




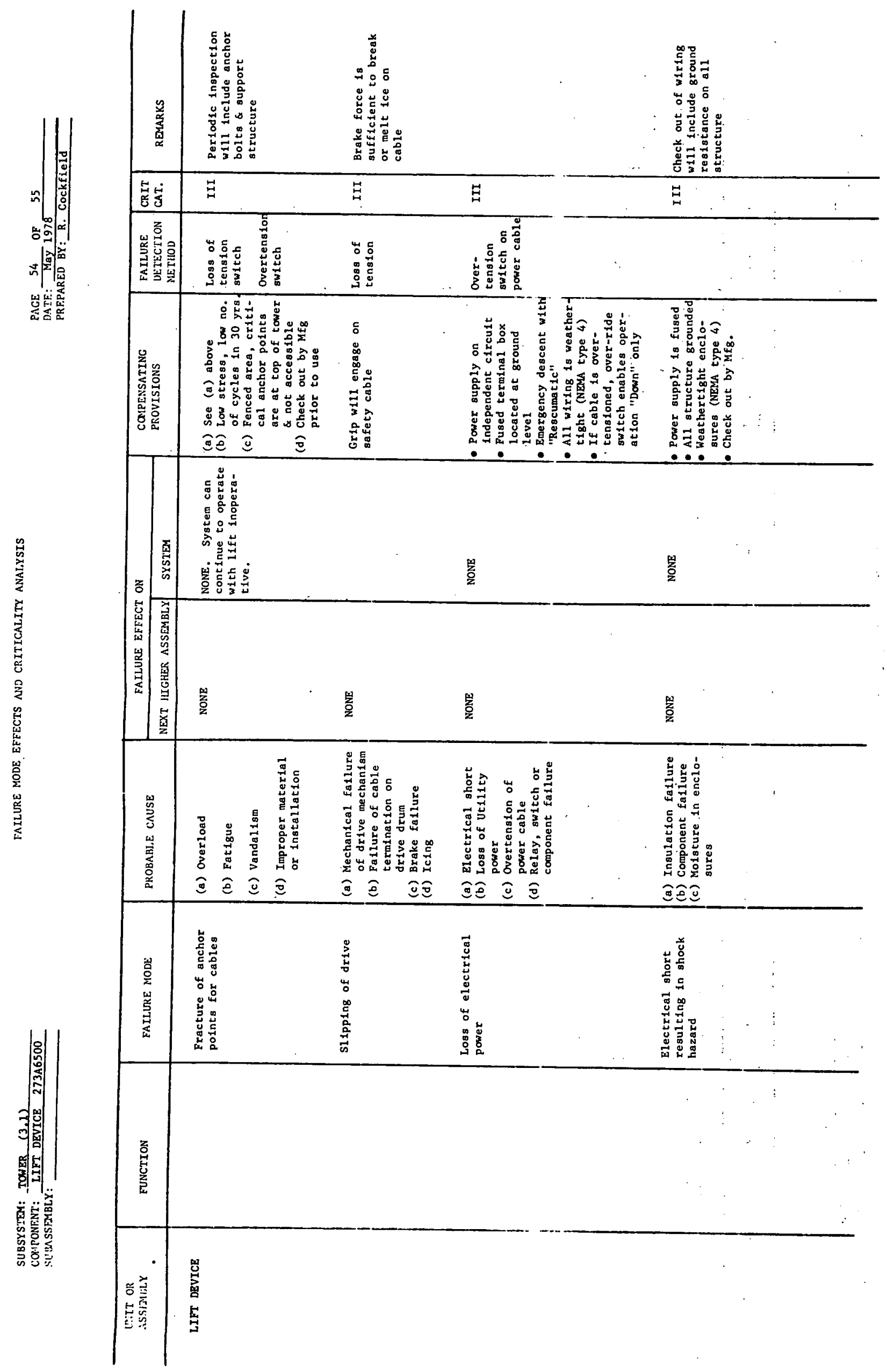




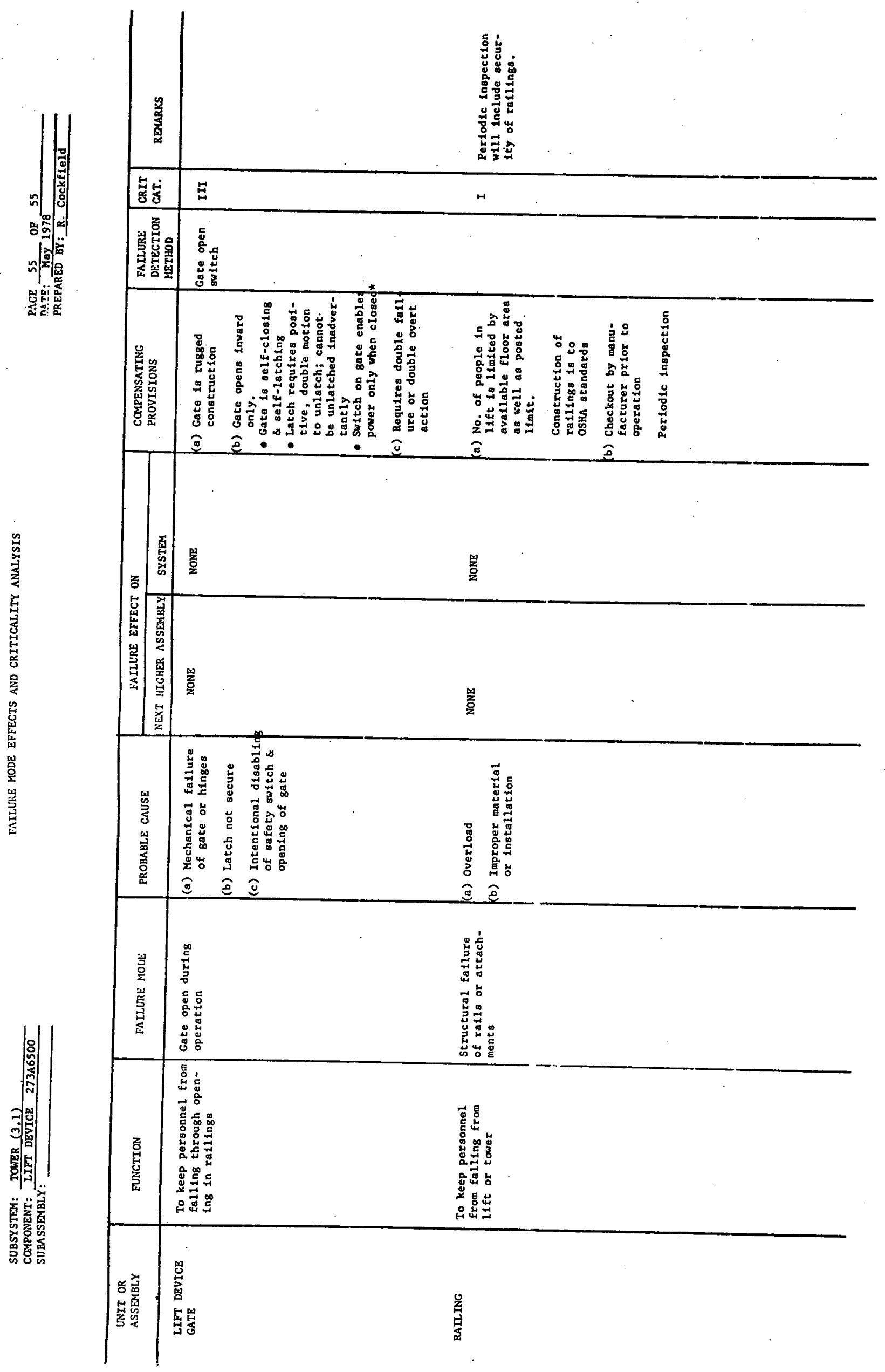




\section{APPENDIX A - BLADE}

Unbalance Loads after Blade Separation

Interface Ring Flange

Test Program

Quality Program 


\section{I-1 UNBALANCED LOADS AFTER BLADE SEPARATION}

A loads analysis was performed to determine the loads on the major items of structure resulting from the loss of a blade. These loads are presented on Table I-1. For comparison purposes, the maximum infrequent loading condition of emergency feather - 15\% overspeed is presented. Effects on major items are:

The remaining blade has loads imposed which are within its capacity and should suffer no damage.

The blade retention bearing in the hub also will be subjected to loads which are within its capacity and will suffer no degradation.

The hub bearing on the bedplate side will be subjected to loads which are substantially higher than the emergency feather condition. The bearing has the capacity to carry these loads for the few cycles they will be imposed with a small reduction in life.

The bedplate will experience local yielding but no failure due to loads somewhat in excess of design values.

The yaw bearing will be subjected to bending moments which approach the maximum moment capability of the bearing. For the few cycles this loading occurs, there should be no damage to the rollers or races. The yaw brake, however, will slip due to the high yawing moment.

The tower base will experience overturning bending moments approaching $50 \times 10^{6} \mathrm{ft-lbs}$. This will result in local yielding of some of the tower secondary members; however, the 4 corner legs have the inherent stability in buckling and as a column to carry the higher loads. 


\section{I-2 BLADE INTERFACE RING FLANGE}

A three-dimensional finite element stress was performed for the WTG blade ring adapter (Boeing DWG \#276-10509, Rev. B, 5/11/78, transmitted via Datafax). It was performed to verify the design and analysis submitted by Boeing.

The ring adapter was analyzed using the latest worst case loads for both fatigue conditions and emergency feather conditions. The equivalent axial load at the blade attachment section was 1,404,000 pounds $(7,152 \mathrm{psil}$ for the fatigue case, and 4,379,130 pounds $(22,310 \mathrm{psi})$ for the emergency feather case. The bolt preload was given as 110,340 pounds $(-31,022 \mathrm{psi})$.

\section{RESULTS}

As expected, the peak stresses in each case occurred at the root of the elliptical transition section on the outer surface of the ring, immediately adjacent to the bolt head location. For the fatigue case, the peak principal tensile (cyclic) stress was found to be 20,200 psi. For the emergency feather case, the peak principal tensile stress was found to be 50,000 psi. The margins of safety were found to be +.416 and +.26 , respectively. Also, the preload applied by the attachment bolts was not exceeded.

\section{ALLOWABLE STRESSES}

The allowable stresses in the ring adapter material are given as

$$
\begin{aligned}
& \text { MAX }_{\text {FATIGUE }}=28,600 \text { psi [Ref: Blade Spec. 273A6684] } \\
& \text { MAX }_{\text {FEATHER }}=63,000 \text { psi }
\end{aligned}
$$


The margins of safety were determined using the peak stresses obtained from the finite element run.

$$
\begin{aligned}
& \text { For the fatigue case: } \quad \text { M.S. }=\frac{28,600}{20,200}-1=.42 \\
& \text { For the emergency feather case:M.S. }=\frac{63,000}{50,000}-1=+.26
\end{aligned}
$$

\section{ANALYSIS}

A sketch showing the modelling approach is presented on Figure I-2.

The stress distribution within the WTG blade ring adapter was determined by using the finite element method, due to the non-uniform geometry of the ring cross-section. The SAP V finite element computer program was used for the actual numerical determination. This code was developed at the University of California, Berkeley, and is well documented and accepted throughout the technical community. Using the initial geometry of Figure I-2, a three-dimensional finite element model was developed for the $1 / 112$ section. This model consisted of 765 elements and 1185 nodes. 
Table I-1

DYNAMIC \& GRAVITY LOADS

\begin{tabular}{|c|c|c|c|c|}
\hline \multirow{2}{*}{$\begin{array}{l}\text { LOAD } \\
\text { LBS FOR SHEAR } \\
\text { T-LBS FOR MOMEN }\end{array}$} & \multicolumn{2}{|c|}{ Two Blades } & \begin{tabular}{ccc} 
& \multicolumn{2}{c}{ One } \\
$35 \mathrm{MPH}$ & $35 \mathrm{RPM}$ \\
\end{tabular} & $\begin{array}{l}31 \text { ade } \\
\text { REV E BLADE }\end{array}$ \\
\hline & MEAN & CYCLIC (+) & MEAN & CYCLIC (t) \\
\hline $\begin{array}{ll} & V_{X} \\
\text { BLADE } & V_{Y} \\
\text { RET BRNG } & V_{Z} \\
\text { (BLADE } & \mathrm{M}_{X}^{X} \\
\text { SIDE) * } & M_{Y}^{X} \\
& M_{Z}^{Y}\end{array}$ & $\begin{array}{r}396,130 \\
-25,435 \\
65,021 \\
5,968 \\
-3,107,330 \\
-1,043,770\end{array}$ & $\begin{array}{r}7,518 \\
18,956 \\
22,400 \\
17,769 \\
1,021,300 \\
792,160\end{array}$ & $\begin{array}{r}293,050 \\
-12,830 \\
31,943 \\
8,399 \\
-1,485,420 \\
-59,430\end{array}$ & $\begin{array}{r}26,138 \\
19,434 \\
12,154 \\
16,195 \\
523,030 \\
733,800\end{array}$ \\
\hline $\begin{array}{ll} & \mathrm{V}_{\mathrm{X}} \\
\text { BLADE } & \mathrm{V}_{\mathrm{Y}} \\
\text { RET BRNG } & \mathrm{M}_{\mathrm{X}}^{\mathrm{Z}} \\
\begin{array}{c}\text { (HUB } \\
\text { SIDE) }+\end{array} & \mathrm{M}_{\mathrm{Y}}^{\mathrm{Y}}\end{array}$ & $\begin{array}{r}396,130 \\
-2,576 \\
69, .130 \\
5,968 \\
3,207,870 \\
10,940\end{array}$ & $\begin{array}{r}7,518 \\
20,684 \\
23,843 \\
17,769 \\
1,126,200 \\
869,910\end{array}$ & $\begin{array}{r}293,050 \\
-5,884 \\
32,522 \\
8,399 \\
-1,556,400 \\
-141,498\end{array}$ & $\begin{array}{r}26,138 \\
19,693 \\
12,810 \\
16,195 \\
670,340 \\
604,410\end{array}$ \\
\hline $\begin{array}{cc}\text { HUB BRNG } & V_{Y}^{X} \\
\text { (HUB } & V_{Y}^{Y} \\
\text { SIDE) } & V^{Z} \\
& M_{X}^{X} \\
& M_{Y}^{Y} \\
& { }_{Z}\end{array}$ & $\begin{array}{r}-52 \\
35 \\
-2,359 \\
106 \\
2,639 \\
66,386\end{array}$ & $\begin{array}{r}66,225 \\
86,466 \\
18,680 \\
606,630 \\
2,339,700 \\
184,210\end{array}$ & $\begin{array}{r}276,610 \\
6,846 \\
-13,432 \\
-50,535 \\
-3,187,200 \\
-194,540\end{array}$ & $\begin{array}{r}833,230 \\
69,698 \\
10,363 \\
266,490 \\
769,480 \\
628,260\end{array}$ \\
\hline $\begin{array}{cc} & V_{X}^{X} \\
\text { HUB BRNG } & V_{Y}^{Y} \\
\text { (B/P SIDE } & \mathrm{M}_{X}^{Z} \\
\text { SIDE) ** } & M_{Y}^{X} \\
& M_{Z}^{Y}\end{array}$ & $\begin{array}{r}-91,795 \\
-5,286 \\
-2,359 \\
82,336 \\
1,311,000 \\
66,386\end{array}$ & $\begin{array}{r}13,970 \\
21,627 \\
18,680 \\
507,490 \\
1,051,600 \\
184,210\end{array}$ & $\begin{array}{r}-66,665 \\
-4,333 \\
-13,432 \\
-3,964 \\
749,170 \\
-194,540\end{array}$ & $\begin{array}{r}52,678 \\
156,720 \\
10,363 \\
2,167,700 \\
1,933,900 \\
628,260\end{array}$ \\
\hline $\begin{aligned} & \text { YAW BRNG* } V_{\mathrm{X}} \\
& \mathrm{V}_{\mathrm{X}}^{\mathrm{X}} \\
& \mathrm{V}_{\mathrm{Z}}^{\mathrm{Y}} \\
& \mathrm{M}_{\mathrm{X}} \\
& \mathrm{M}_{\mathrm{Y}}^{\mathrm{X}} \\
& \mathrm{M}_{\mathrm{Z}}^{\mathrm{Y}}\end{aligned}$ & $\begin{array}{r}-339,830 \\
18,220 \\
-6,105 \\
-5,369 \\
842,030 \\
-35,132\end{array}$ & $\begin{array}{r}17,162 \\
60,879 \\
34,807 \\
636,680 \\
947,600 \\
454,260\end{array}$ & $\begin{array}{r}-318,650 \\
-8,156 \\
-13,586 \\
57,842 \\
103,970 \\
-326,310\end{array}$ & $\begin{array}{r}219,810 \\
268,110 \\
57,064 \\
5,285,900 \\
2,210,700 \\
1,351,600\end{array}$ \\
\hline $\begin{array}{l}\mathrm{v}_{\mathrm{X}} \\
\mathrm{v}_{\mathrm{Y}}^{\mathrm{Y}} \\
\mathrm{v}^{\mathrm{Y}} \\
\mathrm{M}_{\mathrm{Z}}^{\mathrm{Z}} \\
\mathrm{M}_{\mathrm{Y}}^{\mathrm{Y}} \\
\mathrm{M}_{\mathrm{Z}}^{\mathrm{Y}}\end{array}$ & $\begin{array}{r}-680,180 \\
-23,166 \\
-6,779 \\
-4,539 \\
1,168,500 \\
-3,149,500\end{array}$ & $\begin{array}{r}22,181 \\
80,510 \\
45,747 \\
807,110 \\
5,539,300 \\
10,766,000\end{array}$ & $\begin{array}{r}-662,290 \\
-1,227 \\
-9,793 \\
143,550 \\
2,305,400 \\
-797,300\end{array}$ & $\begin{array}{r}382,840 \\
348,320 \\
71,981 \\
6,073,900 \\
5,279,500 \\
47,697,000\end{array}$ \\
\hline
\end{tabular}

*Ref. to blade angle @ 3/4 R +Blade coord (rotating) **Tower coord (stationary)

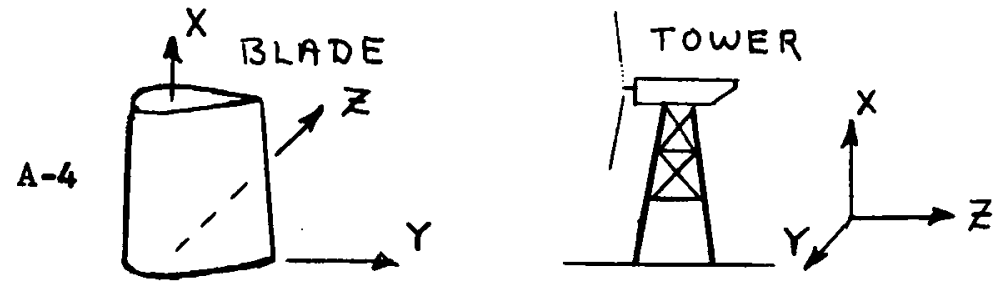




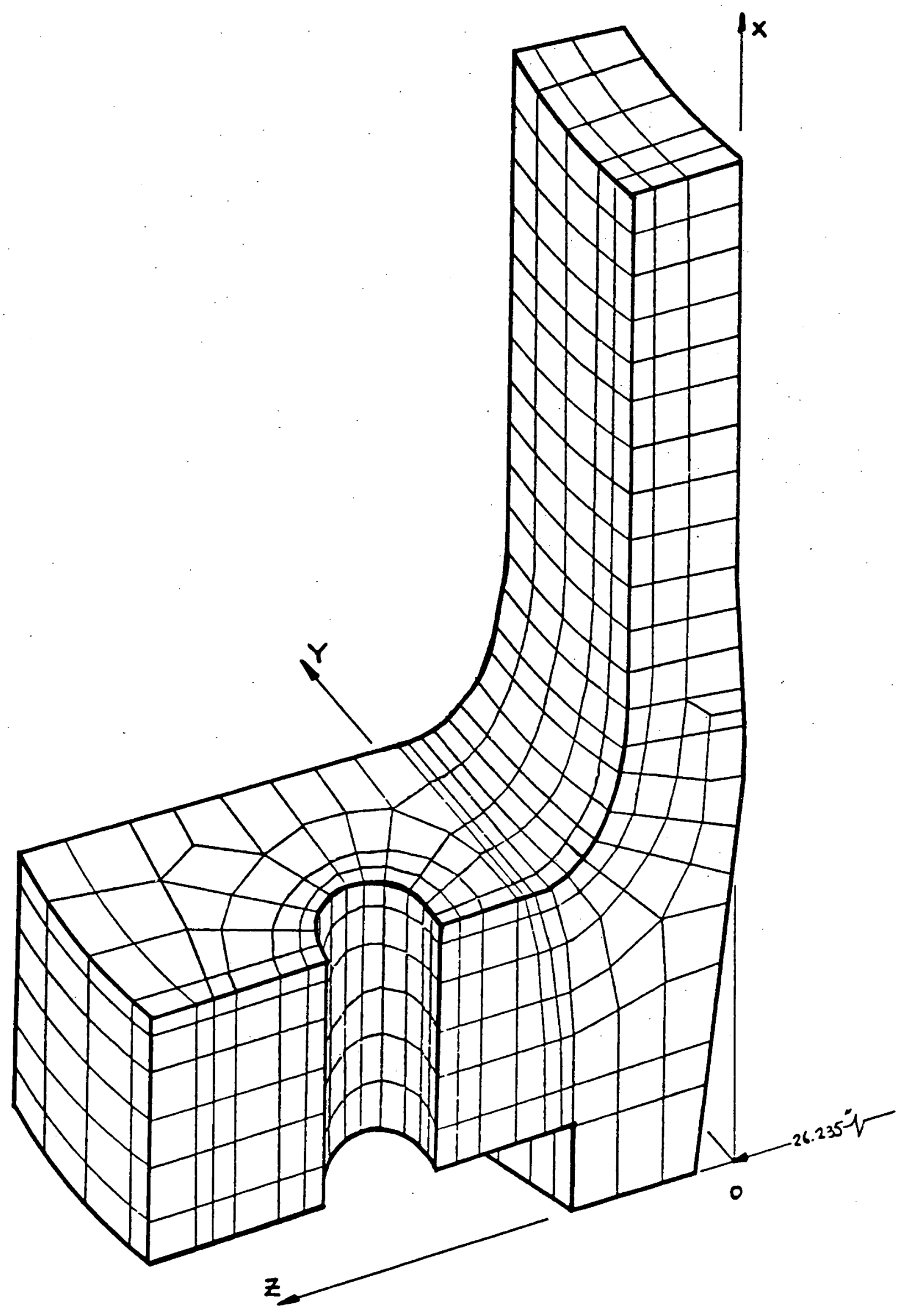

Figure I-2. Model Geometry and Coordinate System 


\section{I-3 BLADE TEST PROGRAM}

Three areas of testing have been planned for the Mod-l blade. To verify design assumptions or to demonstrate specification compliance:

1) ENGINEERING DEVELOPMENT TESTS

Tests performed on sub-element structures to obtain early indication of design adequacy.

2) BLADE DEVELOPMENT TESTS

Tests performed on full-scale portions of the blade to ascertain structural adequacy. In most cases, the test data from these tests will be available after the final design is complete.

3) BLADE TESTS

Tests which will be performed on the completed blade to determine dynamic characteristics or basic property data such as elastic axis location, static moment, chordwise c.g. locations, and stress and deflection data vs. load.

A summary of the tests in each of the above categories follows in Table I-3, I-4 and $I-5$. 


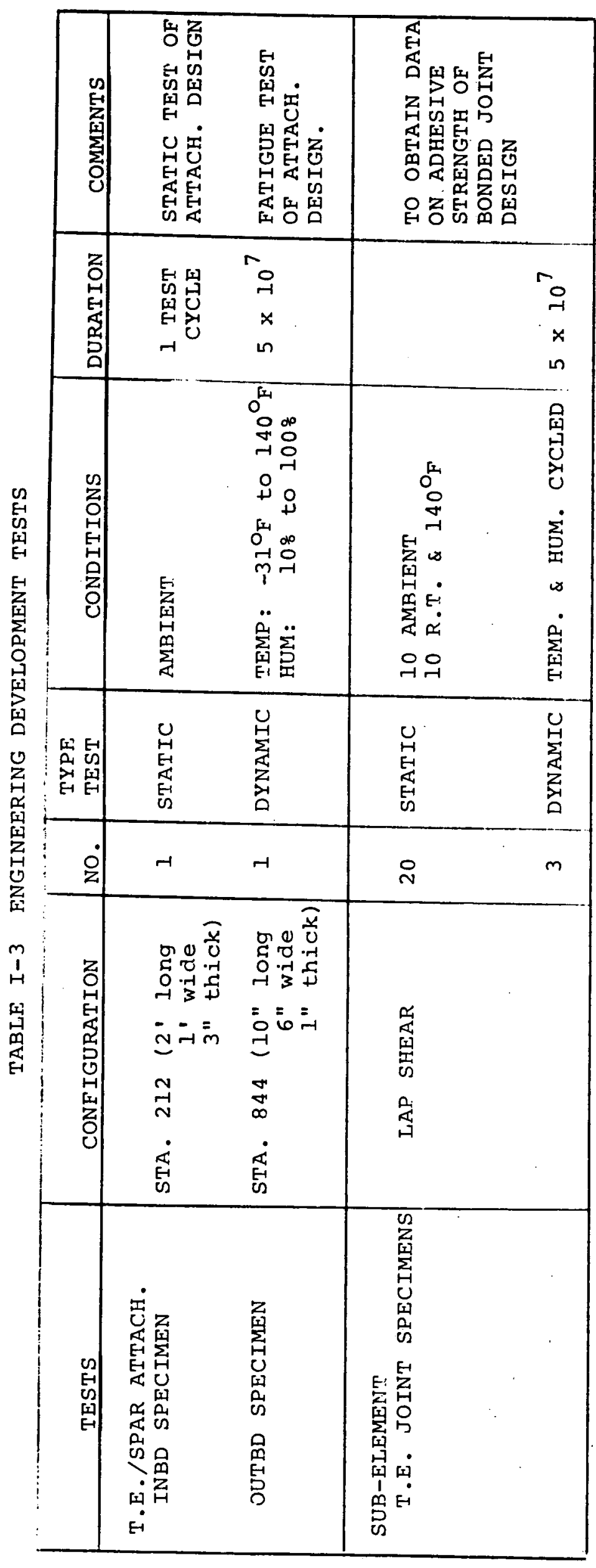




\begin{tabular}{|c|c|c|c|}
\hline 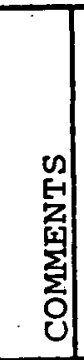 & 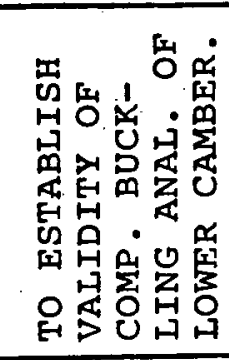 & 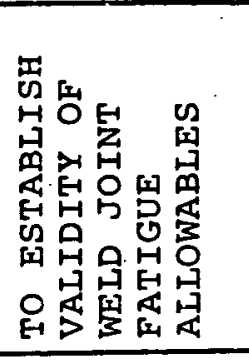 & 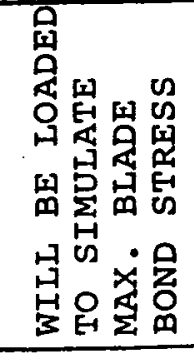 \\
\hline 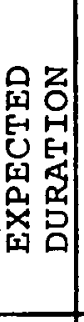 & 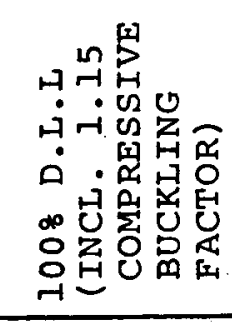 & 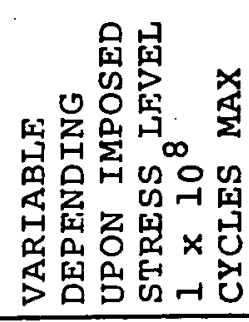 & 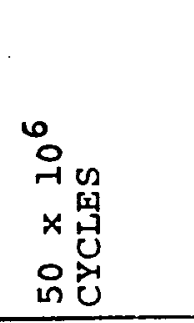 \\
\hline 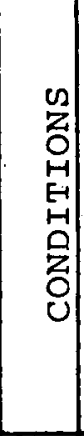 & 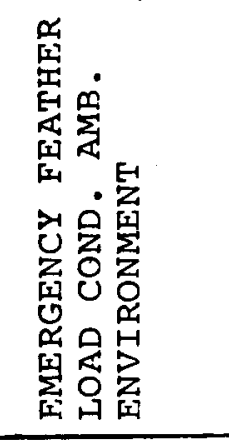 & 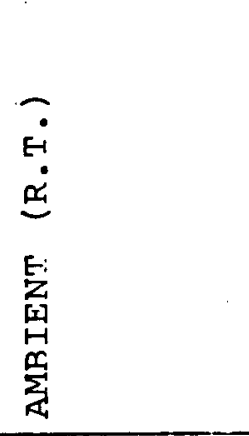 & 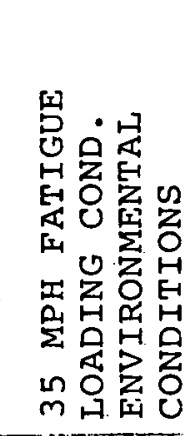 \\
\hline 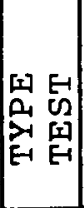 & 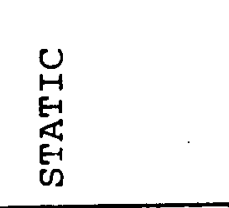 & 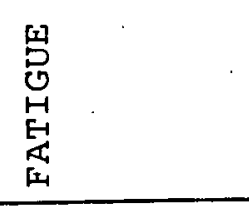 & 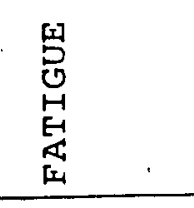 \\
\hline$\dot{0}$ & -1 & 6 & 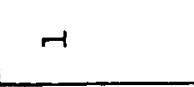 \\
\hline 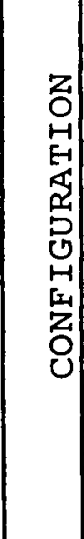 & 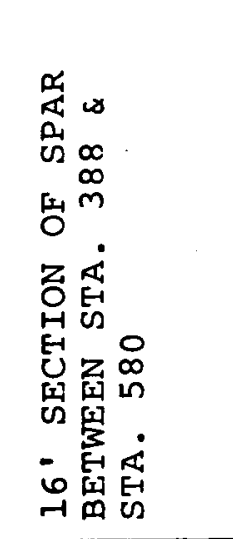 & 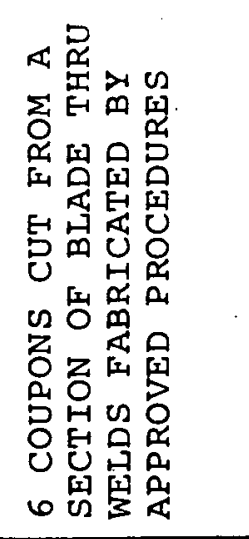 & 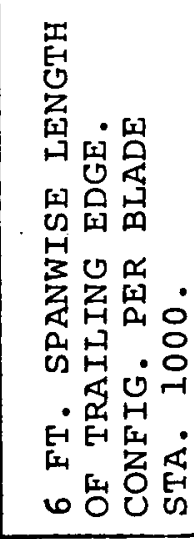 \\
\hline $\begin{array}{l}E \\
0 \\
\text { [ح } \\
E-1\end{array}$ & 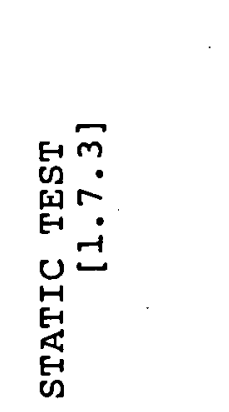 & 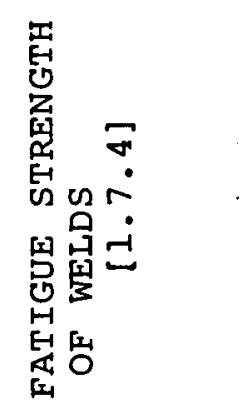 & 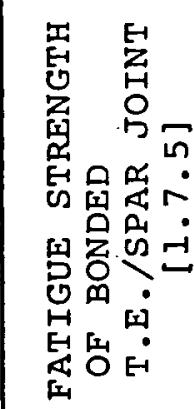 \\
\hline
\end{tabular}




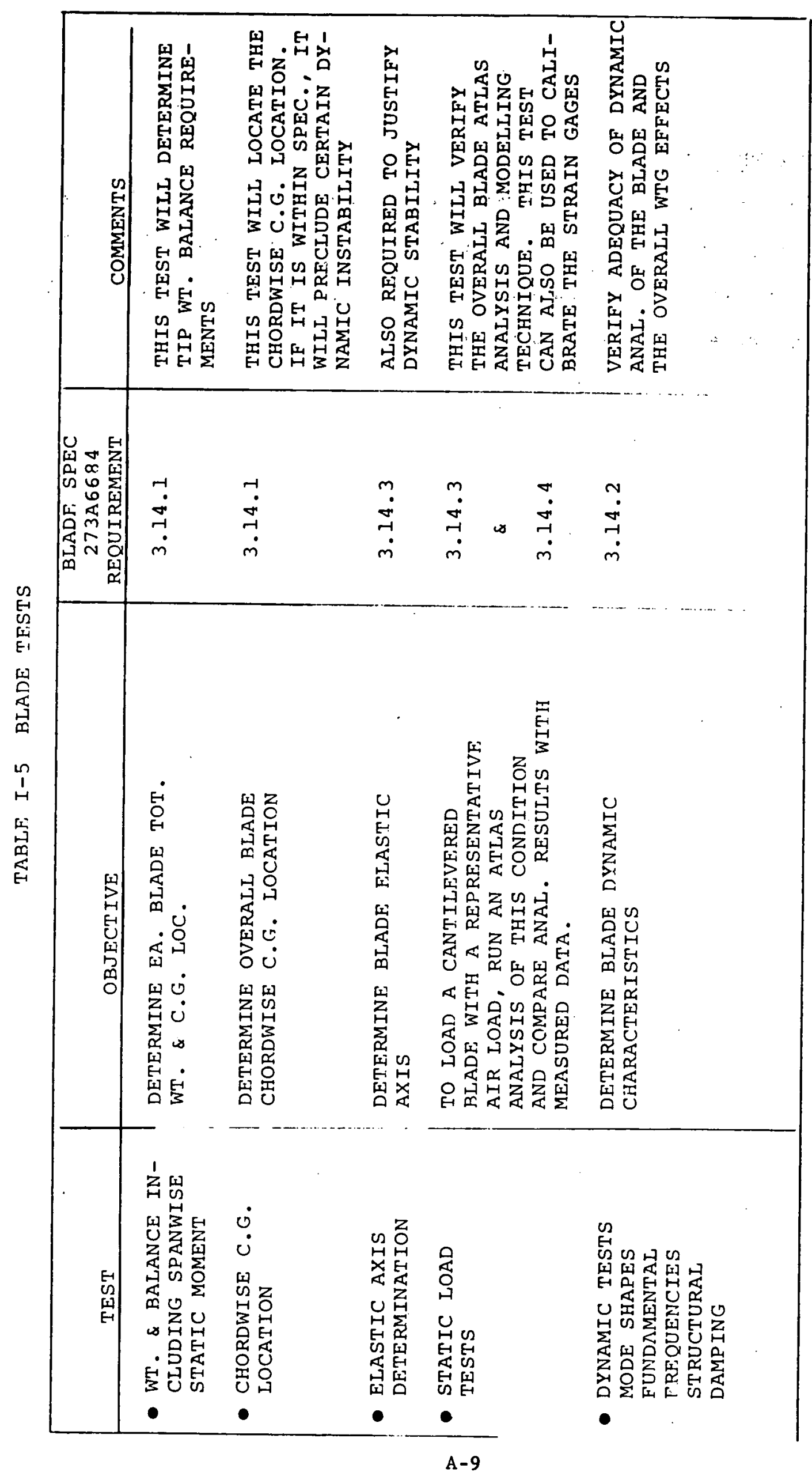




\section{I-4 QUALITY PROGRAM}

The blade Quality Program is summarized on Table I-6. The trailing edge portion of the blade is, at this writing, just completing the development phase. Consequently, the Quality Control plans for it are preliminary and subject to change. 


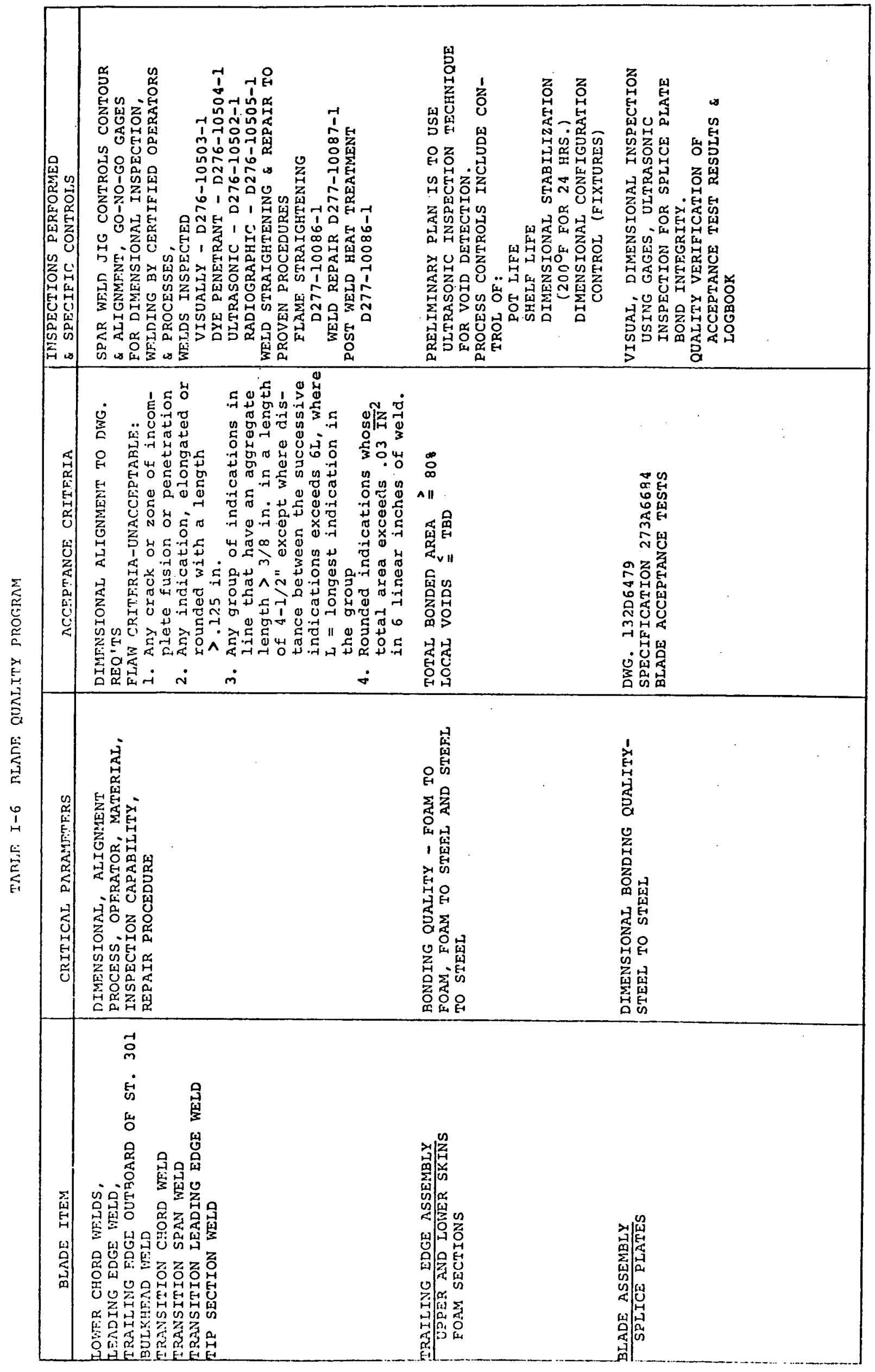




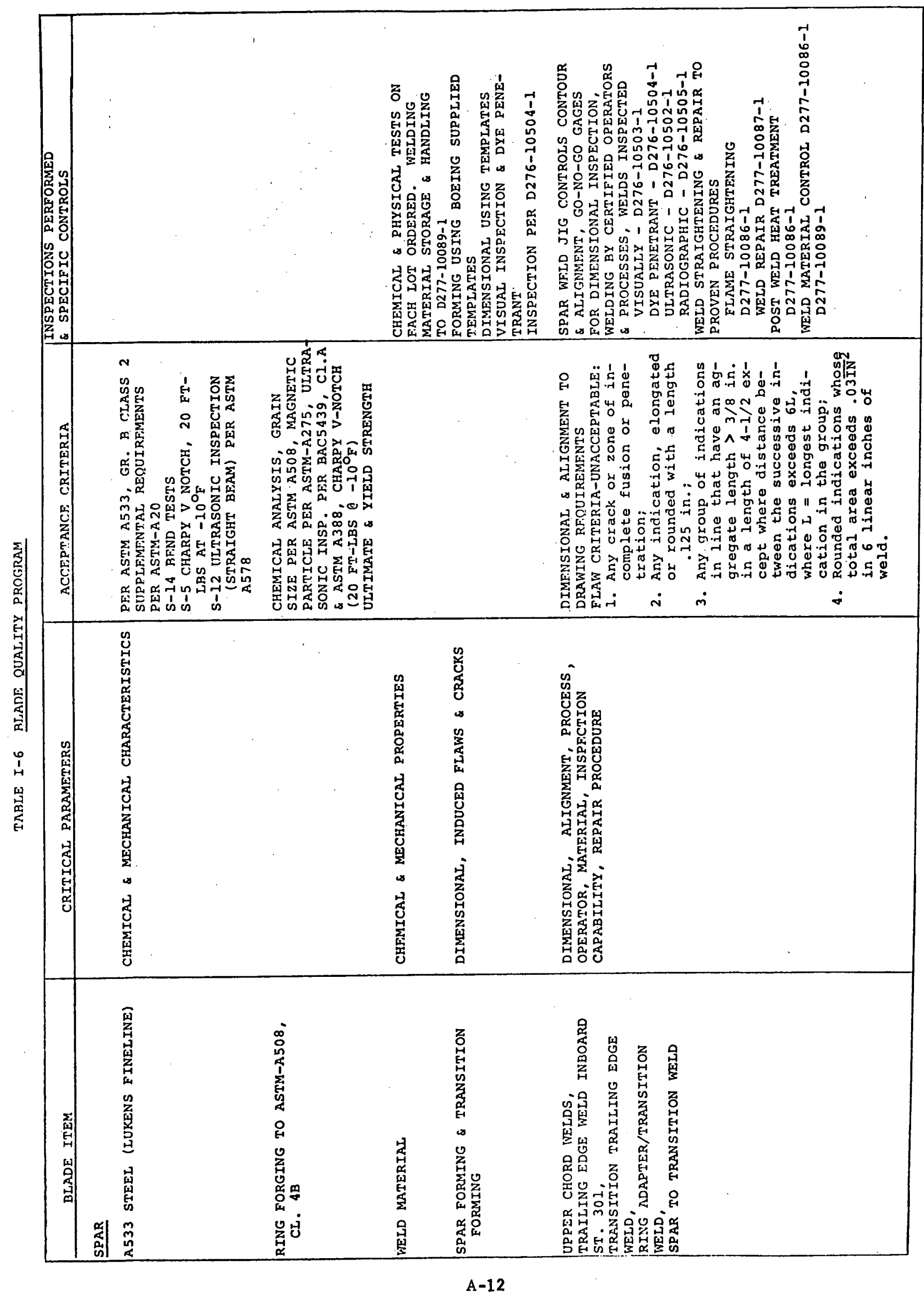


APPENDIX B

ROTOR OVERSPEED 
ROTOR OVERSPEED

One of the more serious fallure scenarios on a wind turbine is rotor overspeed. If perifted to "run-away", blade separation due to large rotor centrifugal stress is a probaile final result. The MOD-1 pitch control-syslem is the mechanisn whereby overspeed is controlled, with redundant stored energy and redundant deadman control valve elements built into the system.

The maximum rotational speed of the rotor is a function of rotor inertia, accelerating torque due to loss of load and wind increases, a time delay from the start of acceleration to initiation of blade pitch motion towards feather, and the torque rate of change with time, which is a function of pitch rate. In order to simplify the following analysis, step changes in wind velocity over the entire rotor disc were assumed, a condition not reasonably occurring in nature. Acceptable response to these step inputs will indicate better than acceptable response to realistic wind perturbations.

Values utilized in the analysis are:

Inertia of rotating system

Rated torque (2160 KW, 34.7 RPM)

Nominal control delay

Maximum blade rate

Maximum torque rate
$2.1 \times 10^{6} 1 \mathrm{~b}-\mathrm{ft}-\mathrm{sec}^{2}$

$4.4 \times 10^{5} \mathrm{ft}-1 \mathrm{~b}(100 \%)$

$0.2 \mathrm{sec}$

$14 \mathrm{deg} / \mathrm{sec}$

$150 \% / \mathrm{sec}$ at $14 \mathrm{deg} / \mathrm{sec}$

Wind steps considered and their torque effects are:

1.0 to 1.4 normalized velocity $=100 \%$ to $235 \%$ normalized torque

1.0 to 1.8 normalized velocity $=100 \%$ to $376 \%$ normal1zed torque

The torque increase does not follow a wind velocity cubic due to assuming initial conditions fust at rated wind velocity near the peak power coefficient value. Any wind increase thus is effective at a reduced power or torque coefficient value. A linear torque-pitch relationship, no compensation for torque change wtth rotor speed, and no losses are assumed. The combined effect of these assumptions is believed to balance out as the sccond and third assumptions are conservative, while the first is not conservative.

Four scenarins, as follows, describe a range of increasingly severe accelerating torque conditions. Loss of load is considered to be a "nornal" design event as the alain circuit breaker can be tripped open due to a varlety of electrical anomolies. 


$\begin{array}{lll}\text { Case 1 } & 1080 \text { of } 40 \% \text { load } & \text { No Gust } \\ \text { Case 2 } & 1038 \text { of } 100 \% \text { load } & \text { No Gust } \\ \text { Case } 3 & 1088 \text { of } 100 \% \text { load } & 1.4 \text { Gust } \\ \text { Casc } 4 & 1088 \text { of } 100 \% \text { load } & 1.8 \text { Gust }\end{array}$

Response was computed on the basis of a normal control system de-energlzation of the feather solenoid valves, permitting the fluld in the feather accumulators to discharge into the blade actuators towards feather through a programmed flow valve. This valve has the characteristics and adjustability shown in Figure 1.

A nominal program for the flow valve has been selected with the dual goals of limitIng peak speed in a significant upgust wind and also limiting blade loading in decelerating torque conditions. The initial rate is at a blade equivalent of $14 \mathrm{deg} / \mathrm{sec}$ for 0.8 seconds, followed by a linear decrease to $4.4 \mathrm{deg} / \mathrm{sec}$ over the next 1.6 seconds, then maintained at $4.4 \mathrm{deg} / \mathrm{sec}$. 'Starting from 0.0 degrees, this schedule reaches 90.0 degrees feather in 17 seconds, with 25 degrees change in the first 2.5 seconds. The flow program is field modifiable for rate change, final rate, and $t$ Ime at maximum rate.

Results, with $0: 2$ second nominal control delay and activation of the feather system due to either high wind, breaker opening, large yaw error, or vibration are as follows :

$\begin{array}{lcccc}\text { Case } & 1 & 2 & 3 & 4 \\ \begin{array}{c}\text { Max. spd } \% \\ \text { over 100\% }\end{array} & .77 & 3.08 & 10.71 & 22.7 \\ \begin{array}{c}\text { Time at max } \\ \text { sec }\end{array} & .47 & .87 & 1.25 & 1.72\end{array}$

Hybrid runs of cases analogous to the above cases 2 and 4 were made during the course of system design simulation. The control algorithm was to shift to speed control at rated speed reference with no delay. On $100 \% 10 a d$ loss, $2.2 \%$ overspeed occurred and with a 1.8 gust, $11 \%$ overspeed occurred. Pitch angle response started at the maximum rate near $14 \mathrm{deg} / \mathrm{sec}$ and maintained a higher rate than the programmed valve, due to the speed control loop gain. These two cases are shown in Figures 2 and 3 .

If a control system failure prevents initlation of the feather system at rated rotor speed, software and hardware switch actuation of the feather valves are provided as backup. Present settings for the software and hardware overspeed switches are $5 \%$ and $10 \%$ respectively. These speeds are additive to the response values and in the case of the realistic 1.4 wind gust, result in 15.7 to $20.7 \%$ overspeed. Resetting of these switches to 3 and $6 \%$ respectively is recommended to reduce maximum speed, providing adequate separation from startup variation, overshoot and switch tolerance bands can be naintalned. The lower settings would result in 13.7 or $16.7 \%$ overspeed for software and hardware inftiated feather with the nominal valve program and a Case 3 scenario. 
To summar1ze, maximum rotor overspecd 18 cxpected to be less than $5 \%$ (3.08\% calculated) on 10:3 of load and lese than 20\% on loss of load plus a sustalned 1.4 upi,ust plus a primary control input or output fallure requiring use of the hardware backup overspeed circuit. These values are acceptable for a rotor and blade system with positive strcss margin at a rotor speed above $20 \%$ overspecd. The MOD-1 blade has positive margin near $20 \%$ overspecd.

Figure $B-1$

Frogrammed Flod Valve Characteristics

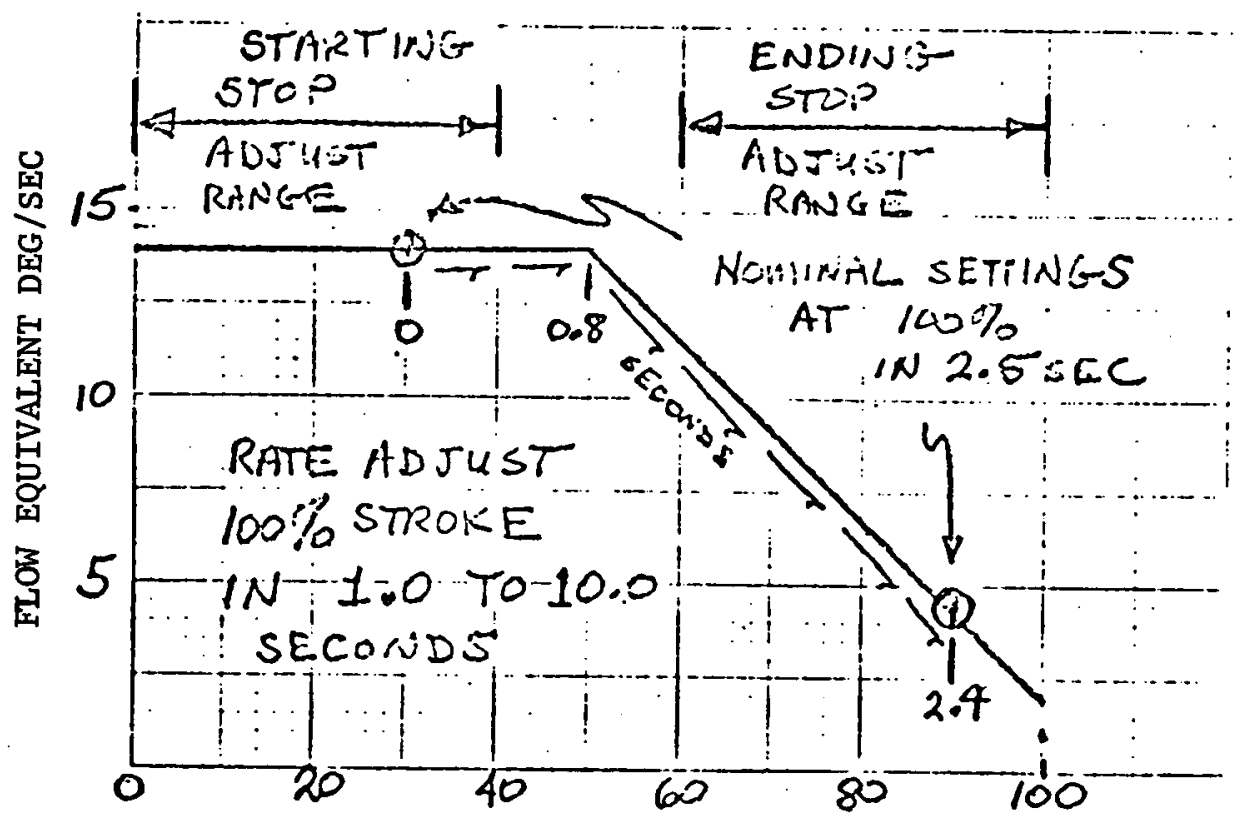

PERCENT VALUE STROKE 
Figure B-2

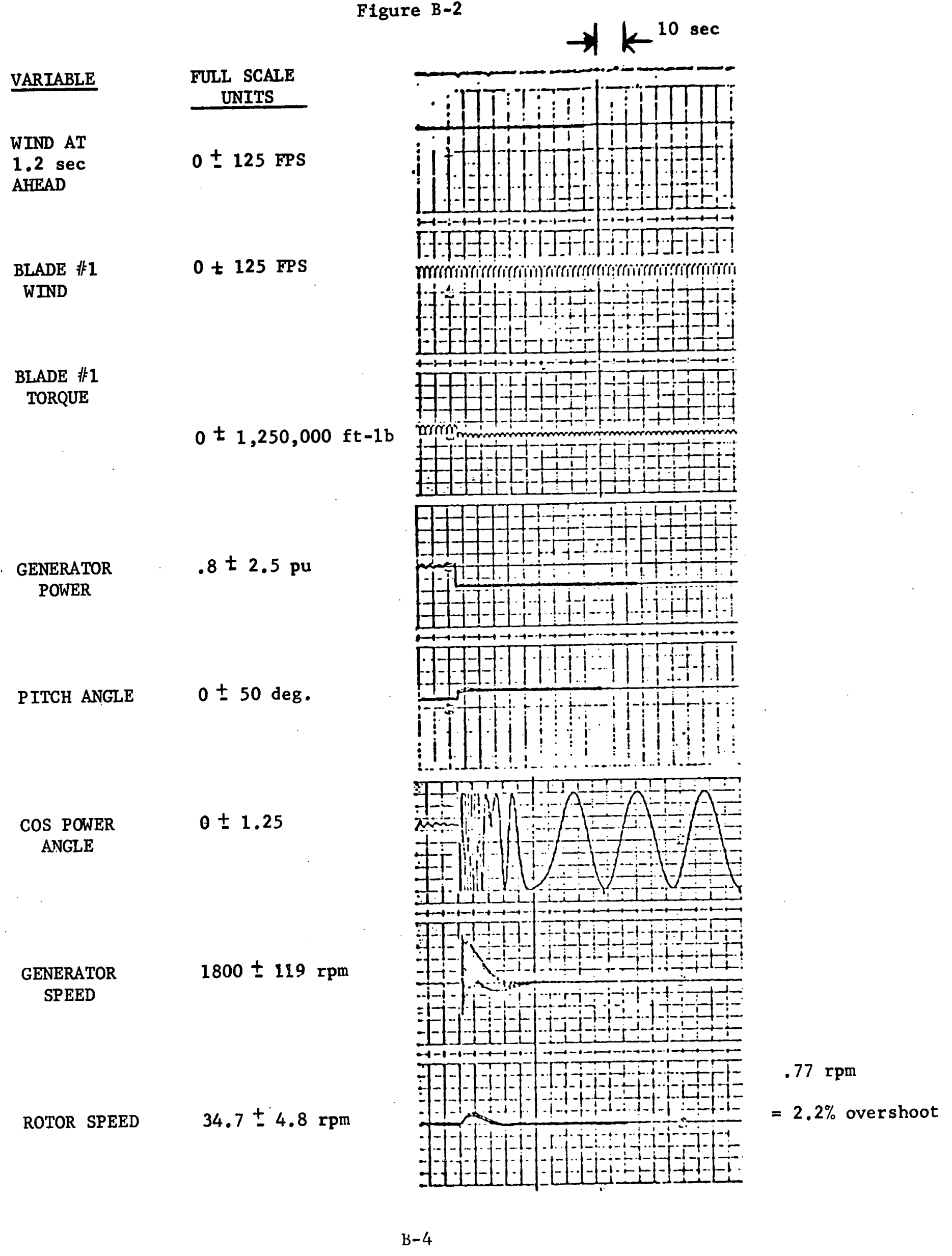


Figure B-3

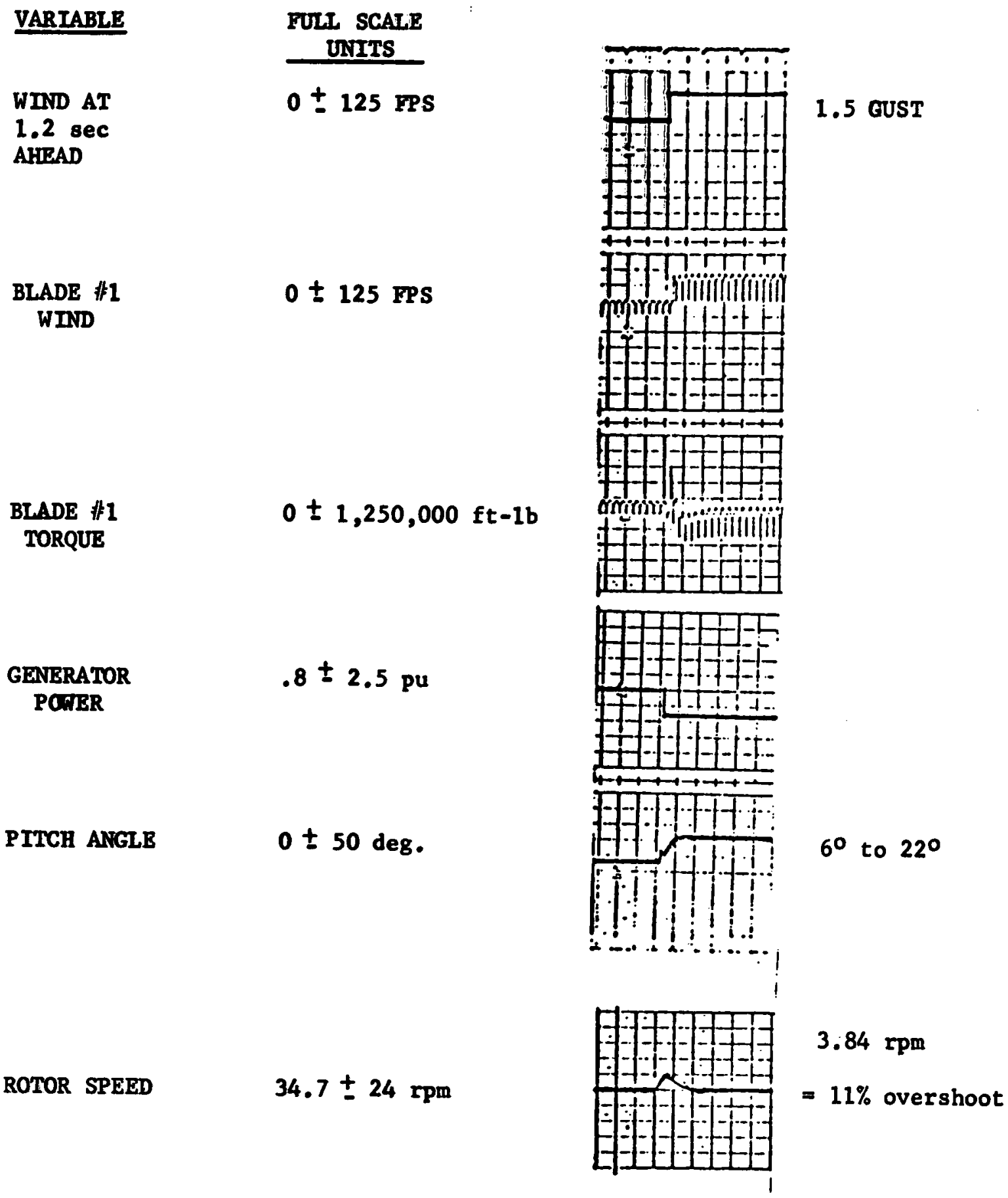




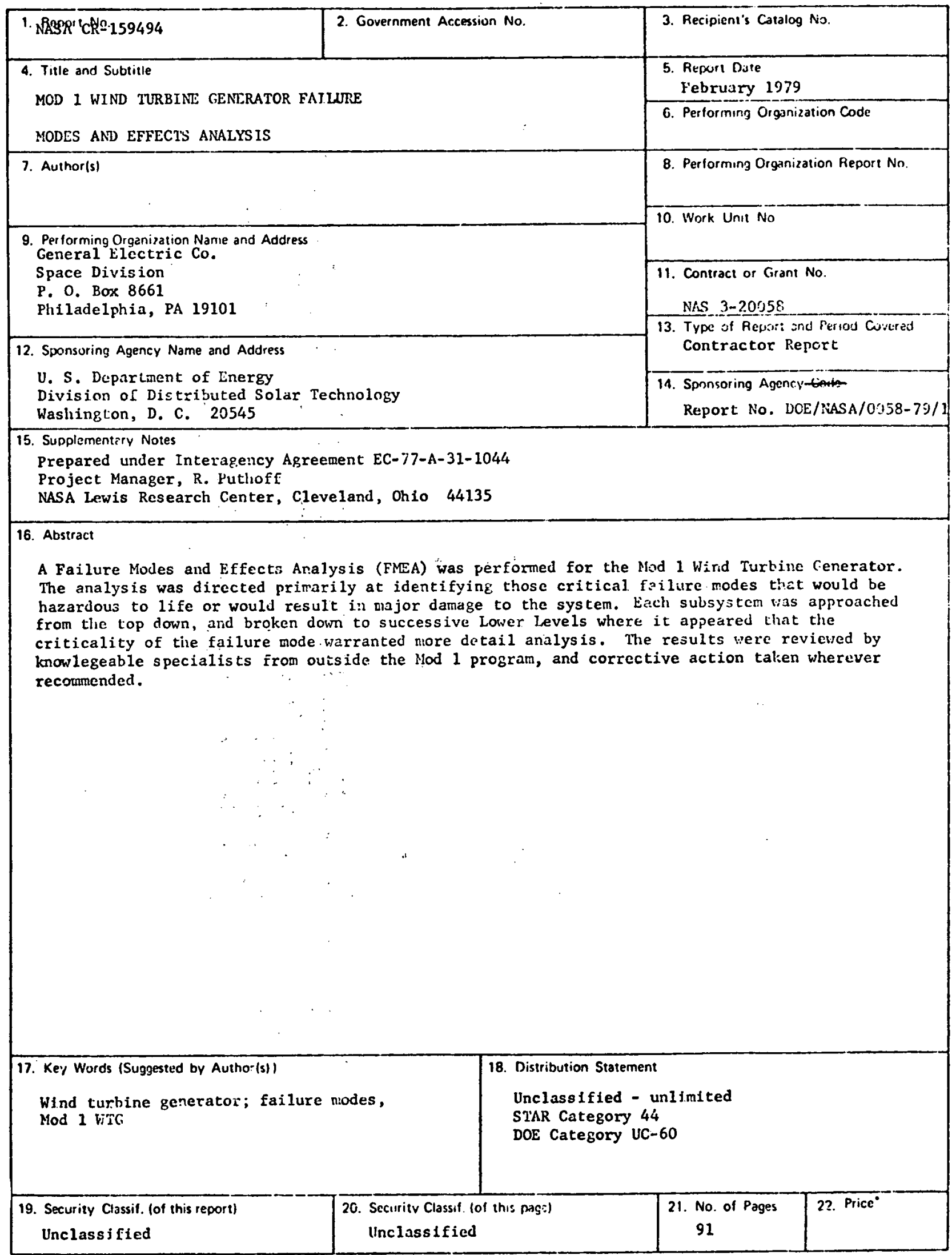

- For sale by the Nationa! Techrucal Information Service. Springliclo. Virginia 22161 